UCRL-ID-119652

\title{
Synthesis and Evaluation of Single Layer, Bilayer, and Multilayer Thermoelectric Thin Films
}

\author{
J. Farmer \\ T. Barbee, Jr. \\ G. Chapline, Jr. \\ M. Olsen \\ R. Foreman \\ L. Summers \\ M. Dresselhaus \\ L. Hicks
}

January 20, 1995

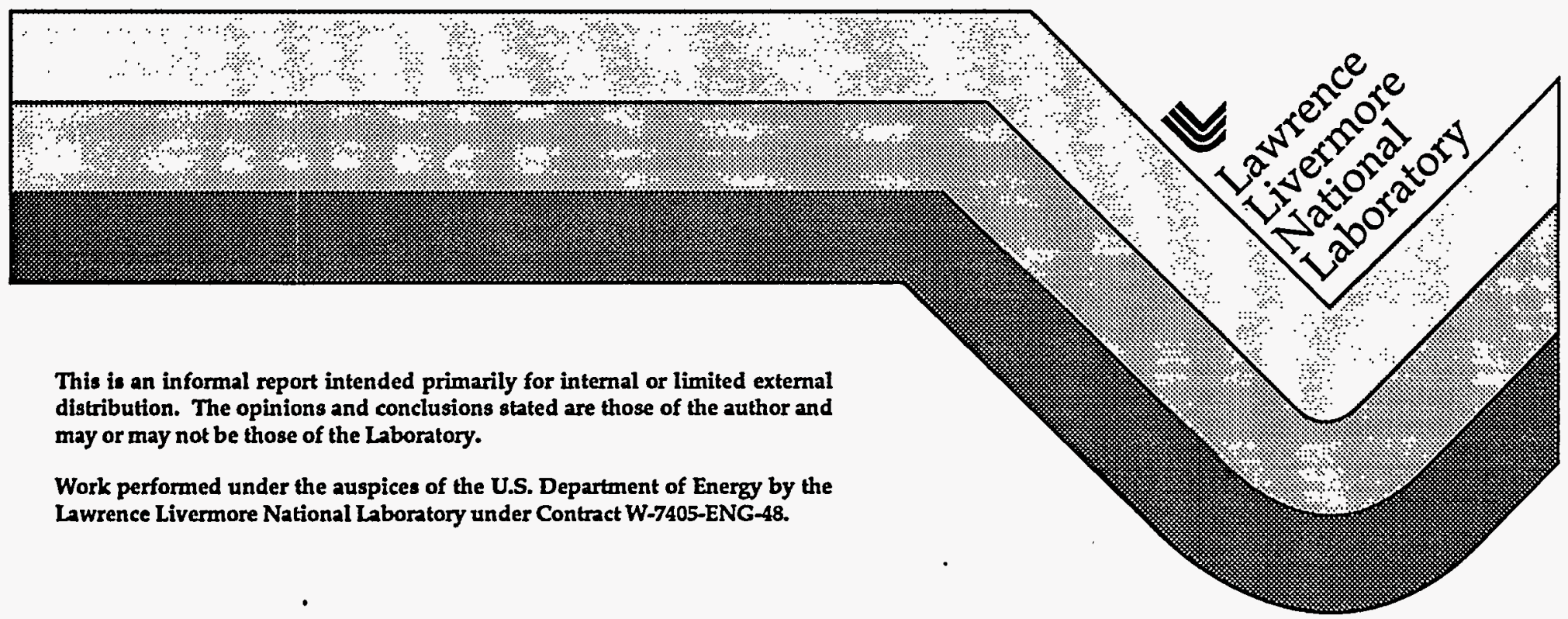




\section{DISCLAIMER}

This document was prepared as an account of work sponsored by an agency of the United States Government. Neither the United States Government nor the University of California nor any of their employees, makes any warranty, express or implied, or assumes any legal liability or responsibility for the accuracy, completeness, or usefulness of any information, apparatus, product, or process disclosed, or represents that its use would not infringe privately owned rights. Reference herein to any specific commercial product, process, or service by trade name, trademark, manufacturer, or otherwise, does not necessarily constitute or imply its endorsement, recommendation, or favoring by the United States Government or the University of California. The views and opinions of authors expressed herein do not necessarily state or reflect those of the United States Government or the University of California, and shall not be used for advertising or product endorsement purposes.

This report has been reproduced directly from the best available copy.

Available to DOE and DOE contractors from the

Office of Scientific and Technical Information

P.O. Box 62, Oak Ridge, TN 37831

Prices available from (615) 576-8401, FTS 626-8401

Available to the public from the

National Technical Information Service

U.S. Department of Commerce

5285 Port Royal Rd.,

Springfield, VA 22161 


\section{DISCLAIMER}

Portions of this document may be illegible in electronic image products. Images are produced from the best available original document. 


\title{
Synthesis and Evaluation of Single Layer, Bilayer, and Multilayer Thermoelectric Thin Films
}

\author{
Tracking Code 94-DE-040 \\ Joseph C. Farmer, Troy W. Barbee, Jr., George C. Chapline, Jr., \\ Margaret L. Olsen, Ronald J. Foreman, and Leslie J. Summers \\ Chemistry and Materials Science Department \\ University of California \\ Lawrence Livermore National Laboratory \\ 7000 East Avemue \\ Livermore, California 94550 \\ Mildred S. Dresselhaus and Lyndon D. Hicks \\ Department of Physics \\ Massachusetts Institute of Technology \\ 77 Massachusetts Avemue \\ Cambridge, Massachusetts 02139
}

\begin{abstract}
The relative efficiency of a thermoelectric material is measured in terms of a dimensionless figure of merit, ZT. Though all known thermoelectric materials are believed to have ZT $\leq 1$, recent theoretical results predict that thermoelectric devices fabricated as two-dimensional quantum wells (2D QWs) or one-dimensional (1D) quantum wires could have ZT $\geq 3$. Multilayers with the dimensions of 2D QWs have been synthesized by alternately sputtering thermoelectric and barrier materials onto a moving single-crystal sapphire substrate from dual magnetrons. These materials have been used to test the thermoelectric quantum well concept and gain insight into relevant transport mechanisms. If successful, this research could lead to thermoelectric devices that have efficiencies close to that of an ideal Carnot engine. Ultimately, such devices could be used to replace conventional heat engines and mechanical refrigeration systems.
\end{abstract}

DISTABBUTION OF THIS DOCUMENT IS UNLIMITED GH

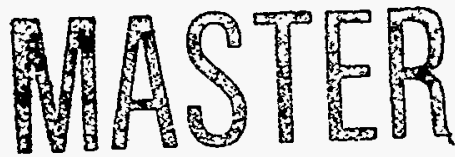




\section{Background}

Introduction. The relative efficiency of a thermoelectric material is measured in terms of the dimensionless figure of merit, ZT. The best known thermoelectric materials are heavily doped, mildly degenerate semiconductors and have $Z T \leq 1$. If materials with $Z T \geq 3$ could be found or developed, thermoelectric devices could be made that would have thermodynamic efficiencies close to that of an ideal Carnot engine. In fact, such materials would make it possible to completely replace conventional heat engines and mechanical refrigeration systems with solid state devices. We are pursuing the development of $2 \mathrm{D} \mathrm{QWs}$ as a means of achieving high ZT. Theory predicts that thermoelectric devices fabricated as $2 \mathrm{D}$ QWs could have ZT $\geq 3$.

Typical thermoelectric device. Thermoelectric devices are $\mathrm{p}-\mathrm{n}$ junctions in which charge carriers and heat flow in parallel (Fig. 1).

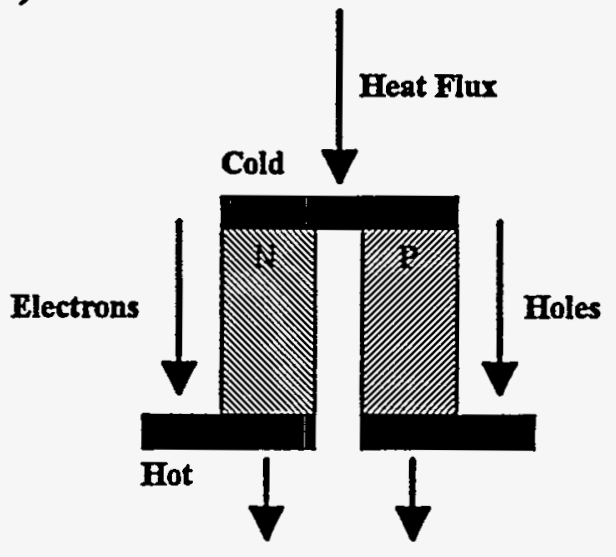

Fig. 1. Peltier cooling element consists of a $p-n$ junction.

Electrons and holes must acquire energy at the $p-n$ junction to flow in a direction opposite to the temperature gradient (from cold to hot). Both ohmic heating and heat conduction must be minimized for the efficient operation of such devices.

Figure of merit determines efficiency. The thermodynamic efficiency of a thermoelectric power generator $(\eta)$ and the coefficient of performance ( $\beta$ or COP) of a Peltier cooler are both calculated from the dimensionless figure of merit (ZT). The coefficient of performance is defined as the ratio of cooling to electrical power. Expressions for $\eta$ and $\beta$ at optimum current levels are

$$
\begin{aligned}
& \eta=\frac{T_{h}-T_{c}}{T_{h}} \frac{\sqrt{1+Z T}-1}{\sqrt{1+Z T}+T_{c} / T_{h}} \\
& \beta=\frac{T_{c}}{T_{h}-T_{c}} \frac{\sqrt{1+Z T}-T_{h} / T_{c}}{\sqrt{1+Z T}+1}
\end{aligned}
$$

where $T_{h}$ is the hot temperature and $T_{c}$ is the cold temperature. To achieve high values of $\eta$ or $\beta$ with a thermoelectric device, a material with a large ZT value must be found [Vining, 1992]. The 
dependence of $\eta$ on ZT and $T_{\mathcal{C}} T_{h}$ is illustrated by Fig. 2. The dependence of $\beta$ on ZT and $T_{h} / T_{c}$ is illustrated by Fig. 3. Conventional thermoelectric materials $(Z T \leq 1)$ are used in nuclearfueled power sources for space exploration, in silent power sources for the military, and in solidstate electrical generators on diesel engines. Thermoelectric devices with ZT $\geq 3$ should have thermodynamic efficiencies approaching those of the ideal Carnot cycle and could even be used to replace the internal combustion engine. A Peltier refrigerator constructed from conventional thermoelectric materials (ZT $\leq 1)$ and operating at $T_{h} / T_{c}=1.2$ has $\beta \leq 0.5$, which is poor compared to a standard chlorofluorocarbon (CFC) refrigeration cycle that has $\beta \approx 1.5$. A breakthrough in thermoelectric materials (ZT $\geq 3$ ) would enable Peltier refrigerators to achieve $\beta \geq 1.5$. Given the environmental problems associated with CFC refrigeration and air conditioning, the demand for efficient solid state alternatives should be great. High-efficiency thermoelectric coolers could also be used to eliminate evaporative losses from storage systems for liquefied nitrogen, oxygen, and hydrogen. Conventional thermoelectric devices are now used to cool: infrared detectors; integrated circuits; food and beverages for long-distance truck drivers; pilots and soldiers involved in desert and chemical warfare; and passenger seats in electric trains, buses, and cars.

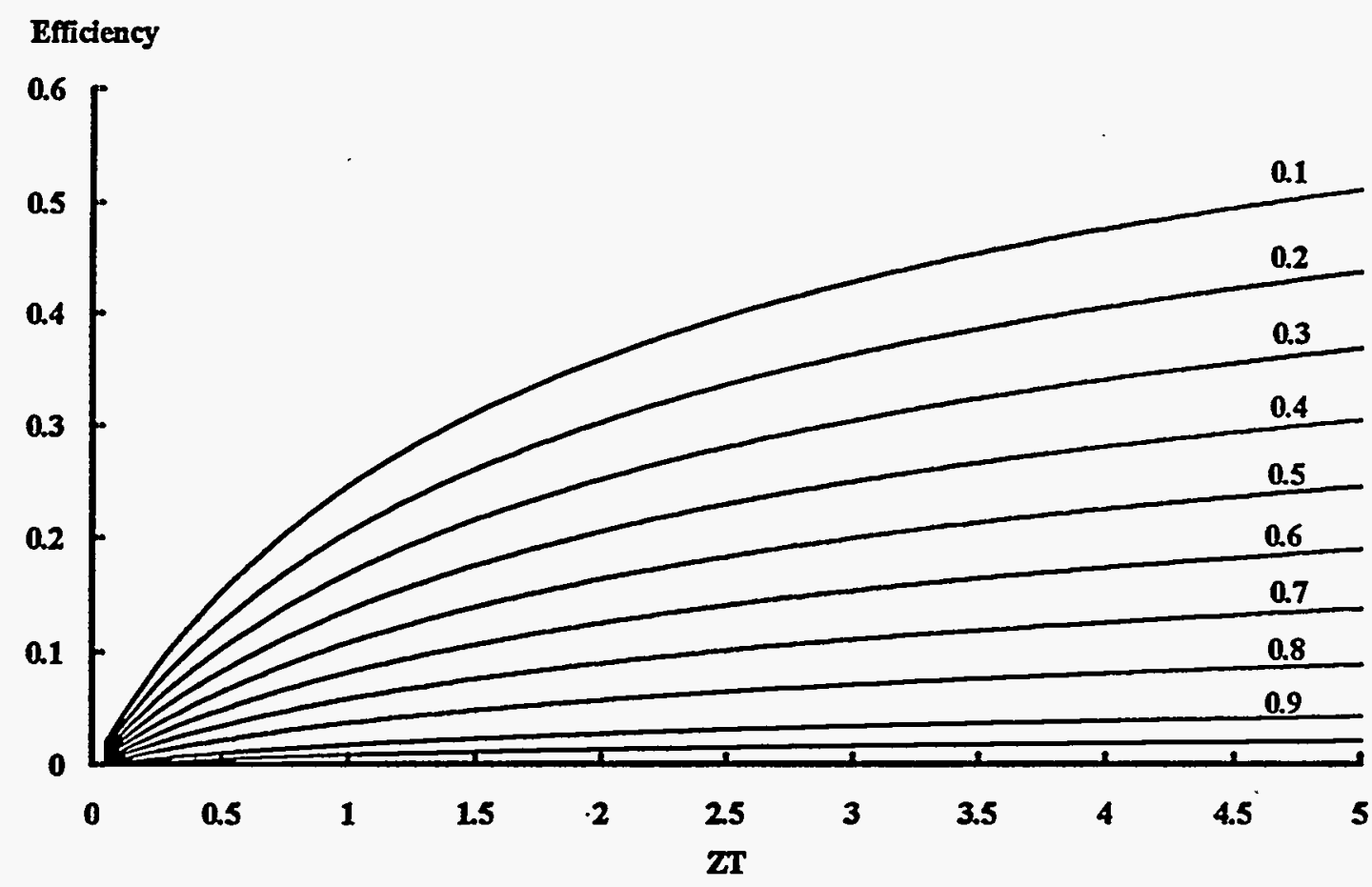

Fig. 2. Thermodynamic efficiency $(\eta)$ as a function of $Z T$ for $T_{d} / T_{h}$ ratios from 0.1 to 0.9 . 


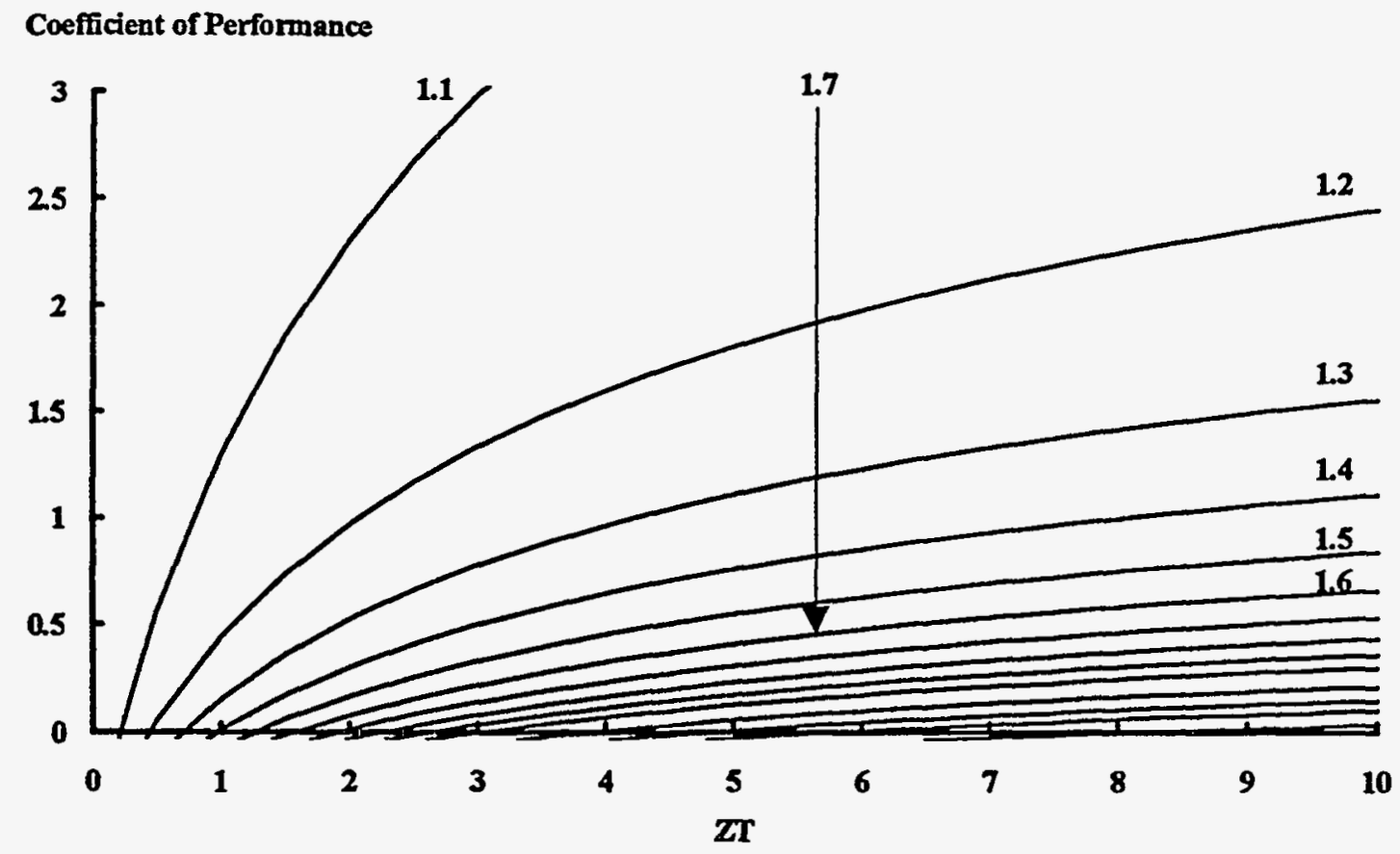

Fig. 3. Coefficient of performance $(\beta)$ as a function of $Z T$ for $T_{h} / T_{c}$ ratios of 1.1 to 2.6.

Conventional Strategies for Mcximizing ZT. The dimensionless figure of merit, ZT, is determined by Seebeck coefficient $(\alpha)$, electrical conductivity $(\sigma)$, electronic thermal conductivity (Kel), and lattice thermal conductivity ( $\mathrm{kph}$ ).

$$
Z T=\frac{\sigma \alpha^{2}}{\kappa_{p h}+\kappa_{a l}} T
$$

Good thermoelectric materials should have large Seebeck coefficients $(\alpha)$, large electrical conductivities $(\sigma)$, and small thermal conductivities $\left(k_{\mathrm{ph}}+\mathrm{k}_{\mathrm{el}}\right)$. Mildly degenerate semiconductors have the best combinations of these intrinsic properties [Comish, 1959]. Unfortunately, attempts to improve ZT by increasing $\sigma$ are eventually counteracted by detrimental changes in $\mathrm{kel}$. The Wiedemann-Franz law requires that $\sigma$ and $\mathrm{kel}$ trend in the same direction. Since $\alpha, \sigma$, and $\mathrm{Kel}_{\mathrm{l}}$ are all sensitive to carrier concentration, ZT is optimized by changing the extent of doping. The optimum is usually in the vicinity of $10^{19} \mathrm{~cm}^{-3}$.

Thermoelectric materials with low lattice thermal conductivities $\left(\kappa_{\mathrm{ph}}\right)$ are desirable. Semiconductor compounds made from elements with high atomic mass tend to have lower $\mathrm{kph}$ than those made from lighter elements. This is illustrated by Keyes' rule and similar expressions which correlate $k_{p h}$ with melting-point temperature $\left(T_{m}\right)$, atomic mass $(A)$, and density $(\rho)$.

$$
\kappa_{p h}=\frac{B T_{m}^{3 / 2} \rho^{2 / 3}}{A^{7 / 6} T}
$$


where $B$ is a constant and $T$ is temperature. It is evident that semiconductors with relatively low melting points should be used for low-temperature applications; i.e., as $T$ is reduced, $T_{m}$ must be reduced to compensate. Low lattice thermal conductivity can also be achieved by forming of a solid solution between isomorphous, heavy-element compounds. Such alloying is believed to lead to more intense scattering of phonons than electrons, thereby decreasing $\mathrm{k}_{\mathrm{ph}}$ without reducing $\sigma$ significantly [Wood, 1988; Ioffe, 1956]. The phonons responsible for heat conduction have wavelengths equivalent to a few interatomic spacings. Since the conduction of these phonons involves atomic motions, they are scattered most effectively by atomic-scale mass variations in the lattice. Fortunately, the scattering of charge carriers by such variations is minimal. If atoms of higher mass but similar valence and ionic size are substituted into a lattice, the effect on the periodic electrostatic potential of the lattice should be small.

Standard Technique for Measurement of ZT. Usually, the Harman technique is used to evaluate bulk thermoelectric materials [Goldsmid, 1964]. Direct and alternating currents, IDC and IAC, are simultaneously passed through the sample, and measurements of the corresponding differential voltages, VDC and VAC, are made. A current lead and thermocouple are fixed to each end of the sample. The current lead is used for introduction of IDC and IAC. In addition to measuring temperatures, thermocouple leads of like composition are also used to measure VDC and VAC. When evaluating materials such as $\mathrm{PbTe}$ and $\mathrm{Bi} 2 \mathrm{Te} 3$, copper current leads and chromel-alumel thermocouples are embedded in beads of solder, which cover the ends of the sample. Electrical conductivity is determined from IAC and VAC.

$$
\sigma=\frac{L}{A} \frac{I_{A C}}{V_{A C}}
$$

where $\mathrm{L}$ and $\mathrm{A}$ are the length and cross-sectional area of the sample, respectively. Determination of the Seebeck coefficient requires only direct-current measurements.

$$
\alpha \cong \frac{V_{D C}-\frac{L}{A} \frac{I_{D C}}{\sigma}}{\Delta T}
$$

where $\Delta T=T_{h}-T_{c}$ and is determined during the direct-current experiment. The thermal conductivity is then

$$
\kappa_{p h}+\kappa_{a l}=\frac{L}{A} \frac{\alpha I_{D C} T}{\Delta T}
$$

where $T$ is the arithmetic average temperature, calculated from $T_{h}$ and $T_{c}$. The dimensionless figure of merit is then

$$
Z T=\frac{\sigma \alpha^{2}}{\kappa_{p h}+\kappa_{a l}}=\frac{\left(V_{D C} / I_{D C}\right)-\left(V_{A C} / I_{A C}\right)}{\left(V_{A C} / I_{A C}\right)}
$$


This technique requires that the sample be thermally isolated and cannot be used for supported thin films.

Bulk Thermoelectric Materials. One of the materials favored for low temperature applications is lead telluride, PbTe. Lead telluride is a IV-VI compound with a band gap of $0.33 \mathrm{eV}$ and a simple FCC, NaCl-type crystal structure. Sodium impurity can be added to produce p-type PbTe, whereas $\mathrm{PbI}_{2}$ can be added to produce n-type $\mathrm{PbTe}$. Alloys of bismuth telluride are also used for low temperature applications. Typical compositions for p-type and n-type materials are $25 \% \mathrm{Bi}_{2} \mathrm{Te}_{3}-75 \% \mathrm{Sb}_{2} \mathrm{Te} 3$ and $90 \% \mathrm{Bi}_{2} \mathrm{Te}_{3}-10 \% \mathrm{Bi}_{2} \mathrm{Se}_{3}$, respectively [Wood, 1988]. In general, these V-VI compound semiconductors can be represented by $(\mathrm{Bi}, \mathrm{Sb})_{2}(\mathrm{Te}, \mathrm{Se})_{3}$. They have complicated rhombohedral crystal structures, with alternating planes of (Bi,Sb) and (Te,Se). Adjacent (Te,Se) layers form characteristic van der Waals planes. The band gaps of pure Bi2Te3, $\mathrm{Bi}_{2} \mathrm{Se}_{3}$, and $\mathrm{Sb}_{2} \mathrm{Te} 3$, and are $0.13,0.28$, and $0.30 \mathrm{eV}$, respectively. In p-type Bi2Te3, carrier concentration has been increased by adding excess $\mathrm{Bi}$ or $\mathrm{Pb}$. In n-type $\mathrm{Bi} 2 \mathrm{Te} 3$, impurities such as $\mathrm{CuI}, \mathrm{CuBr}$, AgI, and Ge have been added [Egli, 1958; Stordeur, 1992], though $\mathrm{Cu}$ has been known to cause problems by diffusing down the van der Waals plane. Bismuth telluride alloys are stable at low temperature, but disproportionate above $600 \mathrm{~K}$. The unusually low thermal conductivities of these bismuth-containing materials, which are usually less than $10 \mathrm{~mW} / \mathrm{cm}-\mathrm{K}$ at $300 \mathrm{~K}$, are the result of forming of a solid solution between isomorphous, heavy-element compounds. It has also been suggested that electrons in these semiconducting compounds travel on the cation (Bi,Sb) sublattice, while holes move on the anion (Te,Se) sublattice [Hyun, 1992; Wood, 1988; Airapetiants, 1957]. Thus, impurities, mass variations, and defects in the cation sublattice will scatter electrons more strongly than defects in the anion sublattice. Similarly, impurities, mass variations, and defects in the anion sublattice will scatter holes more strongly than defects in the cation sublattice. Therefore, the addition of $\mathrm{Bi}_{2} \mathrm{Se}_{3}$ to $\mathrm{Bi}_{2} \mathrm{Te} 3$ should produce a larger increase in the n-type figure of merit than the addition of $\mathrm{Sb}_{2} \mathrm{Te}$. The latter should produce better p-type material. A detailed model has been developed to predict the thermoelectric properties of this alloy system as a function of composition [Fleurial, 1992]. Several optical studies of this alloy system have also been done [Wakaki, 1992; Stordeur, 1992]. Dimensionless figures of merit (ZTs) for these materials have been published Wood [1988], Rosi [1968], Goldsmidt [1964], and others. The best known material for high-temperature thermoelectric generators is Si70Ge30 alloy [Cook, 1992; Slack, 1991; Vining, 1991; Wood, 1988; Rosi, 1968]. Usually, B is used as a dopant to produce p-type Si70Ge30. A combination of $P$ and $\mathrm{GaP}$ can be used to produce n-type GaP. These alloys have the well-known diamond structure. Published data for several transition metal and rare earth sulfides indicate that these materials are also good thermoelectric materials. Cutler and Leavy [1963-64] have investigated nonstoichiometric p-type $\mathrm{Ce}(3-\mathrm{x}) \mathrm{S} 4$. More recently, Kamarzin et al. [1981] and Gschneidner et al. [1982-88] have investigated n-type La(3-x) $S_{4}$. In addition to samples made of pressed and sintered powders, single crystals have been studied. These materials are ionic compounds and maintain their BCC structure over the entire range of stoichiometries investigated. Unfortunately, oxysulfides form at high temperature, giving rise to problems with phase stability. Studies have been conducted and published on several silicides, including doped FeSi2, $\mathrm{Cr}_{28 \mathrm{Si}}$,

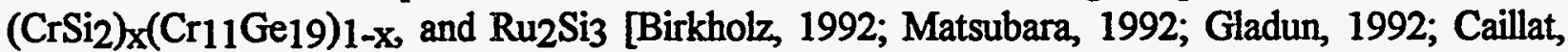
1992; Ohta, 1992]. The thermoelectric properties of these specific materials are poor. It may be 
possible to achieve better performance at high temperature with pseudo binary alloys of (Fe,Os)Si2 [Elsner; 1992]. Covalent IrSb3 has a cubic structure and a measured ZT of 0.50 at $773 \mathrm{~K}$ [Caillat, 1992]. A higher ZT may be possible with this material. Unfortunately, the use of iridium in practical thermoelectric devices will be limited by its expense. The thermoelectric properties of several HTSCs have been determined [Macklin, 1990]. In general, HTSCs are very poor thermoelectric materials. The best results were obtained for $\mathrm{YBa}_{2} \mathrm{Cu} 3 \mathrm{O}_{6.3}$ (ZT $\approx 0.06$ at $300 \mathrm{~K}$ ). Published data for several conductive polymers have been collected and analyzed [Roy, 1991; Yoon, 1989-91; Maddison, 1988-89; Bender, 1987]. The best thermoelectric polymer appears to be polyacetylene doped with 6.6 atomic $\% \mathrm{FeCl}_{3}$ [Yoon, 1991]. Unfortunately, the dimensionless figure of merit of this material is also poor (ZT $\approx 0.02$ at $300 \mathrm{~K}$ ).

Sputtered Thermoelectric Films. George and Pradeep [1985] and Charles et al. [1988] have prepared films of $\mathrm{Bi}_{2} \mathrm{Te} 3$ with excellent thermoelectric properties by reactive coevaporation, achieving stoichiometric composition through careful substrate temperature control. George and Pradeep reported that stoichiometric films could be grown at substrate temperatures between $\mathbf{5 3 0}$ and $545 \mathrm{~K}$ and at a low deposition rate of 0.3-0.4 nm/s. Charles et al. reported that stoichiometric films could be grown over a broader range of substrate temperature, between 523 and $583 \mathrm{~K}$. They maintained a ratio of Te flux to Bi flux greater than two. Boikov et al. [1989] reported stoichiometric films of the ternary compound $\mathrm{Bi} 0.5 \mathrm{Sb} 1.5 \mathrm{Te} 3$ with thermoelectric properties approaching those of bulk single crystals using flash evaporation. These authors also mention the importance of substrate temperature, which was controlled at less than $550 \mathrm{~K}$. Furthermore, they found that the thermoelectric properties of films could be improved by annealing in argon at approximately $670 \mathrm{~K}$. They attributed this improvement to relaxation of the crystal structure and the corresponding reduction in concentrations of defects. In a subsequent paper [1991], they deposited n-type Bi2Te3 films onto freshly cleaved mica plates. Since Bi2Te3 exhibits incongruent sublimation and tellurium has a very high vapor pressure, they found it necessary employ an additional tellurium source and heat the walls of their system to obtain the desired stoichiometry. This is known as the "hot wall" technique in the thin-film community. They measured the electrical conductivity and Hall Coefficient as functions of temperature from approximately 110 to $600 \mathrm{~K}$. Over this range of temperature, they concluded that the main electron-scattering mechanism involved interactions with lattice vibrations. Stolzer and Stordeur [1992] have used planar magnetrons to deposit single-layer films of $\mathrm{Bi}_{0.5 \mathrm{Sb}} .5 \mathrm{Te} 3$ having thicknesses of $2 \mu \mathrm{m}$ onto $\mathrm{Si}_{/} \mathrm{SiO}_{2}$ wafers. The substrate temperature was controlled at 323-573 $\mathrm{K}$. During sputtering, the argon pressure was maintained at $\sim 3.8 \times 10^{-3}$ torr, while the discharge voltage and power were held at $320 \mathrm{~V}$ and $50 \mathrm{~W}$, respectively. Under these conditions, deposition rates of $\sim 6 \mathrm{~nm} / \mathrm{s}$ were achieved. Films were shown to be polycrystalline by X-ray diffraction (XRD). After annealing, measurements of the Seebeck coefficient and electrical conductivity were made at temperatures from 100 to $350 \mathrm{~K}$. Mobilities observed in the films were approximately five times lower than those observed in single crystals. This disappointing reduction in mobility was attributed to the scattering of charge carriers by imperfections, though the work appears to be inconclusive. We believe that the best work to date on sputtered films of (Bi,Sb)2(Te,Se)3 was recently published by Noro, Sato, and Kagechika [1993]. Crystals of $\mathrm{Bi} 0.45 \mathrm{Sb} 1.55 \mathrm{Te} 2.94 \mathrm{Se} 0.11$ were fabricated by the Bridgeman method and used as targets. Before sputtering, a base pressure of $5 \times 10^{-6}$ torr was achieved with a cryopump. Then argon was introduced into the system, raising the pressure to $2 \times 10^{-4}$ torr. The beam of argon ions was 
accelerated by a potential difference of $1200 \mathrm{~V}$ and had an angle of incidence of $45^{\circ}$ relative to the surface of the target. Polycrystalline films having thicknesses of $4 \mathrm{~mm}$ were deposited at rates of $0.7-1.1 \mathrm{~nm} / \mathrm{s}$. Silica substrates having finishes of optical quality were used to support the films. During deposition, substrate temperature could be monitored with a copper-constantan thermocouple and controlled with an electrical resistance heater having tungsten filaments. The Seebeck coefficient $(\alpha)$ and electrical conductivity $(\sigma)$ were measured at ambient temperature. Measurements were made for films prepared with different substrate and annealing temperatures. As the substrate temperature was increased from 300 to $500 \mathrm{~K}$, the power factor measured at ambient temperature $\left(\sigma \alpha^{2}\right)$ increased to a maximum. The same result could have been obtained by post-process annealing. Their careful analyses with both energy dispersive X-ray spectroscopy and XRD showed that this increase in thermoelectric performance was due in turn to a slight temperature-induced change in stoichiometry, which caused a phase transformation. For example, films deposited at substrate temperatures of $300 \mathrm{~K}$ were not quite stoichiometric $(\mathrm{Bi}, \mathrm{Sb})_{2}(\mathrm{Te}, \mathrm{Se})_{3}$ and had a metastable FCC, NaCl-type crystal structure. Furthermore, these films were relatively poor n-type thermoelectric materials. By annealing at a temperature above $500 \mathrm{~K}$, these films became stoichiometric and developed the classic rhombohedral, Bi2Te3-type crystal structure. Annealing also converted films into p-type thermoelectric materials with very good power factors. Though the phase transformation appears to have been complete at $500 \mathrm{~K}$, annealing at higher temperatures continued to improve thermoelectric performance. This may have been due to the relaxation of defects in the crystal structure. The elimination of defects should reduce carrier scattering. The same results have been obtained by depositing films on heated substrates, maintained at approximately $500 \mathrm{~K}$. These investigators conclude that potentially, sputtered polycrystalline films can have the same thermoelectric performance as bulk single crystals.

\section{Theoretical Basis for Synthesizing Thermoelectric Multilayer Films}

$2 D \mathrm{QW}$ Model Predicts $Z T \geq 3$. From reviewing published data, we have concluded that no dramatic improvement in the dimensionless figure of merit, i.e. ZT $\gg 1$, has been achieved during the past thirty years. However, Hicks and Dresselhaus of MTT have recently developed a model for the thermoelectric properties of 2D QWs, which has led to some promising predictions [199293]. They begin their development with the electronic dispersion relationship for motion confined in a $2 \mathrm{D} \mathrm{QW}$ :

$$
\varepsilon\left(k_{x}, k_{y}, k_{z}\right)=\frac{\hbar^{2} k_{x}^{2}}{2 m_{x}}+\frac{\hbar^{2} k_{y}^{2}}{2 m_{y}}+\frac{\hbar^{2} \pi^{2}}{2 m_{z} a^{2}}
$$

where $m_{x}, m_{y}$, and $m_{z}$ are components of the effective mass tensor, $k_{x}$ and $k_{y}$ are the wave vectors in the $x$ - and $y$-directions; $a$ is the width of the QW (layer thickness), and $\hbar$ has its usual meaning (Planck's constant divided by $2 \pi$ ). In contrast, the expression for a bulk (3D) material has more allowed states for electrons, due to the wavevector $\mathrm{k}_{\mathrm{z}}$.

$$
\varepsilon\left(k_{x}, k_{y}, k_{z}\right)=\frac{\hbar^{2} k_{x}^{2}}{2 m_{x}}+\frac{\hbar^{2} k_{y}^{2}}{2 m_{y}}+\frac{\hbar^{2} k_{z}^{2}}{2 m_{z}}
$$


The Seebeck coefficient, electrical conductivity, and electronic contribution to the thermal conductivity of the 2D QW are derived from the dispersion relationship and are given as follows:

$$
\begin{gathered}
\alpha=-\frac{k_{B}}{e}\left(\frac{2 F_{1}}{F_{0}}-\zeta\right) \\
\sigma=\frac{1}{2 \pi a}\left(\frac{2 k_{B} T}{\hbar^{2}}\right)\left(m_{x} m_{y}\right)^{\frac{1}{2}} F_{0} e \mu_{x} \\
\kappa_{e l}=\frac{\tau \hbar^{2}}{4 \pi a}\left(\frac{2 k_{B} T}{\hbar^{2}}\right)^{2}\left(\frac{m_{y}}{m_{x}}\right)^{\frac{1}{2}} k_{B}\left(3 F_{2}-\frac{4 F_{1}^{2}}{F_{0}}\right)
\end{gathered}
$$

where $k_{B}$ is Boltzmann's constant; $F \lambda$ is the Fermi-Dirac integral, $e$ is the electronic charge; $T$ is temperature; $\mathrm{m}_{\mathrm{X}}$ is the mobility in the $\mathrm{X}$-direction; and $\tau$ is the relaxation time. The Fermi-Dirac integral is given by

$$
F_{2}=F_{\lambda}(\zeta)=\int_{0}^{\infty} \frac{x^{2} d x}{e^{(x-\zeta)}+1}
$$

where $\zeta^{*}$ is the reduced chemical potential relative to the edge of the conduction band (Fermi energy level) and is defined as

$$
\zeta=\frac{\zeta-\frac{\hbar^{2} \pi^{2}}{2 m_{z} a^{2}}}{k_{B} T}
$$

The dimensionless figure of merit for a $2 \mathrm{D}$ material is

$$
Z T_{2 D}=\frac{\left(\frac{2 F_{1}}{F_{0}}-\zeta\right)^{2} F_{0}}{\frac{1}{B}+3 F_{2}-\frac{4 F_{1}^{2}}{F_{0}}}
$$

where the parameter B accounts for the phonon contribution to the thermal conductivity and is

$$
B=\frac{1}{2 \pi a}\left(\frac{2 k_{B} T}{\hbar^{2}}\right)\left(m_{x} m_{y}\right)^{\frac{1}{2}} \frac{k_{B}^{2} T \mu_{x}}{e K_{p h}}
$$

Thus, for the 2D case, ZT may be varied both by changing doping and changing the layer thickness. Predictions of ZT as a function of layer thickness were made with the HicksDresselhaus model, assuming optimum doping, and are shown in Fig. 4. Two crystal orientations 
are considered for the $\mathrm{Bi}_{2} \mathrm{Te} 3 \mathrm{QW}$ : [1] parallel to the a0-c0 plane and [2] parallel to the a0-b0 plane. In the case of 10 angstrom layers, $Z_{2} \mathrm{D} \approx 3$ ( $6 \mathrm{X}$ enhancement) is predicted for a0-c0 orientation and $Z T_{2 D} \approx 1$ ( $2 \mathrm{X}$ enhancement) is predicted for $\mathrm{a} 0-\mathrm{b}_{0}$ orientation. Atomic monolayers with a0-c0 orientation are predicted to have $\mathrm{ZT}_{2 \mathrm{D}} \approx 7$ (14X enhancement). The line with no discrete points represents bulk $\mathrm{Bi}_{2} \mathrm{Te} 3$ and is given for reference (ZT3D $\left.\approx 0.5\right)$. According to their model, the confined motion of electrons in the $\mathrm{QW}$ increases the figure of merit of a highly anisotropic materials like $\mathrm{Bi}_{2} \mathrm{Te} 3$, provided that the superlattice is in a particular orientation. Harman, also of MIT, has used MBE to make short-period superlattices of Bi0.9Sb0.1 and $\mathrm{PbTe} 0.8 \mathrm{Se} 0.2$ [1992]. He claims to have produced multilayer structures with up to 4000 monolayers and "encouraging" thermoelectric properties. Apparently, semiconductor behavior is induced in the layer of Bio.9Sb0.1, which usually behaves like a semimetal (conduction and valence bands overlap). This superlattice behaves like a single-band, $2 \mathrm{D} \mathrm{QW}$ and has also been modeled by Hicks and Dresselhaus [1993]. Their predictions of ZT as a function of layer thickness are shown in Fig. 5. In this case, quantum theory indicates that it should be possible to achieve $Z T \geq 3$ with relatively thick layers (approximately 75 angstroms).

Confirmation of Quantum Well Model. Measurements of electrical conductivity alone should be sufficient to confirm the predicted QW behavior. From Hicks and Dresselhaus [1993], we know that the ratio of the $2 \mathrm{D}$ and $3 \mathrm{D}$ electrical conductivities is

$$
\frac{\sigma_{2 D}}{\sigma_{3 D}}=\frac{\pi}{a} \frac{F_{0,2 D}}{F_{1 / 2,3 D}} \frac{\hbar}{\sqrt{2 m_{z} k_{B} T}}
$$

From this ratio, we conclude that the critical dimension for $\mathrm{QW}$ enhancement of the electrical conductivity.

$$
a \leq \pi \frac{F_{0,2 D}}{F_{1 / 2,3 D}} \frac{\hbar}{\sqrt{2 m_{z} k_{B} T}}
$$

Note that the Fermi-Dirac transport integrals have different values, depending on whether they are calculated with $\zeta^{*}$ for $2 \mathrm{D}$ or 3D. Therefore, the Hicks-Dresselhaus model predicts that the electrical conductivity should increase as the width of the $\mathrm{QW}, \mathrm{a}$, is decreased. If we observe that $\sigma_{2 D} / \sigma_{3 D}$ has such a dependence, we will have at least a partial confirmation of the theory, as well as evidence that the multilayer thermoelectric film is exhibiting QW behavior. A more complete confirmation could be done if we know the Seebeck coefficient. Hicks and Dresselhaus also give theoretical expressions for both $\alpha_{2 D}$ and $\alpha_{32}$. These expressions and those for the 2D and 3D electrical conductivities can be used to predict the $Q W$ enhancement of the thermoelectric power factor, $\sigma \alpha^{2}$.

$$
\frac{\sigma_{2 D} a_{2 D}{ }^{2}}{\sigma_{3 D} \alpha_{3 D}{ }^{2}}=\frac{\pi}{a} \frac{F_{0,2 D}}{F_{1 / 2,3 D}} \frac{\hbar}{\sqrt{2 m_{z} k_{B} T}}\left(\frac{\frac{2 F_{1,2 D}}{F_{0,2 D}}-\zeta_{2 D}}{\frac{5 F_{3 / 2,3 D}}{3 F_{1 / 2,3 D}}-\zeta_{3 D}}\right)^{2}
$$




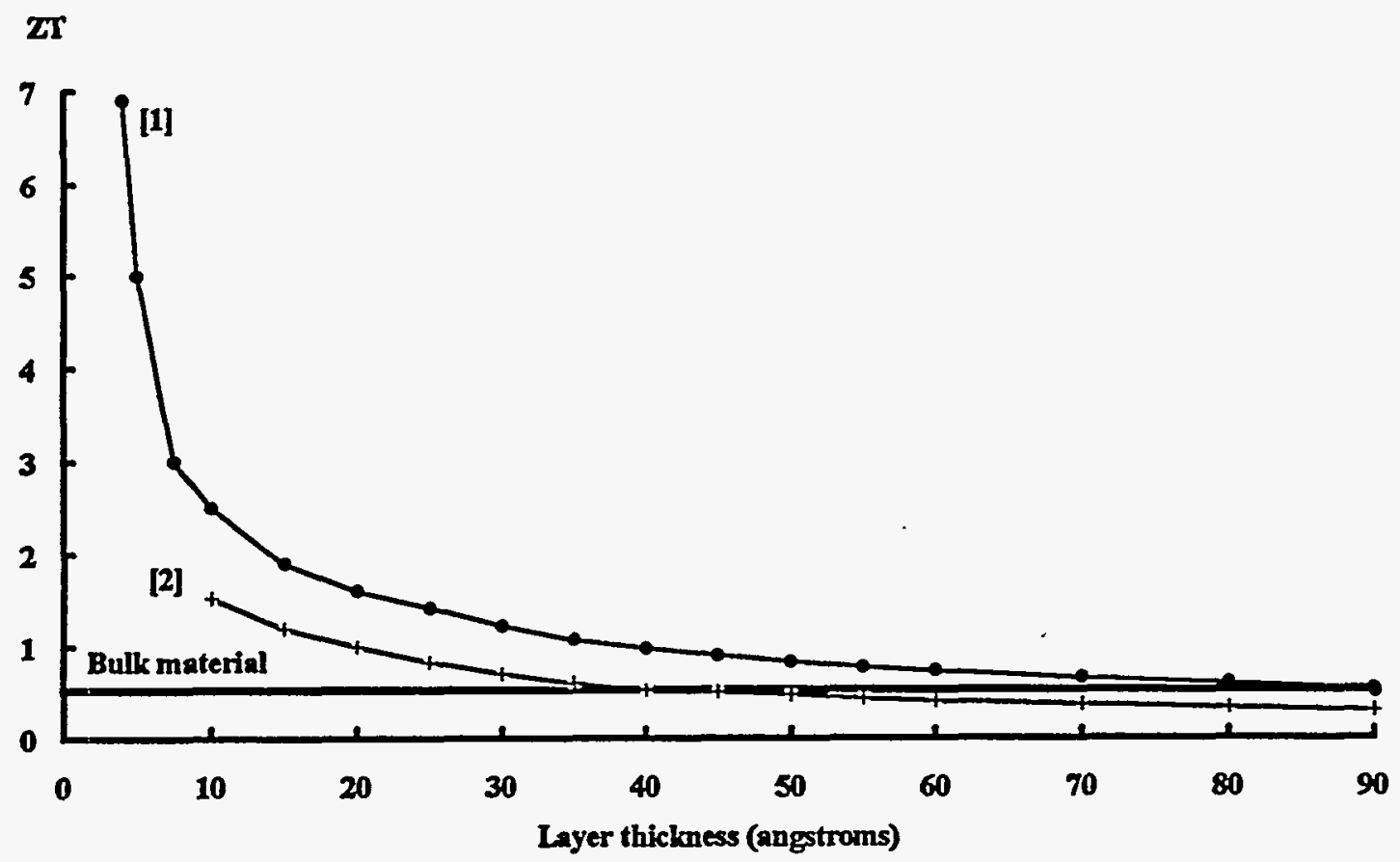

Fig. 4. Predicted $\mathrm{ZT}_{2 \mathrm{D}}$ for two-dimensional $\mathrm{Bi}_{2} \mathrm{Te} 3 \mathrm{QWs}$ as a function of thickness.

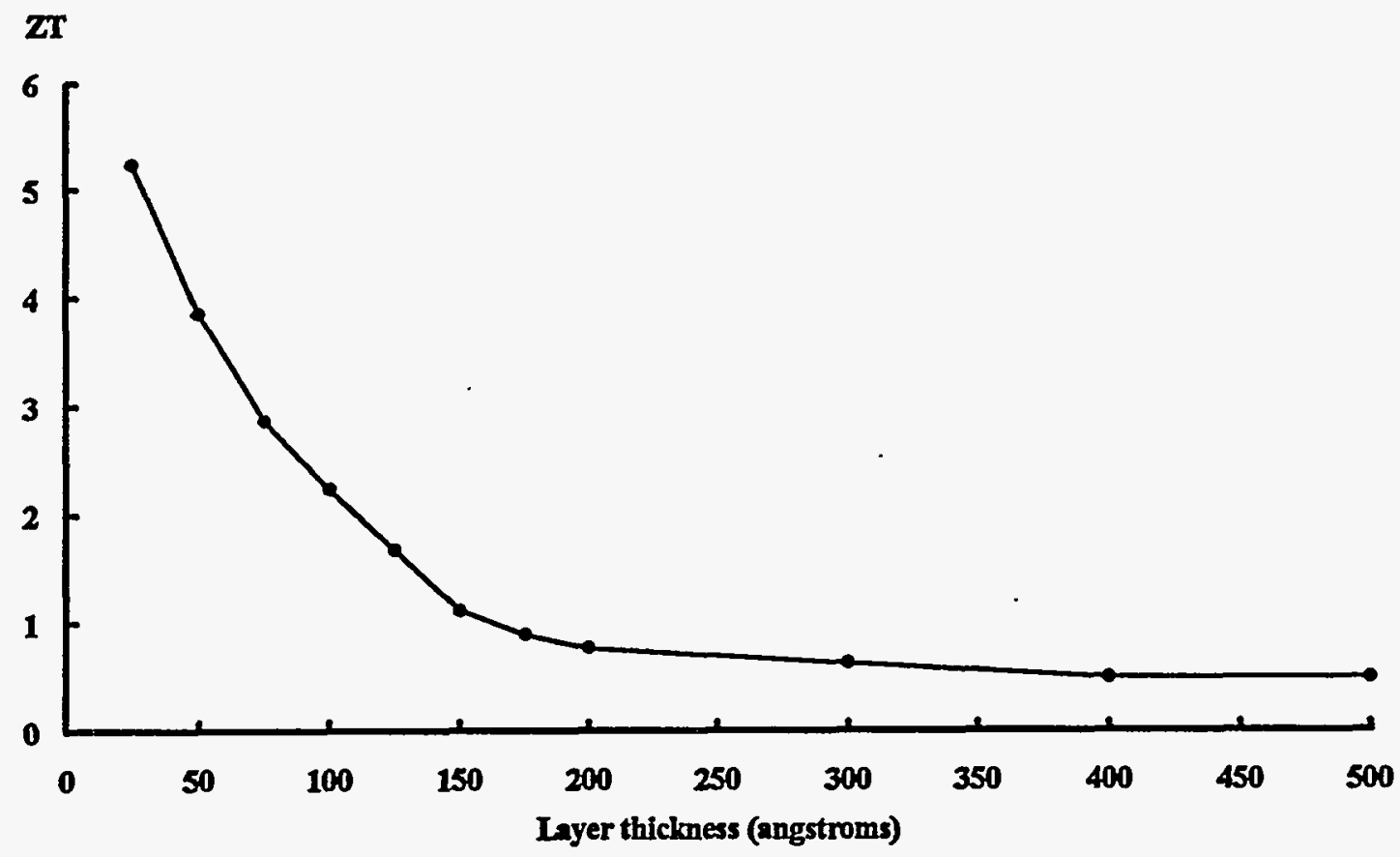

Fig. 5. Predicted $\mathrm{ZT}_{2 \mathrm{D}}$ for $\mathrm{Bi} 0.9 \mathrm{Sb} 0.1 / \mathrm{PbTe} 0.8 \mathrm{Se} 0.2$ layer pairs as a function of thickness. 
Usually, high power factors $\left(\sigma \alpha^{2}\right)$ are indicative of good thermoelectric materials. If we could determine the thermal conductivity, $\mathrm{Kel}_{\mathrm{l}}+\mathrm{K}_{\mathrm{ph}}$ the figure of merit, $\mathrm{Z}$, could be calculated. However, it is important to note that both the theory and material can be tested without measurement of the thermal conductivity.

Recognized Deficiencies of Quantum Well Model. The original theory developed by Hicks and Dresselhaus for 2D QWs shows the advantage of QW thermoelectric devices, but does not account for the scattering of charge carriers by defects, impurities, rough interfaces, and phonons. The model also fails to account for the trapping of charge carriers. These deficiencies are recognized and deserve the attention of theoretical solid-state physicists. Data presented here should facilitate the development of more complete theories.

\section{Technique for Synthesizing Multilayer Thermoelectric Films}

A Practical Approach to Synthesis. MBE is believed to be too expensive for the production of practical thermoelectric materials. However, sputtering, which is more than two orders of magnitude $(\sim 140 \mathrm{X})$ faster, has been demonstrated to allow fabrication of high-quality films and multilayers with QW dimensions [Barbee, 1984-91; Jankowski, 1991]. Single-layer, bilayer, and multilayer $\mathrm{Bi}_{2} \mathrm{Te} 3 / \mathrm{B} 4 \mathrm{C}$, Si $80 \mathrm{Ge}_{20} / \mathrm{Si}$, and $\mathrm{Bi} 0.9 \mathrm{Sb} 0.1 / \mathrm{PbTe}_{0} .8 \mathrm{Se}_{0.2}$ films have been deposited by sputtering. Sputtered $\mathrm{Si}^{8} \mathrm{Ge}_{20} / \mathrm{Si}$ multilayers can be compared to similar heterostructures synthesized with MBE. Furthermore, this system should have good thermoelectric properties at high temperature. The $\mathrm{Bi}_{2} \mathrm{Te}_{3} / \mathrm{B}_{4} \mathrm{C}$ and $\mathrm{Bi}_{0.9} \mathrm{Sb}_{0.1} / \mathrm{PbTe}_{0.8} \mathrm{Se}_{0.2}$ systems are expected to have better thermoelectric properties at low temperature. Bi0.9Sb0.1 quantum wells of practical thickness are predicted to have better thermoelectric performance than those made of $\mathrm{Bi}_{2} \mathrm{Te} 3$. The effects of substrate temperature on the structure and orientation of deposited layers has been investigated. The Seebeck coefficient, electrical conductivity, and power factor of each film have been determined as functions of temperature (ambient to $500 \mathrm{~K}$ ) by the techniques described in a subsequent section.

Details of the Sputtering Process. Multilayer thermoelectric films (2D QWs) are synthesized by sputtering onto a moving substrate from dual magnetrons, as illustrated by Fig. 6 . The quantumwell layer (QW) is sandwiched between two barrier layers (B). Typically, the QW material has a very narrow band gap and the barrier material has a relatively large band gap. Sputtering is being done in an existing sputtering system that was developed for the fabrication of X-ray optics. This novel system has a stainless steel vacuum chamber. Vacuum is established and maintained by a two-stage mechanical roughing pump and a high-capacity cryogenic pump. The system usually achieves base pressures of $\sim 10-8$ torr after bake-out and before sputtering. Single-crystal sapphire or high-resistance $(1000 \Omega-\mathrm{cm})$ silicon substrates are mounted on a rotating carousel driven by a precision stepper motor. Substrates can be heated or cooled by the carousel during sputtering. Heating of the substrate during deposition and subsequent annealing is used as means of controlling the structure and orientation of individual crystalline layers, as well as means of reducing the number of defects in films. One of the essential conditions for epitaxial film growth is a high mobility of condensed atoms and molecules on the surface of the substrate. Since mobility depends upon kinetic energy, it is desirable to heat the substrate during deposition. Two $1 \mathrm{~kW}$ magnetrons, each having a 2.5 -inch diameter target and a $1 \mathrm{~kW}$ power supply, are used to 
deposit films. The sputter sources are operated at an argon pressure between 0.001 and 0.1 torr. Argon is admitted to the system by a precision flow controller. All functions of the system, including movement of the carousel, rates of heating and cooling, magnetron power, and argon pressure, are computer controlled. A photograph of this system is shown in Appendix A.

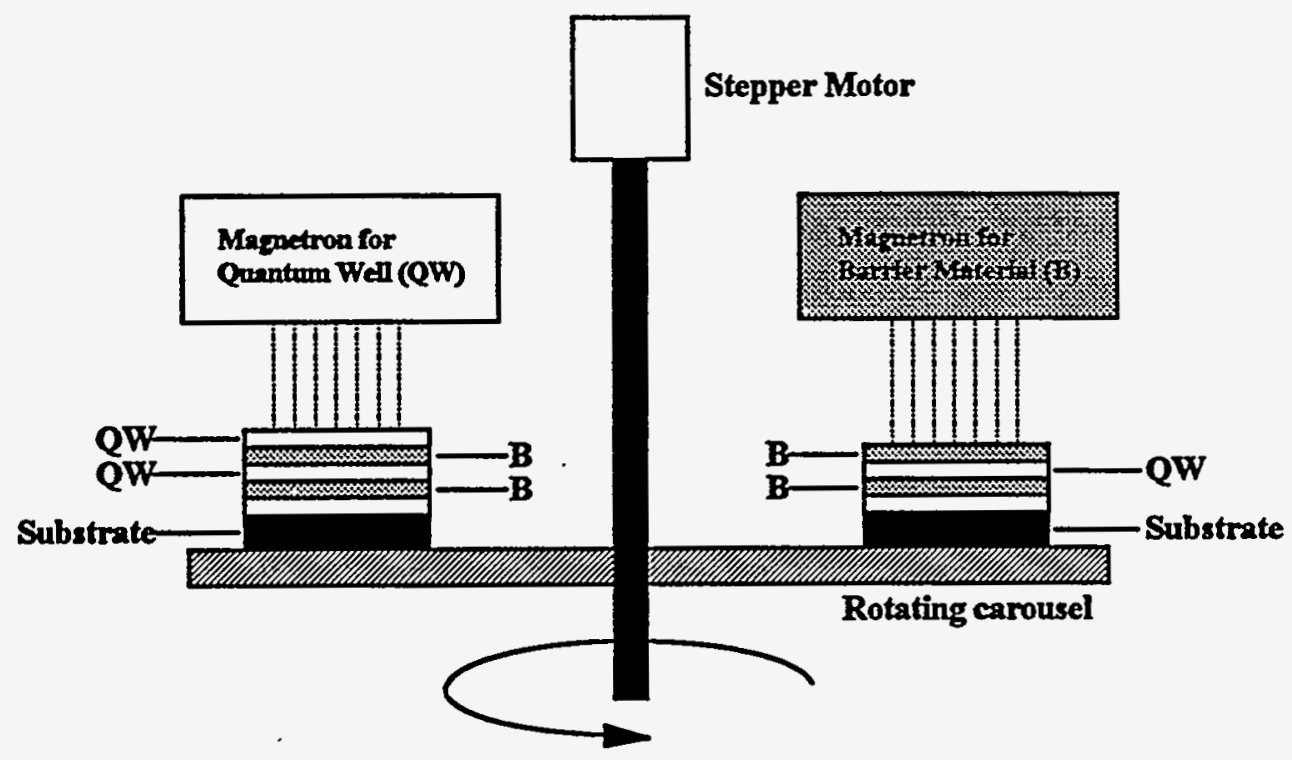

Fig. 6. Dual-magnetron sputtering process for fabrication of 2D QWs.

Preparation of Targets and Standards. Sputtering targets of $(\mathrm{Bi}, \mathrm{Sb})$ and $\mathrm{Pb}(\mathrm{Te}, \mathrm{Se})$ were obtained from Target Materials, Inc. of Columbus, Ohio. Targets of Si80Ge20 and Si were provided by Hi-Z Technology of San Diego, CA and were prepared by General Electric of Valley Forge, PA. Targets and bulk (3D) standards were made by standard powder metallurgy techniques. For example, the procedure used by the authors for the preparation of bulk standards is described. Ingots were made by melting zone-refined elements under vacuum in sealed, quartz ampoules. Powders were then made by grinding ingots in a mortar and pestle made of boron carbide. A particle size of 200 mesh was selected by sieving. All powder processing was conducted in a glove box under dry, oxygen-free argon ( $\left.\leq 10 \mathrm{ppm} \mathrm{O}_{2}\right)$ or vacuum $(\leq 0.01$ torr). Finished powder was poured into a cylindrical die made of high-purity graphite and compressed by a vacuum hot press at $3500 \mathrm{psi}$ and $80 \%$ of the melting point of the material. The vacuum hot press that was used was equipped with a hydraulic ram, tungsten-mesh filaments and heat shields, and an array of thermocouples. After purging with argon from a large dewer, vacuum was established and maintained at a level below 0.06 torr.

\section{Techniques for Characterizing Thermoelectric Thin Films}

Structural Characterization. First, X-ray fluorescence (XRF) is used to verify the composition of the sputtering targets. Then, X-ray diffraction (XRD) is used to determine the crystal structure. Transmission electron microscopy (TEM) with selected-area transmission electron diffraction is used to determine characteristics of single-layer, bilayer, and multilayer thermoelectric films such as crystallographic orientation and thickness of individual layers. Auger electron spectroscopy 
(AES) with depth profiling is used to study compositional variations across interfaces. Results are discussed in a subsequent section.

Seebeck Coefficient. The Seebeck coefficient, electrical conductivity, and power factor of all thin films are determined as functions of temperature. Since these films are supported by a substrate and cannot be thermally isolated, the standard Harman technique cannot be used. As illustrated in Fig. 7, the Seebeck coefficient is determined with a differential hot stage.

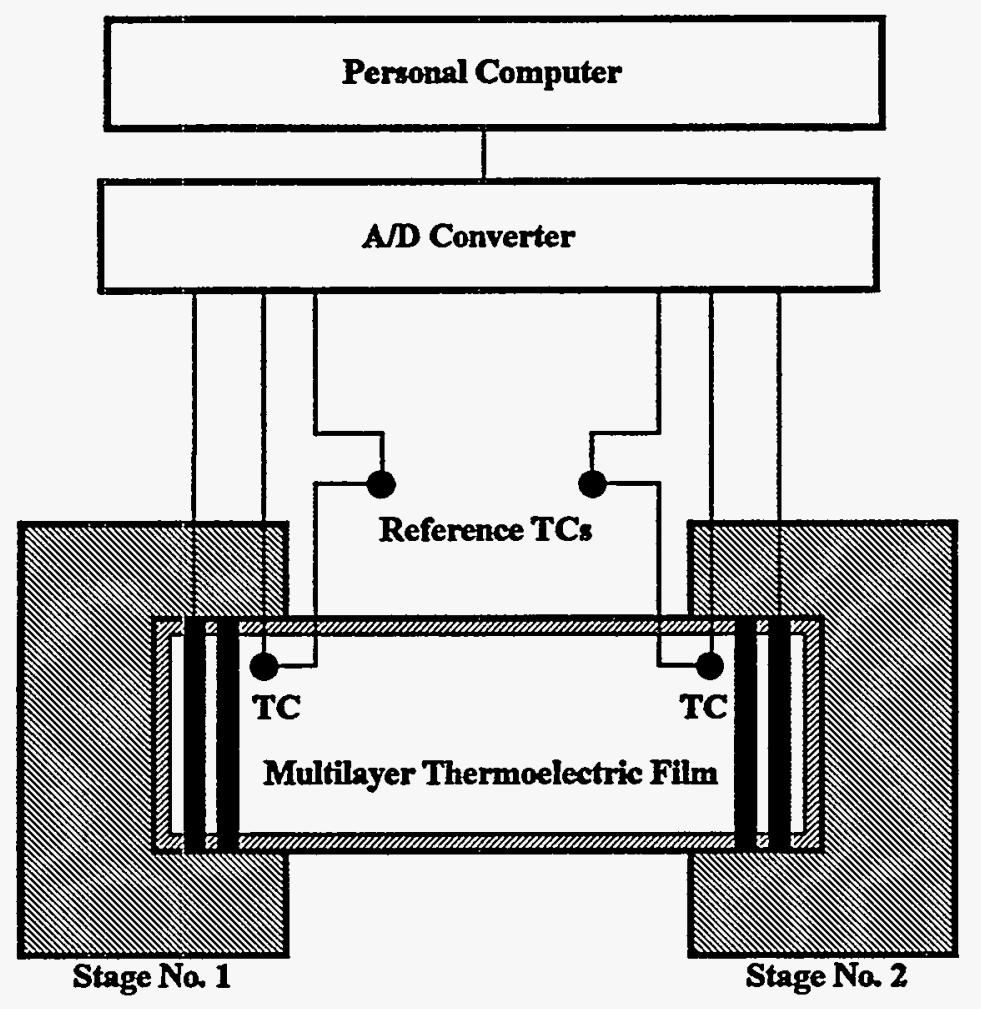

Fig. 7. Differential hot stage for measurement of the Seebeck coefficient of a supported thermoelectric film.

One end of the film is heated while the opposite end is cooled. During the first phase of the experiment, Stage No. 1 serves as the heat sink and Stage No. 2 serves as the heat source, thereby producing a positive temperature gradient. During the second phase of the experiment, Stage No. 1 serves as the heat source and Stage No. 2 serves as the heat sink, thereby producing a negative temperature gradient. The film is electrically isolated from the two stages by the sapphire substrate. The Seebeck coefficient of the film, $\alpha$ film, is estimated from the temperature difference, $\Delta \mathrm{T}$, and the voltage difference, $\Delta \mathrm{V}_{\text {film }}$.

$$
\alpha_{\text {film }} \cong \frac{-\Delta V_{\text {fllm }}}{\Delta T}
$$

Note that $\Delta V_{\text {film }}$ is a corrected value of the measured voltage difference, $\Delta V_{\text {measured, }}$ and accounts for substrate contributions to the thermoelectric voltage, $\Delta \mathbf{V}_{\text {substrate. }}$ 


$$
\Delta V_{f i m}=\left(1+\frac{R_{f i m}}{R_{\text {substrate }}}\right) \Delta V_{\text {mearuned }}-\left(\frac{R_{f i m}}{R_{\text {substrate }}}\right) \Delta V_{\text {subitrate }}
$$

where $\mathbf{R}_{\text {film }}$ and $\mathrm{R}_{\text {substrate }}$ are the overall resistances of the film and substrate, respectively. If

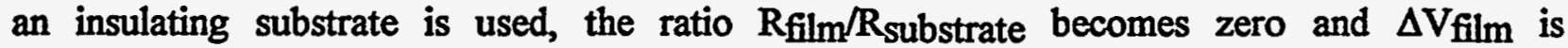

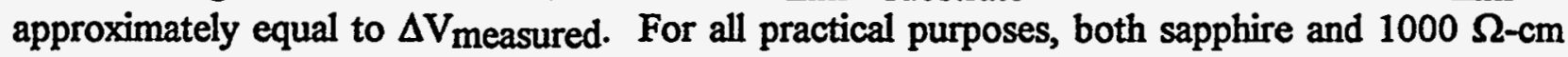
silicon can both be treated like insulating substrates. However, if $10 \Omega$-cm device-quality silicon is used as a substrate, substrate contributions to the measured voltage must be accounted for. This approach has been applied to a number of single-layer, bilayer, and multialyer $\mathrm{Si}_{80 \mathrm{Ge}} \mathrm{O} / \mathrm{Si}$ films, as well as to single-layer, bilayer, and multilayer $\mathrm{Bi} 0.9 \mathrm{Sb} 0.1 / \mathrm{PbTe} 0.8 \mathrm{Se} 0.2$ films. For example, the Seebeck coefficient of an n-type Si80Ge20/Si multilayer with 133 angstrom layer pairs and a total thickness of 8500 angstroms was determined. The temperature profiles and the corresponding differential voltage are shown in Figs. 8 and 9, respectively. Similar data for a single-layer $\mathrm{PbTe} 0.8 \mathrm{Se} 0.2$ film having a thickness of 7,896 angstroms are shown in Figs. 10 and 11 , respectively. Data for a $\mathrm{Bi} 0.9 \mathrm{Sb} 0.1 / \mathrm{PbTe} 0.8 \mathrm{Se} 0.2$ multilayer film having a total thickness of 17,029 angstroms are shown in Figs. 12 and 13. Results are discussed in a subsequent section.

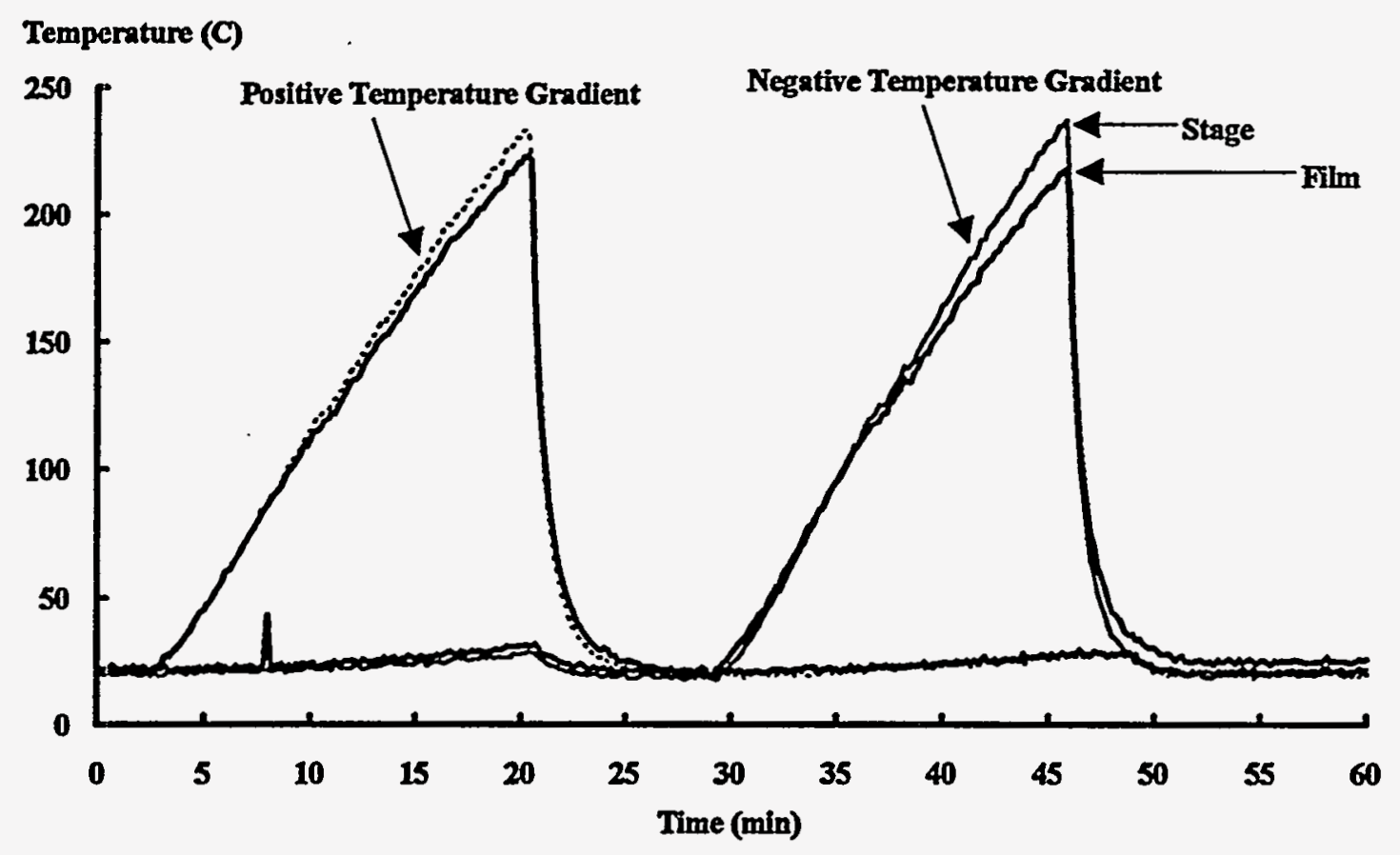

Fig. 8. Use of differential hot stage to determine the Seebeck coefficient of a SisoGe20/Si multilayer film having a total thickness of 8500 Angstroms and 133 Angstrom layer pairs. The corresponding differential voltage is shown in Fig. 9. 


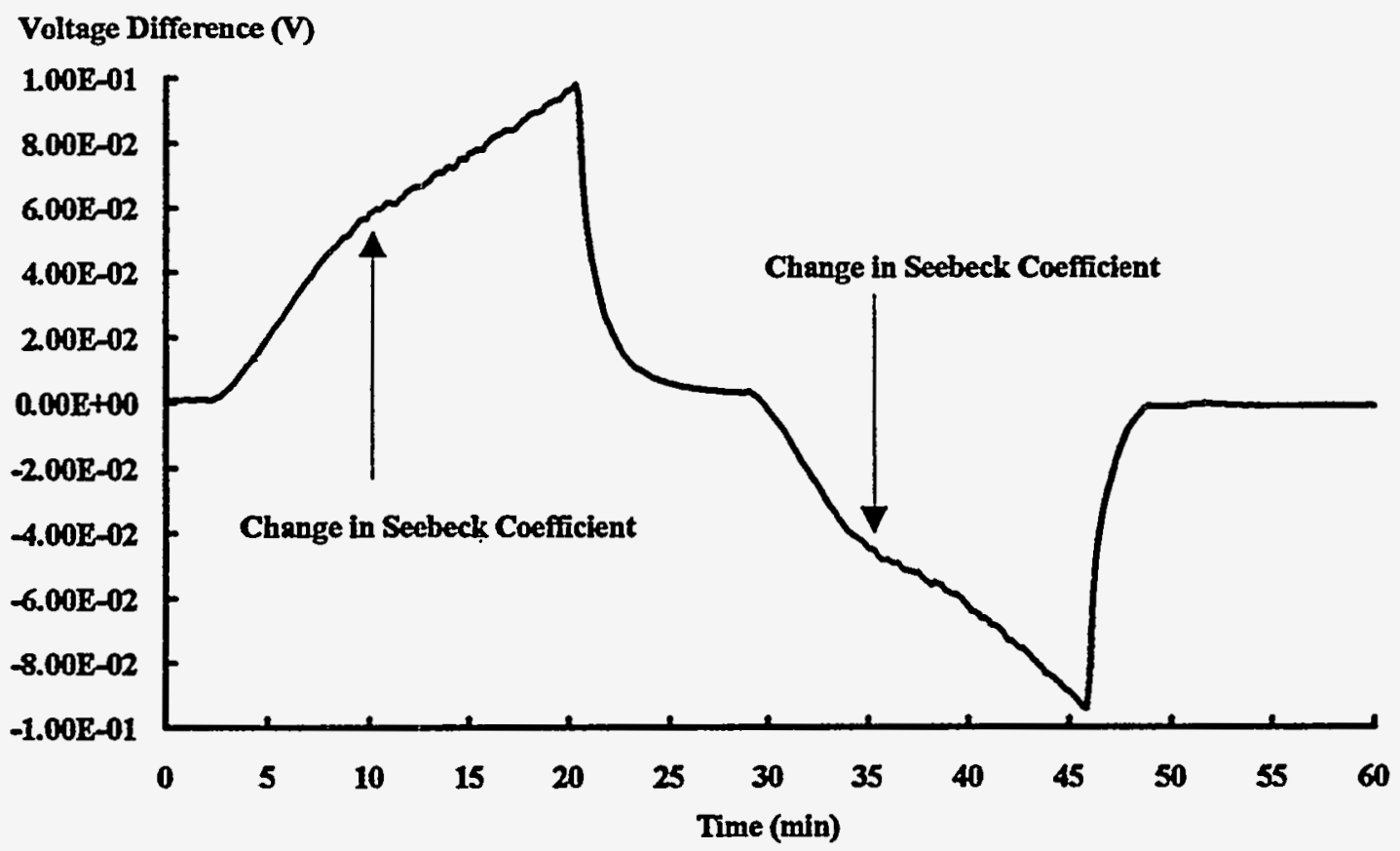

Fig. 9. Use of differential hot stage to determine the Seebeck coefficient of a $\mathrm{Si}_{80 \mathrm{Ge}} \mathrm{O} / \mathrm{Si}$ multilayer film having a total thickness of 8500 Angstroms and 133 Angstrom layer pairs. Potential difference due to imposed temperature gradients shown in Fig. 8.

Temperature (C)

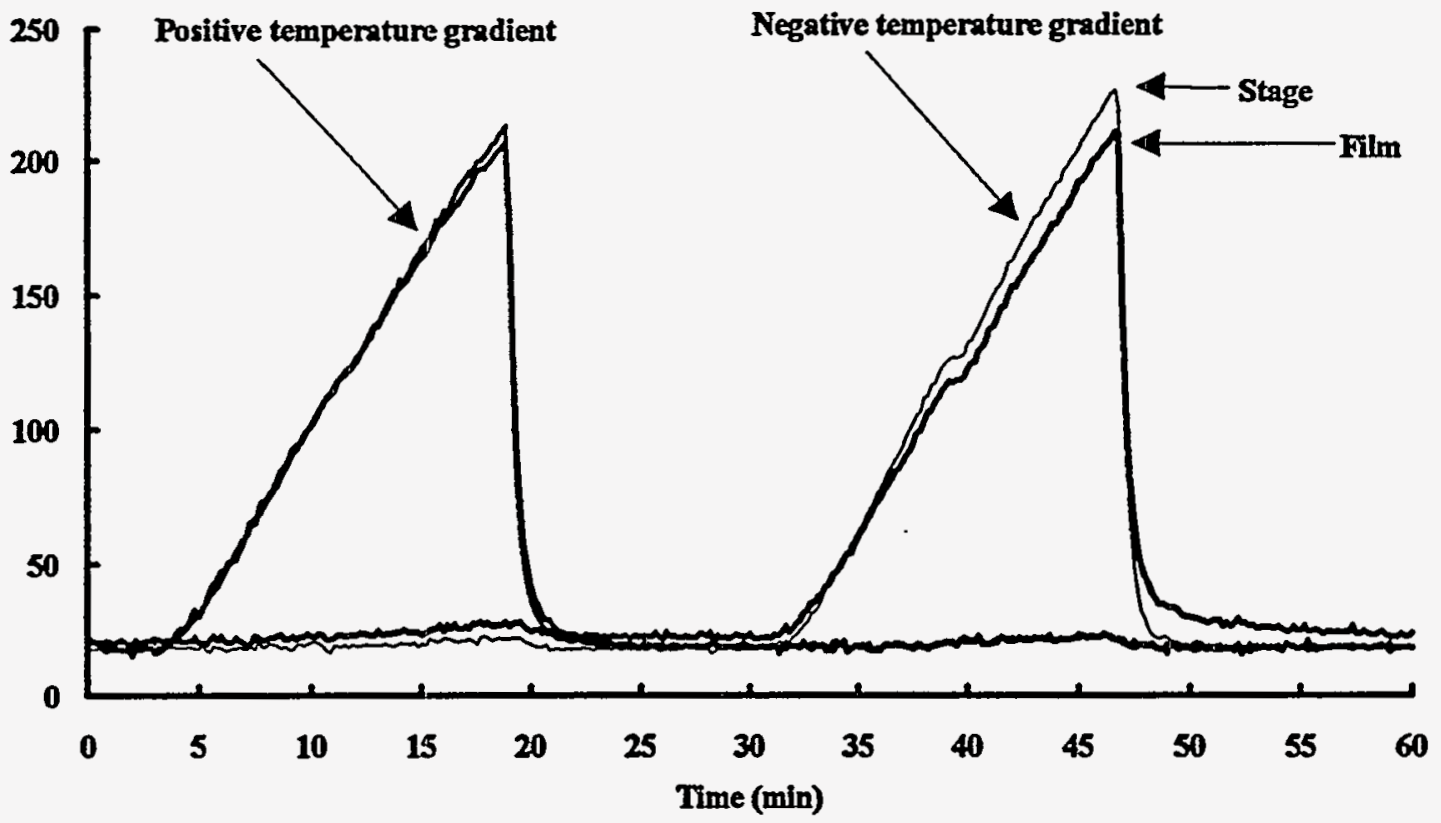

Fig. 10. Use of differential hot stage to determine the Seebeck coefficient of a single-layer $\mathrm{PbTe} 0.8 \mathrm{Se} 0.2$ film having a thickness of 7,896 angstroms. The corresponding differential voltage is shown in Fig. 11.

16 


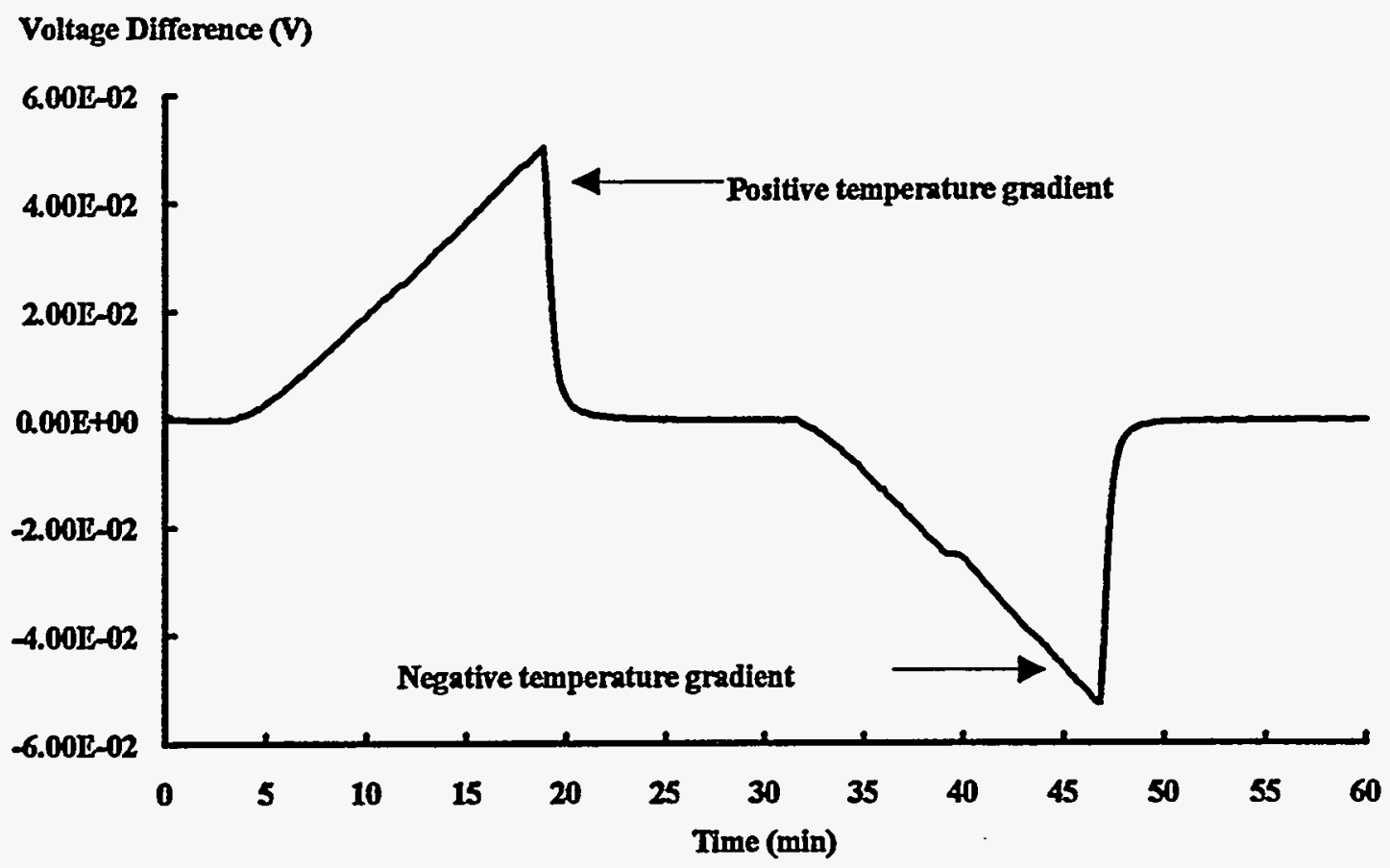

Fig. 11. Use of differential hot stage to determine the Seebeck coefficient of a single-layer $\mathrm{PbTe} 0.8 \mathrm{Se} 0.2$ film having a thickness of 7,896 angstroms. Potential difference due to imposed temperature gradients shown in Fig. 10.

Temperature (C)

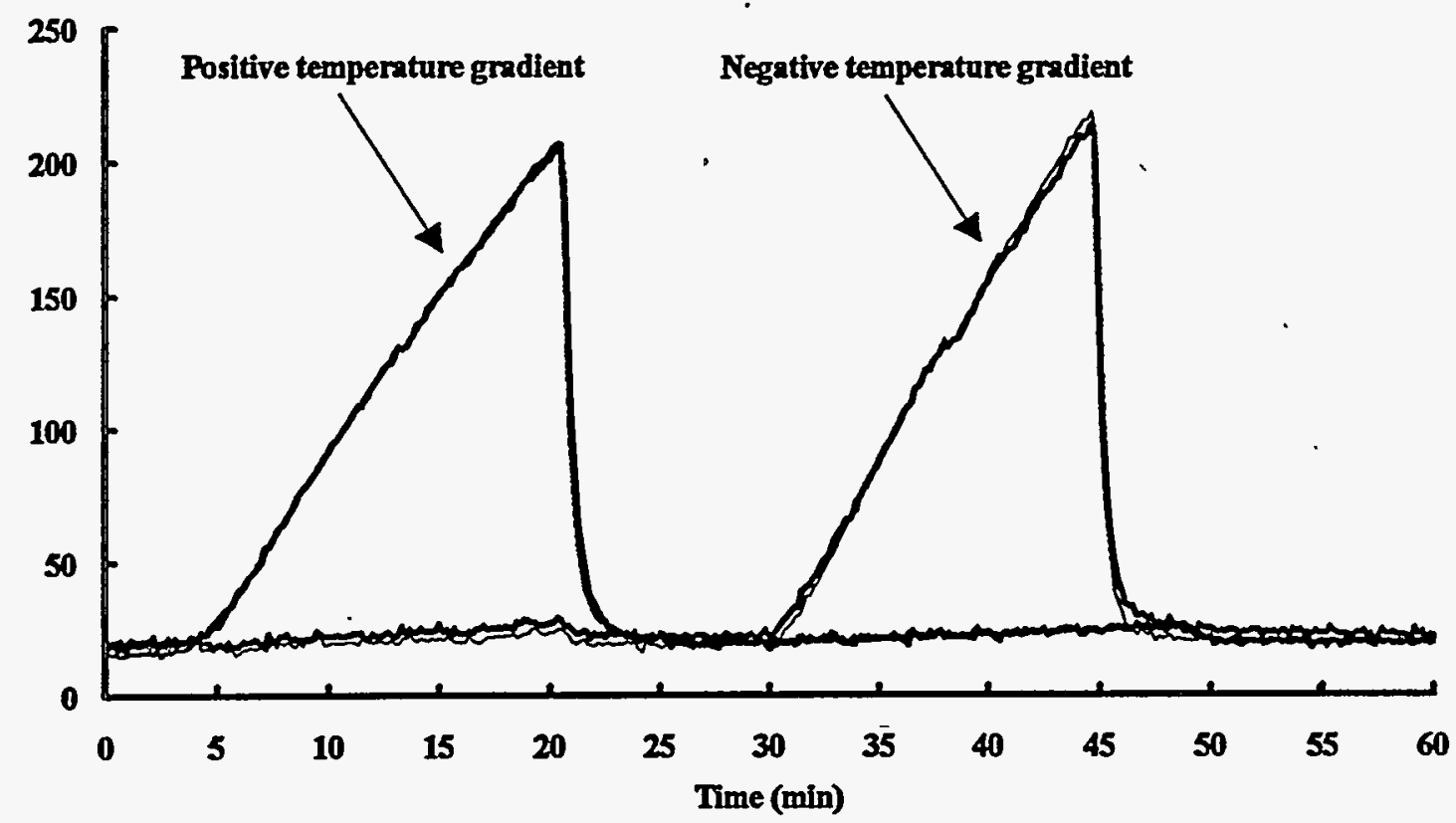

Fig. 12. Use of differential hot stage to determine the Seebeck coefficient of a Bi0.9Sb0.1/PbTe $0.8 \mathrm{Se} 0.2$ multilayer film having a total thickness of 17,029 angstroms. Temperature profiles of the two stages (opposite ends of the film) are shown. The corresponding differential voltage is shown in Fig. 13. 
Voltage Difference $(V)$

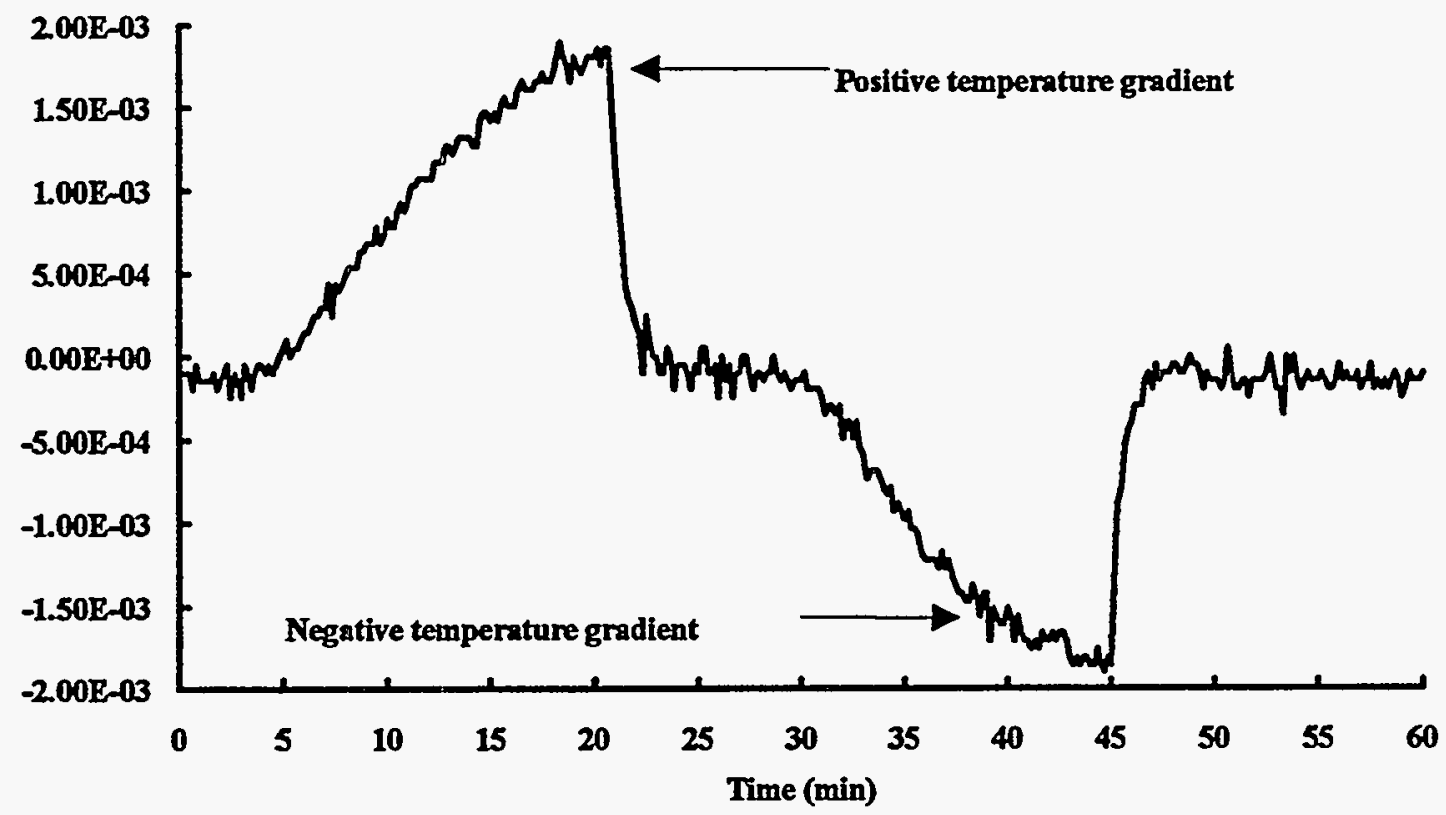

Fig. 13. Use of differential hot stage to determine the Seebeck coefficient of a $\mathrm{Bi} 0.9 \mathrm{Sb0} 0.1 / \mathrm{PbTe} 0.8 \mathrm{Se} 0.2$ multilayer film having a total thickness of 17,029 angstroms. Potential difference due to imposed temperature gradients shown in Fig. 12.

Electrical conductivity. Variations of ASTM Standards F43 and F46 are used to evaluate these novel thin films. As illustrated in Fig. 14, the samples are configured in accordance with the twoprobe method. First, a precision resistor is connected in series with the thin film. Then, a standard adder potentiostat is used to apply a bipolar potential pulse across the terminals of the resistor. A corresponding current pulse, Ipulse, must flow through both the resistor and thin film simultaneously. Two spring-loaded probes and one channel of a two-channel digital oscilloscope

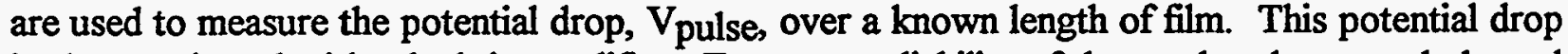
is also monitored with a lock-in amplifier. To assure reliability of the results, the second channel of the oscilloscope is used to monitor the $100 \mathrm{mV}$ differential across the resistor. The overall electrical resistance of the film, Rfilm, can be calculated direcly from the ratio of the amplitudes of $I_{\text {pulse }}$ and $V_{\text {pulse, }}$ provided that the electrical resistance of the underlying substrate, $R_{\text {substrate }}$ is known.

$$
\frac{1}{R_{\text {flim }}}=\frac{I_{\text {pulse }}}{V_{\text {pulse }}}-\frac{1}{R_{\text {substrate }}}
$$

As in the case of the Seebeck coefficient, it is desirable to use insulating substrates. The electrical conductivity of the film, $\sigma$ film, can be calculated directly from overall electrical resistance of the film, Rfilm; the length of the film, Lfilm; and the cross-sectional area of the film, Afilm. 


$$
\sigma_{f l m}=\frac{L_{f l m}}{A_{f l m}} \frac{1}{R_{f l i m}}
$$

Note that the power factor of the film, PFfilm, can be calculated from the Seebeck coefficient and the electrical conductivity.

$$
P F_{f i l m}=\sigma_{f i m} \alpha_{f l m}^{2}
$$

The reliability of this experimental technique has been checked by evaluating several metallic films. For example, the resistivities $(\rho=1 / \sigma)$ of several sputtered copper films were determined at ambient temperature and found to be in the range of 1.80 to $2.32 \mu \Omega-\mathrm{cm}$. These measurements compare reasonably well to a published value of $1.77 \mu \Omega$-cm for crystalline copper.

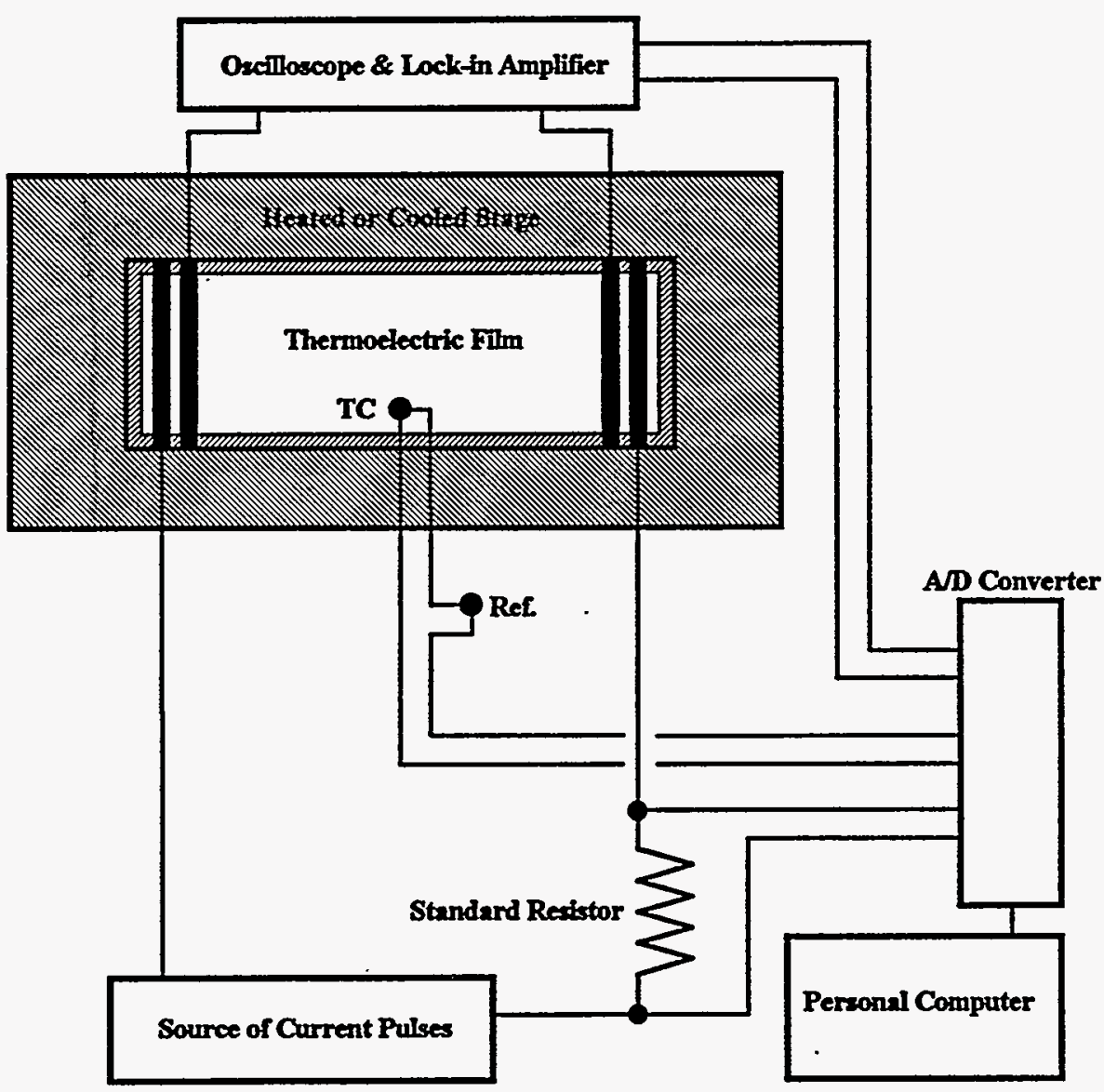

Fig. 14. Apparatus for measurement of electrical resistivity of a supported thermoelectric film.

As an example, resistivity data for the Si80Ge20/Si multilayer having 133 angstom layer pirs and a total thickness of 8500 angstroms is shown in Fig. 15. The same film was used for the Seebeck cefficient measurements illustrated by Figs. 8 and 9 . Note that the time axis has been labled with the film temperature. Results for $\mathrm{Bi} 0.9 \mathrm{Sb} 0.1 / \mathrm{PbTe} 0.8 \mathrm{Se} 0.2$ films are discussed in a subsequent section. 


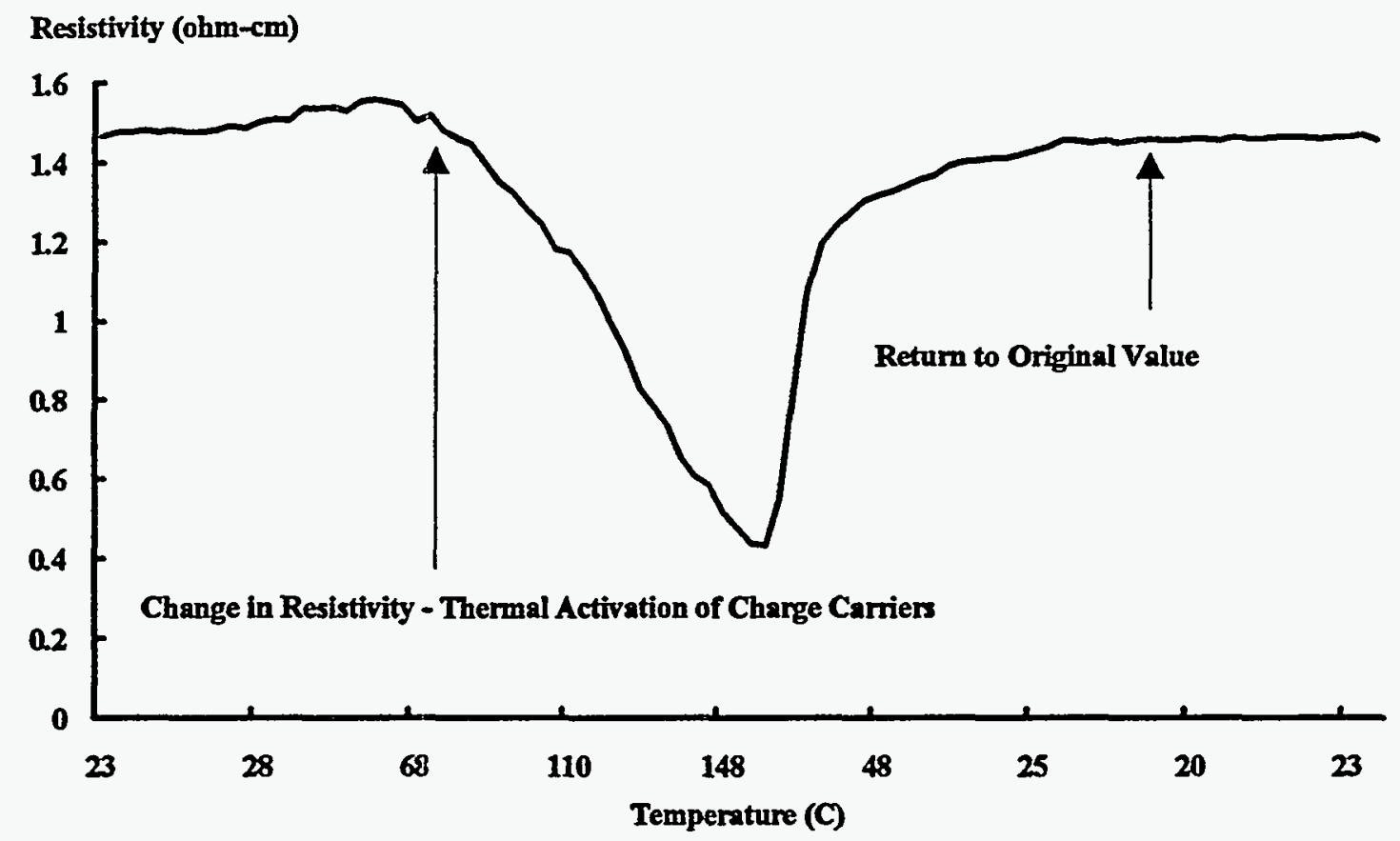

Fig. 15. Resistivity of Si80Ge20/Si multilayer having 133 angstrom layer pairs and a total thickness of 8500 angstroms.

\section{Earlier Attempts to Synthesize Thermoelectric Quantum Wells}

$B i_{2} \mathrm{Te}_{3} / \mathrm{B}_{4} \mathrm{C}$ System. Initially, we attempted to prepare multilayers from $\mathrm{Bi} 2 \mathrm{Te} 3$, a well known, low-temperature thermoelectric material [Farmer, 1993-94]. We made a number of unsuccessful attempts with dual-magnetron sputtering to deposit thin layers of $\mathrm{Bi}_{2} \mathrm{Te} 3$, separated by a variety of barrier materials. Eventually, some degree of success was achieved by using B4C as a barrier layer. These films were characterized by X-ray diffraction (XRD), transmission electron microscopy (TEM), and electron diffraction. The structure of the film was disappointing. The $\mathrm{B} 4 \mathrm{C}$ layer was virtually amorphous, while the $\mathrm{Bi}_{2} \mathrm{Te} 3$ was polycrystalline. Data indicated the presence of two crystalline phases, rhombohedral and rock-salt structures, respectively. Interfaces were unusually rough. As expected from the structural characterization, initial measurements of the Seebeck coefficient and electrical conductivity between ambient temperature and $100^{\circ} \mathrm{C}$ were disappointing. For example, a film with a total thickness of 6900 angstroms and 235 angstrom layer pairs had an electrical resistivity of $38 \mathrm{~m} \Omega-\mathrm{cm}$ and a Seebeck coefficient of $480 \mathrm{mV} / \mathrm{K}$ near ambient temperature. The $\mathrm{n}$-type behavior of this film is surprising and may be due to the presence of the rock-salt phase. These measured properties are poor in comparison to those published for single crystals of $\mathrm{Bi}_{2} \mathrm{Te} 3$ at $300 \mathrm{~K}$, which are $2 \mathrm{~m} \Omega-\mathrm{cm}$ and $+220 \mathrm{mV} / \mathrm{K}$, respectively [D.-B. Hyun et al., 1992]. Carrier transport in the imperfect $\mathrm{Bi2}$ Te3/B4C multilayer was probably limited by scattering and interfacial trapping. 


\section{Results with Si80Ge $20 /$ Si on Silicon}

Sis0Ge20/Si System. Data from other laboratories indicated that it might be possible to achieve high ZT with Si80Ge20/Si heterostructures synthesized with molecular beam epitaxy (MBE) [Elsner, 1994]. This heterostructure system was of particular interest since Si80Ge20 is the preferred thermoelectric material for high-temperature applications. These factors prompted the authors to use dual-magnetron sputtering to synthesize $\mathrm{Si} 80 \mathrm{Ge} 20 / \mathrm{Si}$ multilayers by alternating heavily doped, n-type Si80Ge20 and lightly doped Si [Farmer, 1994]. The corresponding singlelayer films were also produced for comparison. Based upon Hall effect measurements, the carrier density in the Si80Ge20 sputtering target was determined to be approximately $1019 \mathrm{~cm}^{-3}$. Films were deposited on doped single-crystal silicon (100) substrates having a resistivity of $10 \Omega-\mathrm{cm}$, high-purity single-crystal substrates having a resistivity of $1000 \Omega$-cm, and single-crystal sapphire (1102) substrates. We attempted to manipulate the film structure and electronic properties by controlling the substrate temperature during deposition. Films deposited on $1000 \Omega-\mathrm{cm}$ silicon (100) at $410^{\circ} \mathrm{C}$ were polycrystalline and conductive. This substrate temperature corresponds to approximately $35 \%$ of the melting point of the film and enhanced the conductivity of films by a factor of five (X5). Beautiful multilayer films with excellent interfaces were produced with 133 angstrom layer pairs and thicknesses up to 8500 angstroms. In contrast, films deposited on lowtemperature silicon, as well as on sapphire, were amorphous and proved to be very poor electronic conductors. The differential hot stage described in the previous sections was used to measure the Seebeck coefficient and electrical resistivity between ambient temperature and $200^{\circ}$ C. Dramatic drops in both Seebeck coefficient and electrical resistivity were observed as samples were heated above a threshold temperature. These drops were attributed to a thermal activation of charge carriers. For example, a Si80Ge20/Si multilayer deposited on heated $\mathrm{Si}(100)$ had a Seebeck coefficient of $-650 \mu \mathrm{V} / \mathrm{K}$ (Figs. 8 and 9) and a resistivity of $\sim 1.5 \Omega$-cm (Fig. 15) at ambient temperature. These values dropped to less than $-350 \mu \mathrm{V} / \mathrm{K}$ and $\sim 0.4 \Omega-\mathrm{cm}$, respectively, as the temperature was increased through $90^{\circ} \mathrm{C}$ to a maximum of $200^{\circ} \mathrm{C}$. Further increases in temperature might have enhanced the electrical conductivity even more. The change in transport properties was completely reversible. As the film cooled, the Seebeck coefficient and electrical resistivity returned to their original values of $-650 \mu \mathrm{V} / \mathrm{K}$ and $\sim 1.5 \Omega-\mathrm{cm}$. While performing a similar experiment with a Si80Ge20/Si multilayer deposited on cooled $\mathrm{Si}(100)$, significant irreversibility due to annealing was observed. In this case, measured properties failed to return to original values after cooling. As the sample was heated, the resistivity dropped to a minimum of $0.1 \Omega$-cm. Comparable values for bulk n-type Sis0Ge20 have been recently published and are -90 $\mu \mathrm{V} / \mathrm{K}$ and $0.75 \mathrm{~m} \Omega-\mathrm{cm}$, respectively [Fu, 1992]. Data for an entire parametric study of this thinfilm system are given in Table I. These sputtered single layer and multilayer Si80Ge20 films are scientifically interesting in that they provide insight into the trapping of charge carriers in materials with unusually high interfacial areas, as well as insight into the trapping of charge carriers by broken bonds in disordered $\mathrm{Si}$ and Si-Ge alloys. However, they do not appear to be promising thermoelectric materials. Si80Ge20/Si heterostructures fabricated by $\mathrm{MBE}$ deserve more attention. 
Table I. Summary of Thermoelectric Measurements of Si80Ge20/Si Sputtered Films on HighReistance Single-Crystal Silicon.

\begin{tabular}{|c|c|c|c|c|c|c|c|}
\hline Film & $\begin{array}{l}1000 \Omega-\mathrm{cm} \\
\text { Si Substrate }\end{array}$ & $\begin{array}{l}\text { Thickness } \\
\text { (Angstroms) }\end{array}$ & $\begin{array}{l}-\alpha(\mu V / K) \\
+d T / d x\end{array}$ & $\begin{array}{l}+\alpha(\mu V / K) \\
-d T / d x\end{array}$ & $\begin{array}{l}\rho(\Omega-\mathrm{cm}) \\
22^{\circ} \mathrm{C}\end{array}$ & $\begin{array}{l}\rho(\Omega-\mathrm{cm}) \\
100^{\circ} \mathrm{C}\end{array}$ & $\begin{array}{l}\rho(\Omega-\mathrm{cm}) \\
150^{\circ} \mathrm{C}\end{array}$ \\
\hline $\begin{array}{l}\text { First Series } \\
\text { Si (SL) } \\
\text { Si (SL) } \\
\text { Si80Ge20 (SL) } \\
\text { Si80Ge20 (SL) } \\
\text { Si80Ge20/Si (ML) } \\
\text { Si80Ge20/Si (ML) }\end{array}$ & $\begin{array}{l}\text { cold } \\
\text { hot } \\
\text { cold } \\
\text { hot } \\
\text { cold } \\
\text { hot }\end{array}$ & $\begin{array}{l}4977 \\
4977 \\
4873 \\
4873 \\
8502 \\
8502\end{array}$ & $\begin{array}{l}869 \\
790 \\
885 \\
643 \\
810 \\
646\end{array}$ & $\begin{array}{l}\mathbf{5 6 8} \\
\mathbf{7 7 1} \\
\mathbf{7 3 6} \\
\mathbf{5 4 9} \\
\mathbf{7 4 2} \\
\mathbf{5 8 7}\end{array}$ & $\begin{array}{l}3.09 \\
1.99 \\
1.82 \\
0.75 \\
3.32 \\
1.46\end{array}$ & $\begin{array}{l}1.71 \\
0.97 \\
1.47 \\
0.33 \\
1.80 \\
1.28\end{array}$ & $\begin{array}{l}0.27 \\
0.39 \\
0.30 \\
\\
0.50 \\
0.47\end{array}$ \\
\hline $\begin{array}{l}\text { Second Series } \\
\text { Si (SL) } \\
\text { Si (SL) } \\
\text { Si80Ge20 (SL) } \\
\text { Si80Ge20 (SL) } \\
\text { Si80Ge20/Si (ML) } \\
\text { Si80Ge20/Si (ML) }\end{array}$ & $\begin{array}{l}\text { cold } \\
\text { hot } \\
\text { cold } \\
\text { hot } \\
\text { cold } \\
\text { hot }\end{array}$ & $\begin{array}{l}4372 \\
4372 \\
5637 \\
5637 \\
9606 \\
9606\end{array}$ & $\begin{array}{l}938 \\
1170 \\
790 \\
805 \\
1270 \\
718\end{array}$ & $\begin{array}{l}778 \\
956 \\
529 \\
736 \\
1220 \\
575\end{array}$ & $\begin{array}{l}1.29 \\
1.64 \\
2.75 \\
1.92 \\
3.86 \\
3.50\end{array}$ & $\begin{array}{l}1.07 \\
1.37 \\
1.99 \\
1.36 \\
4.10 \\
2.93\end{array}$ & $\begin{array}{l}0.28 \\
0.32 \\
0.49 \\
0.50 \\
0.74 \\
1.00\end{array}$ \\
\hline $\begin{array}{l}\text { Third Series } \\
\text { Si80Ge20/Si (ML) }\end{array}$ & cold & 9071 & 747 & 655 & 3.49 & 2.38 & $\mathbf{0 . 5 3}$ \\
\hline
\end{tabular}

\section{Results with Bi0.9Sb0.1/PbTe0.8Se0.2 on Sapphire}

Synthesis of Bi0.9Sb0.1/PbTe0.8Se0.2 2D QWs. The Hicks-Dresselhaus model for twodimensional quantum wells predicts that an exceptional ZT should be achievable with 75 angstrom layers of $\mathrm{Bi} 0.9 \mathrm{Sb} 0.1$ separated by $\mathrm{PbTe} 0.8 \mathrm{Se} 0.2$ barrier. Good progress has been made towards synthesizing such $\mathrm{Bi} 0.9 \mathrm{Sb} 0.1 / \mathrm{PbTe} 0.8 \mathrm{Se} 0.2$ multilayer films on single-crystal $(100)$ silicon and (1i02) sapphire substrates. Substrates were either maintained at ambient temperature or heated to approximately $35 \%$ of the melting point of the film. Results with sapphire substrates are reported here. The ability to make $\mathrm{Bi} 0.9 \mathrm{Sb0} 0.1$ and $\mathrm{PbTe} 0.8 \mathrm{Se} 0.2$ single-layer films, as well as $\mathrm{Bi} 0.9 \mathrm{Sb} 0.1 / \mathrm{Pb} 0.8 \mathrm{Te} 0.2$ bilayer and multilayer films with $\mathrm{Bi} 0.9 \mathrm{Sb} 0.1$ layers less than 75 angstroms thick, has been demonstrated. The abrupt compositional change at the $\mathrm{Bi} 0.9 \mathrm{Sb} 0.1-\mathrm{PbTe} 0.8 \mathrm{Se} 0.2$ interface was verified by Auger electron spectroscopy (AES) with depth profiling. Structural analyses have been done with TEM and XRD. Surprisingly, columnar growth was evident in the bilayer and multilayer films. Such growth is common in single-layer films, but not in layered films. Well-defined individual layers of Bio.9Sb0.1 and $\mathrm{PbTe} 0.8 \mathrm{Te} 0.2$ were continuous and extend across virtually all columner crystals. The interface between individual layers did not interupt columnar growth. A typical columnar crystal had a characteristic lateral dimension (dimension parallel to film-substrate interface) of 1000-3000 angstroms. Despite the scattering of charge carriers by defects and interfaces between columnar crystals, it might be possible to achieve some degree of quantum-well confinement in such films. Thermoelectric properties of these singlelayer, bilayer, and multilayer films were determined over a temperature range extending from ambient to $200^{\circ} \mathrm{C}$.

Resistivity Measurements. First, consider a relatively thick single-layer film of Bi0.9Sb0.1 having a thickness of 8,800 angstroms and depositied on single-crystal sapphire maintained at ambient 
temperature. Resistivity measurements were made while cycling the temperature of the sample between ambient and approximately $190^{\circ} \mathrm{C}$. As shown in Fig. 16, the resistivity of this relatively thick film dropped from $9.2 \mathrm{~m} \Omega-\mathrm{cm}$ at ambient temperature to $7.1 \mathrm{~m} \Omega-\mathrm{cm}$ at approximately $150^{\circ}$ C. Thermal cycling had very little effect on conductivity. Recently, the thermoelectric properties of extruded and single-crystal Bi0.91Sb0.01 alloys were published by Sidorenke and Mosalon [1992]. Unfortunately, they provide no data for the temperature range shown in Fig. 16. However, they give a representative resistivity of approximately $0.1 \mathrm{~m} \Omega-\mathrm{cm}$ at $200 \mathrm{~K}$. By extrapolating the data shown in Fig. 16 to $200 \mathrm{~K}$, we conclude that sputtered single-layer films of Bio.9Sb0.1 are not as conductive as bulk single crystals. The relatively high resisitivity of the sputtered film may be due to a greater degree of disorder. It may also be due to the formation of oxides in the film. The films are exposed to air during transfer from the sputtering system to the environmental chamber where electronic measurements are made. Since thermal cycling does not increase the resistivity, we conclude that no deterioration of the film occurs during such electronic characterization. Additional work is being done to assess the extent of oxidation in these singlelayer $\mathrm{Bi} 0.9 \mathrm{Sb} 0.1$ films during sample transfer. Due to this uncertainty, we cannot determine whether or not such sputtered films can be used as the basis of synthesizing 2D QWs.

Next, consider a relatively thick film of $\mathrm{PbTe} 0.8 \mathrm{Se} 0.2$ having a thickness of 25,959 angstroms and deposited on single-crystal sapphire maintained at ambient temperature. Resistivity measurements were made while cycling the temperature of the sample between ambient and approximately $190^{\circ} \mathrm{C}$. As shown in Fig. 17, the resistivity of this relatively thick film dropped from $3 \Omega-\mathrm{cm}$ at ambient temperature to $0.5 \Omega-\mathrm{cm}$ at approximately $190^{\circ} \mathrm{C}$. We conclude that the resistivity of undoped $\mathrm{PbTe} 0.8 \mathrm{Se} 0.2$ is three orders of magnitude greater than the resistivity of Bi0.9Sb0.1. Furthermore, thermal cycling has very little effect on conductivity. These thick $\mathrm{PbTe} 0.8 \mathrm{Se} 0.2$ films have sufficiently high resistivities and stabilities to qualify them as candidate barrier layers for Bi0.9Sb0.1 quantum wells.

Single-layer films of $\mathrm{PbTe} 0.8 \mathrm{Se} 0.2$ having thicknesses of 7,896 angstroms were also deposited onto ambient-temperature, single-crystal sapphire and evaluated. Resistivity measurements were made while cycling the temperature of the sample between ambient and approximately $150^{\circ} \mathrm{C}$. As shown in Fig. 18, the resistivity of this relatively thick film dropped from $1.7 \Omega$-cm at ambient temperature to less than $0.5 \Omega-\mathrm{cm}$ at approximately $150^{\circ} \mathrm{C}$. The ambient temperature resistivity of the film at the end of the cycle was about $0.7 \Omega-\mathrm{cm}$. In this case, thermal cycling enhanced the conductivity, probably by reducing the number of defects in film. Such irreversibility raises concern about the structural stability of this candidate barrier material at elevated temperature. An elevated temperature is any temperature greater than that at which the film was deposited. 


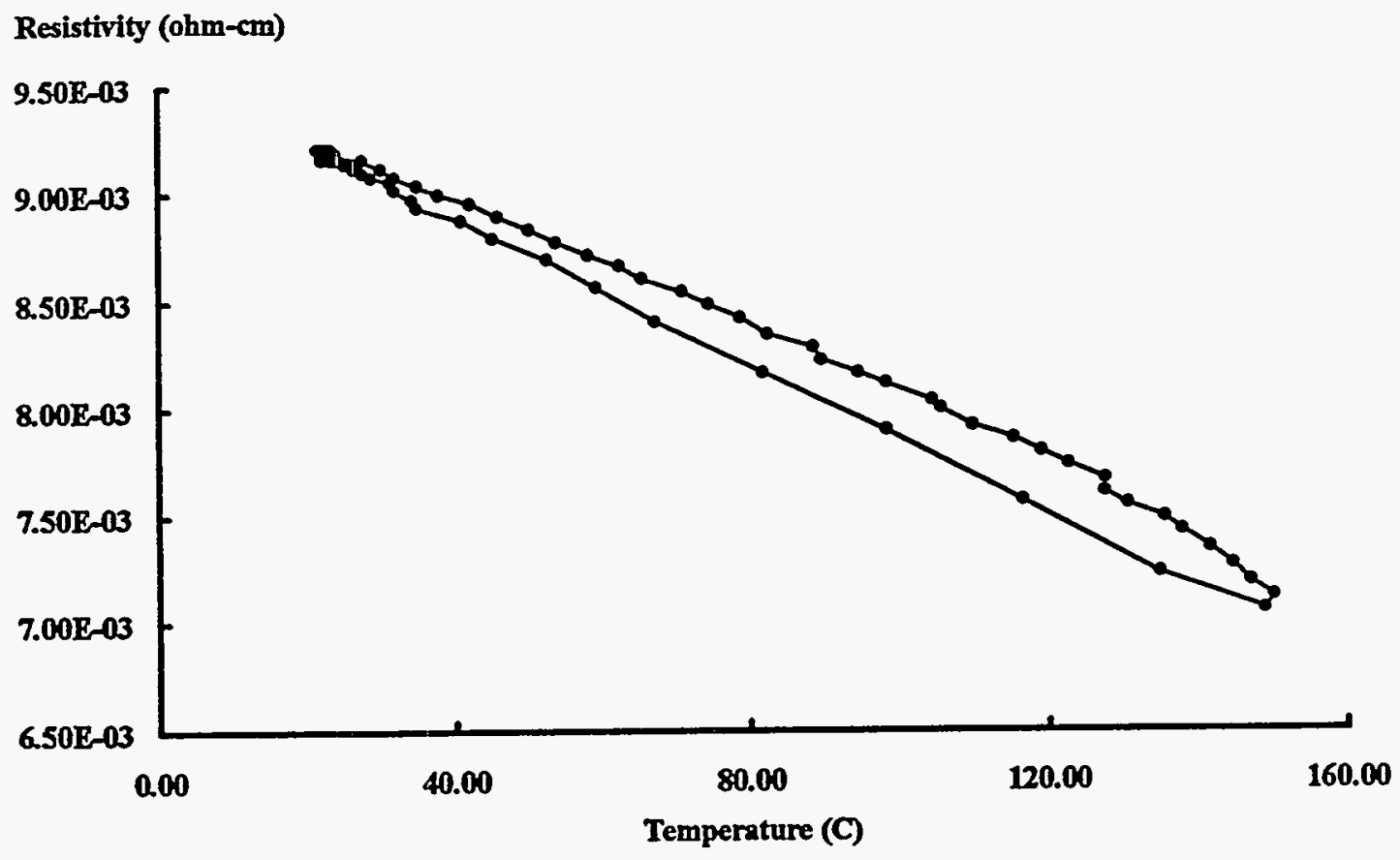

Fig. 16. Resistivity of single-layer films of Bi0.9Sb0.1 having a thickness of 8,800 angstroms.

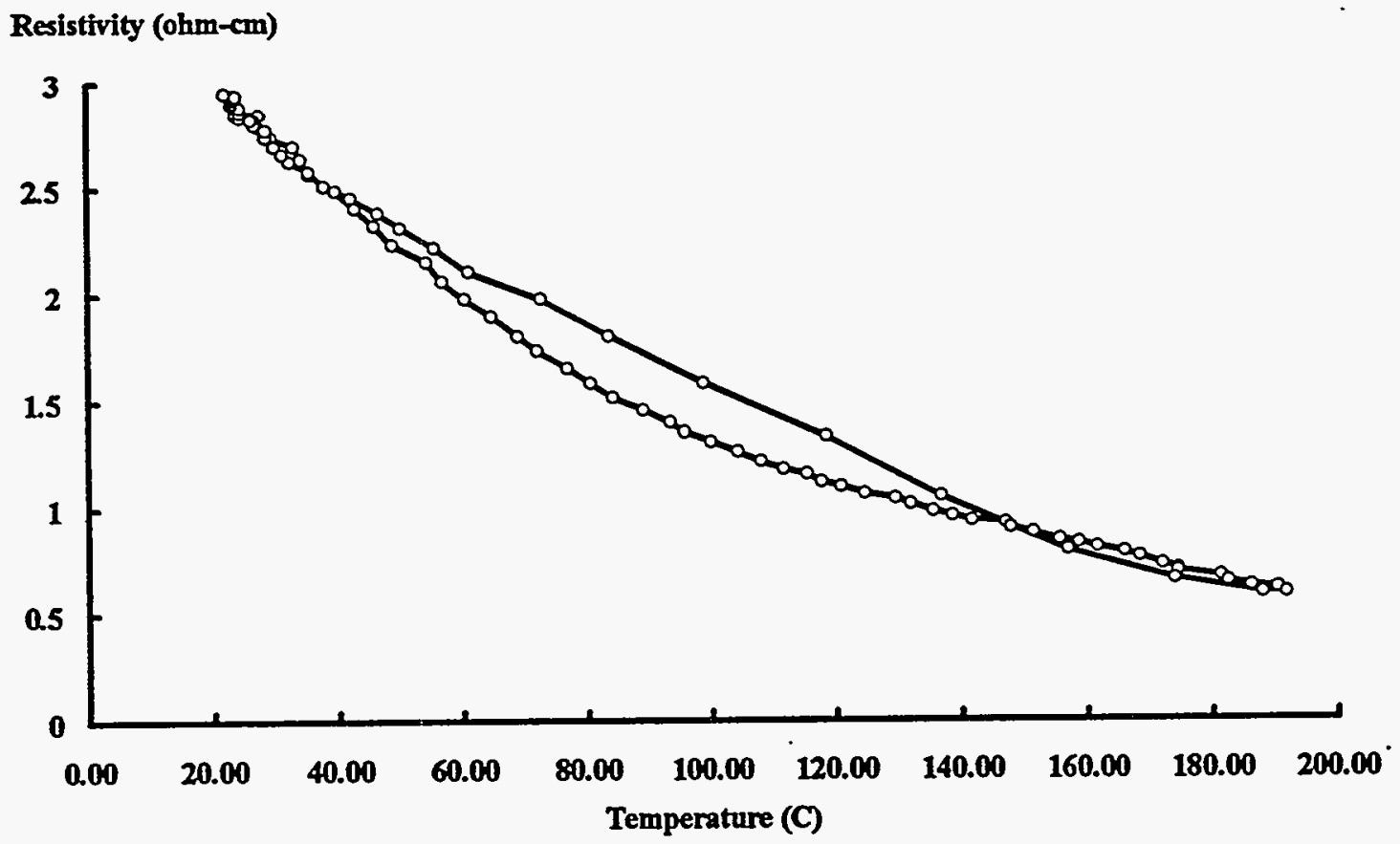

Fig. 17. Resistivity of single-layer films of $\mathrm{PbTe} 0.8 \mathrm{Se} 0.2$ having a thickness of 25,959 angstroms. 


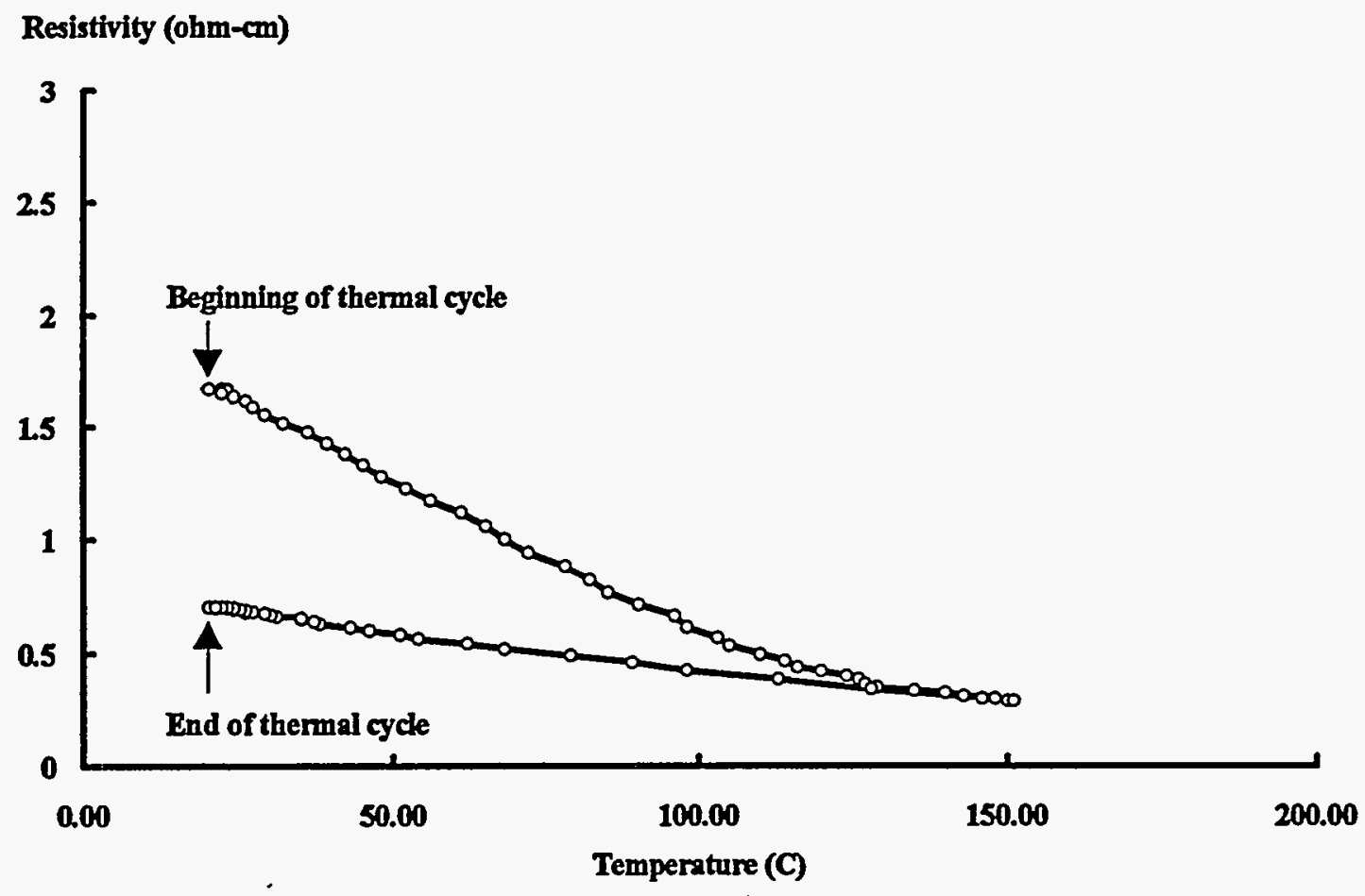

Fig.18. Resistivity of single-layer films of $\mathrm{PbTe} 0.8 \mathrm{Se} 0.2$ having a thickness of 7,896 angstroms. Resistivity (ohm-cm)

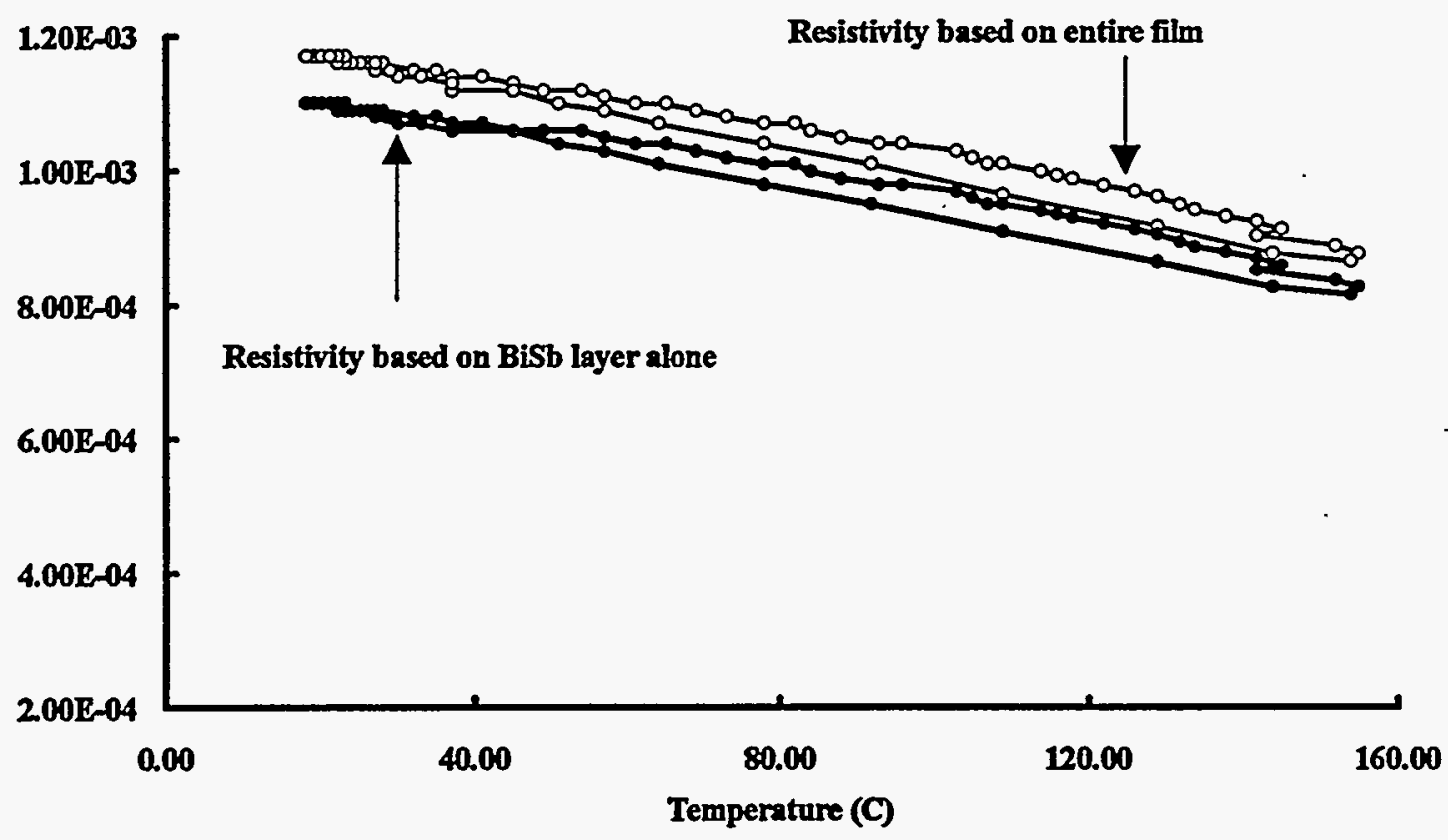

Fig. 19. Resistivity of bilayer film consisting of 6,498 angstroms of Bi0.9Sb0.1 and 400 angstroms of $\mathrm{PbTe} 0.8 \mathrm{Se} 0.2$. 
Bilayer films of $\mathrm{Bi} 0.9 \mathrm{Sb} 0.1$ and $\mathrm{PbTe} 0.8 \mathrm{Se} 0.2$ were made by depositing 6,498 angstroms of $\mathrm{Bi} 0.9 \mathrm{Sb} 0.1$ directly onto the ambient-temperature, single-crystal sapphire and subsequently depositing 400 angstroms of $\mathrm{PbTe} 0.8 \mathrm{Se} 0.2$ onto the $\mathrm{Bi} 0.9 \mathrm{Sb} 0.1$ layer. Resistivity measurements were been made over a range of temperature extending from ambient to approximately $160^{\circ} \mathrm{C}$, as illustrated by Fig. 19. The resistivity based on the entire film (assuming conduction in both layers) dropped from $1.2 \mathrm{~m} \Omega-\mathrm{cm}$ at ambient temperature to $0.90 \mathrm{~m} \Omega-\mathrm{cm}$ at $160^{\circ} \mathrm{C}$. However, from the data shown in Figs. 16, 17, and 18, we conclude that conduction in undoped $\mathrm{PbTe} 0.8 \mathrm{Se} 0.2$ layers should be negligible compared to conduction in the $\mathrm{Bi} 0.9 \mathrm{Sb} 0.1$ layers. The resistivity based on the $\mathrm{Bi}_{0.9 \mathrm{Sb} 0.1}$ layer alone dropped from $1.1 \mathrm{~m} \Omega-\mathrm{cm}$ at ambient temperature to $0.85 \mathrm{~m} \Omega-\mathrm{cm}$ at $160^{\circ} \mathrm{C}$. In this case, thermal cycling had very little effect on electronic conduction. From the data shown in Fig. 19, we conclude that thick $\mathrm{Bi} 0.9 \mathrm{Sb0} 0.1 / \mathrm{PbTe} 0.8 \mathrm{Se} 0.2$ bilayers have much better conductivity than single-layer films of either $\mathrm{Bi} 0.9 \mathrm{Sb} 0.1$ or $\mathrm{PbTe} 0.8 \mathrm{Se} 0.2$. In the case of bilayer films, we believe that the $\mathrm{PbTe} 0.8 \mathrm{Se} 0.2$ cap, which is thermodynamically stable in air, prevents

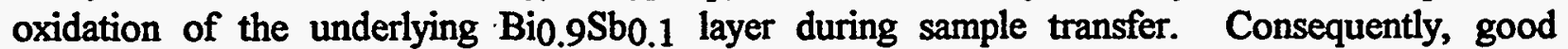
conductivity is maintained. However, we also recognize that some enhancement in conductivity could be due to the doping of $\mathrm{Bi} 0.9 \mathrm{Sb} 0.1$ by $\mathrm{PbTe} 0.8 \mathrm{Se} 0.2$, or the doping of $\mathrm{PbTe} 0.8 \mathrm{Se} 0.2$ by $\mathrm{Bi} 0.9 \mathrm{Sb} 0.1$. In this case, the individual layers are too thick for any enhancement due to quantumwell confinement.

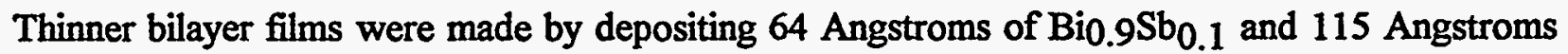
of $\mathrm{PbTe} 0.8 \mathrm{Se} 0.2$ onto ambient-temperature, single-crystal sapphire. Data are shown in Fig. 20. In this case, enhanced conductivity of the Bi0.9Sb0.1 layer is correlated with reduced dimensionality and may be due to quantum-well confinement. The profound impact of such effects at a layer thickness of only 64 angstroms is illustrated by the theoretical predictions shown in Fig. 5. Enhanced conductivity of the Bi0.9Sb0.1 layer may also be due to ambipolar doping by the $\mathrm{PbTe} 0.8 \mathrm{Se} 0.2$ layer, as well as unexpected conduction in the $\mathrm{PbTe} 0.8 \mathrm{Se} 0.2$ layer due to unintentional doping. Thermal cycling degrades conductivity slightly, possibly due to enhanced interdiffusion of layers.

Multilayer films were made by depositing alternating layers of $\mathrm{Bi} 0.9 \mathrm{Sb}_{0.1}$ and $\mathrm{PbTe} 0.8 \mathrm{Se} 0.2$ onto ambient-temperature, single-crystal sapphire substrates. Layers of $\mathrm{Bi}_{0.9} \mathrm{Sb}_{0.1}$ were 143 angstroms thick, layers of $\mathrm{PbTe} 0.8 \mathrm{Se} 0.2$ were 115 angstroms thick, and the total film thickness was 17,029 angstroms. From the data shown in Fig. 21, it is evident that reduced dimensionality also improves the conductivity of $\mathrm{Bi}_{0.9} \mathrm{Sb}_{0.1}$ incorporated into multilayer films. Here too the improvement may be due to either quantum-well confinement or unexpected doping. 
Resistivity (ohm-cm)

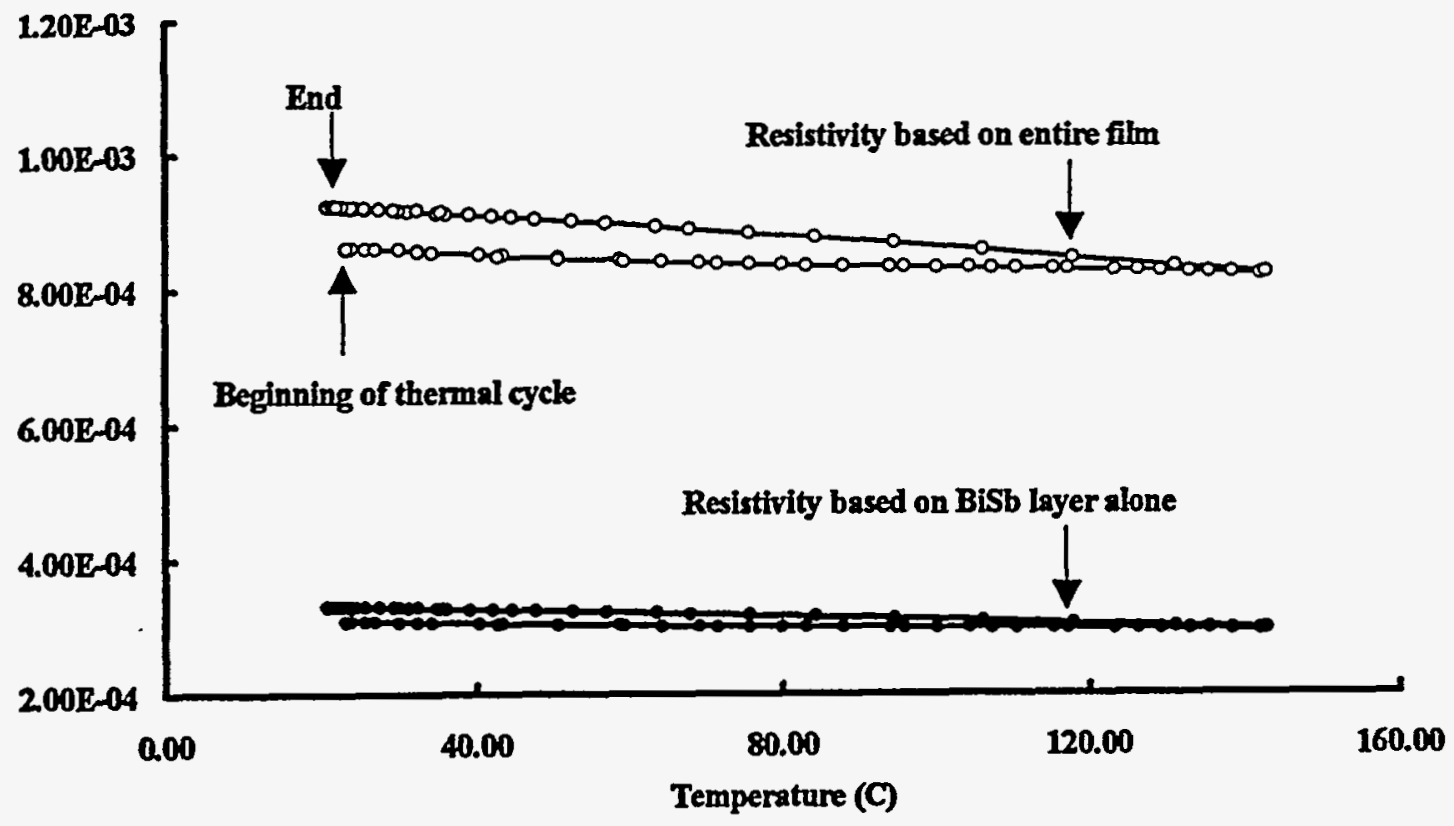

Fig. 20. Resistivity of bilayer film consisting of 64 angstroms of Bi0.9Sb0.1 and 115 angstroms of $\mathrm{PbTe} 0.8 \mathrm{Se} 0.2$.

Resistivity (ohm-cm)

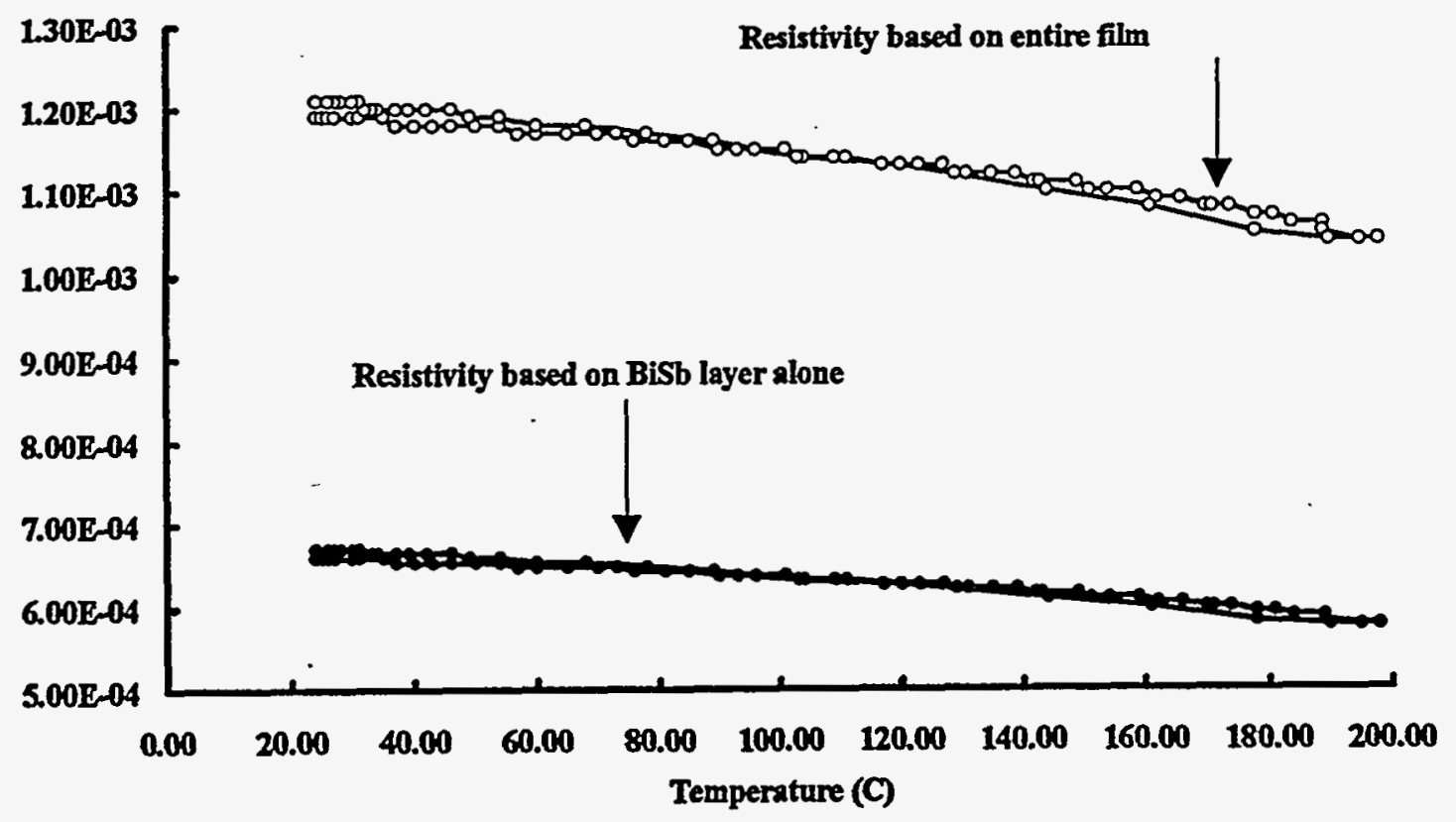

Fig. 21. Resistivity of multilayer film consisting of alternating layers of Bi0.9Sb0.1 and $\mathrm{PbTe} 0.8 \mathrm{Se} 0.2$ on a single-crystal sapphire substrate. 
Seebeck Coefficient Measurements. The differential hot stage described in a previous section was used to determine Seebeck coefficients of thermoelectric thin films. An imposed temperature gradient was used to produce a differential voltage in a single-layer film of $\mathrm{Bi}_{0.9} \mathrm{Sb}_{0.1}$ which was deposited on ambient-temperature, single-crystal sapphire and had a thickness of 8,800 angstroms. Data are shown in Fig. 22. Recall that the resistivity measurements of this film were shown in Fig. 16. The single-crystal sapphire substrate was completely insulating and did not contribute to the observed Seebeck voltage. While imposing the positive temperature gradient, the average Seebeck coefficient of this n-type material was determined to be $-45.3 \mu \mathrm{V} / \mathrm{K}$. While imposing the negative temperature gradient, a value of $-47.0 \mu \mathrm{V} / \mathrm{K}$ was determined. As expected, the two measurements are in close agreement (within 4\%). As previously discussed, Sidorenke and Molsolon [1992] have published thermoelectric properties of extruded and single-crystal Bio.91 Sb0.09 alloys. A representative Seebeck coefficient for these bulk materials is slightly less than $-100 \mu \mathrm{V} / \mathrm{K}$ at $200 \mathrm{~K}$, which is about twice the average value reported here for a sputtered single-layer film between ambient temperature and $160^{\circ} \mathrm{C}$.

As shown in Fig. 23, an imposed temperature gradient was also used to produce the observed Seebeck voltage in a single-layer $\mathrm{PbTe} 0.8 \mathrm{Se} 0.2$ film, which had a thickness of 25,959 angstroms. The average Seebeck coefficient was determined from the slope of the voltage-temperature curve and is approximately $-187 \mu \mathrm{V} / \mathrm{K}$. The negative Seebeck coefficient indicates that the film is ntype. The corresponding resistivity measurement for this film is shown in Fig. 17. This singlelayer film is a n-type semiconductor. The Seebeck voltage of a thinner $\mathrm{PbTe} 0.8 \mathrm{Se} 0.2 \mathrm{film}$ deposited under the same conditions and having a thickness of only 7,896 angstroms is shown in Fig. 24. In this case, the average Seebeck coefficient was determined to be approximately -232 $\mu \mathrm{V} / \mathrm{K}$, which is similar to that of the thicker film. The corresponding resistivity measurement is shown in Fig. 17. Though temperature cycling changed the resistivity slightly, it had no noticable effect on the Seebeck coefficient. The Seebeck voltage of a bilayer film consisting of 6,498 Angstroms of $\mathrm{Bi} 0.9 \mathrm{Sb0} 0.1$ and 400 Angstroms of $\mathrm{PbTe} 0.8 \mathrm{Se} 0.2$ deposited onto ambienttemperature, single-crystal sapphire is shown in Fig. 25. The average Seebeck coefficient is approximately $-59.6 \mu \mathrm{V} / \mathrm{K}$, which is considerably less than that of a $\mathrm{PbTe} 0.8 \mathrm{Se} 0.2$ single-layer film. However, it is slightly greater than that of a single-layer Bi0.9Sb0.1 film. Recall that the corresponding Seebeck coefficient of uncapped Bi0.9Sb0.1 is approximately $-45.3 \mu \mathrm{V} / \mathrm{K}$. As shown in Fig. 26, the Seebeck voltage of a bilayer consisting of 64 angstroms of $\mathrm{Bi} 0.9 \mathrm{Sb}_{0.1}$ and 115 angstroms of $\mathrm{PbTe} 0.8 \mathrm{Se} 0.2$ deposited onto ambient-temperature, single-crystal sapphire was measured. This film has a very unusual non-linear voltage-temperature curve. As the film was heated, the differential voltage first increased to a maximum and then fell to zero. This is indicative of either a semiconductor-to-metal transition, or a transition from n-type to p-type behavior. The Seebeck coefficient near ambient temperature is only $-4.4 \mu \mathrm{V} / \mathrm{K}$. Reduced dimensionality has a profound effect on the observed Seebeck voltage. This observation supports the hypothesis that improved conduction in ultra-thin $\mathrm{Bi} 0.9 \mathrm{Sb}_{0.1}$ layers is due to ambipolar doping by adjacent $\mathrm{PbTe} 0.8 \mathrm{Se} 0.2$ layers. Such doping would degrade the Seebeck coefficient, as it does in bulk thermoelectric materials. The Seebeck voltage for a multilayer film made by depositing alternating $\mathrm{Bi} 0.9 \mathrm{Sb}_{0.1}$ and $\mathrm{PbTe} 0.8 \mathrm{Se} 0.2$ layers onto an ambient-temperature, singlecrystal sapphire substrate is shown in Fig. 27. 


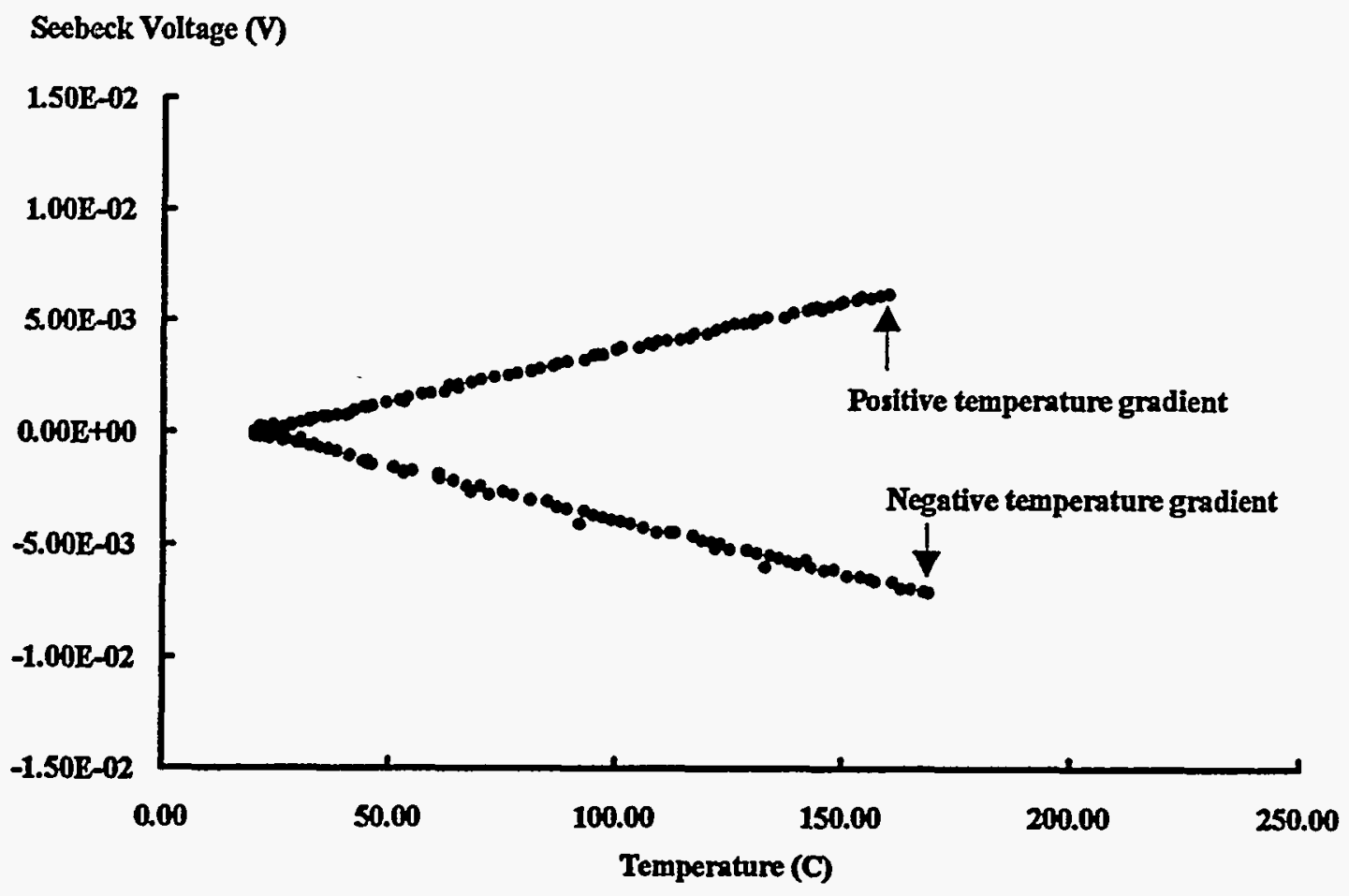

Fig. 22. Seebeck voltage of single-layer films of $\mathrm{Bi}_{0.9 \mathrm{Sb}_{0.1}}$ having a thickness of 8,000 angstroms.

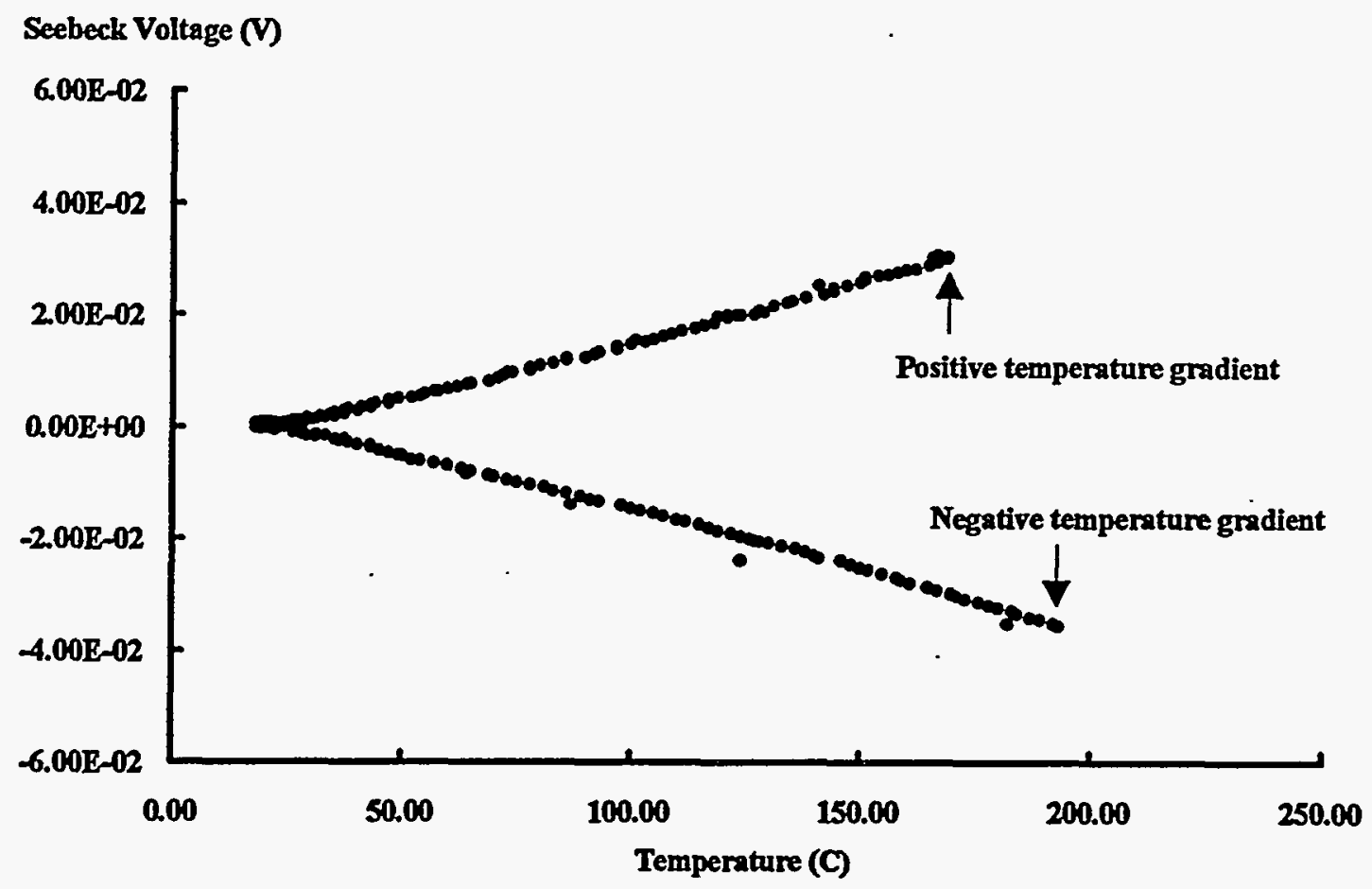

Fig. 23. Seebeck voltage of single-layer films of $\mathrm{PbTe} 0.8 \mathrm{Se} 0.2$ having a thickness of 25,959 angstroms. 


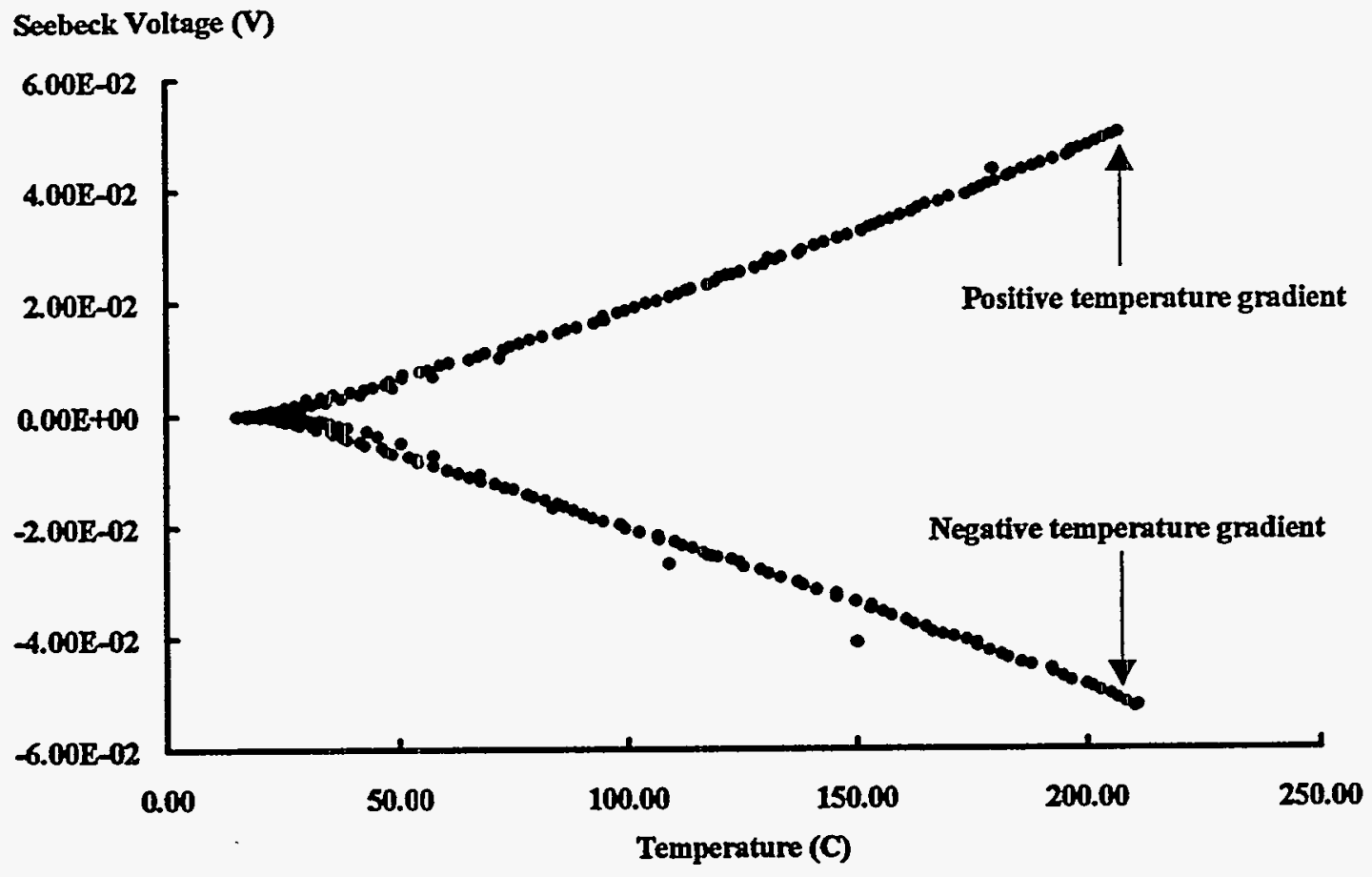

Fig. 24. Seebeck voltage of single-layer films of $\mathrm{PbTe} 0.8 \mathrm{Se} 0.2$ having a thickness of 7,896 angstroms.

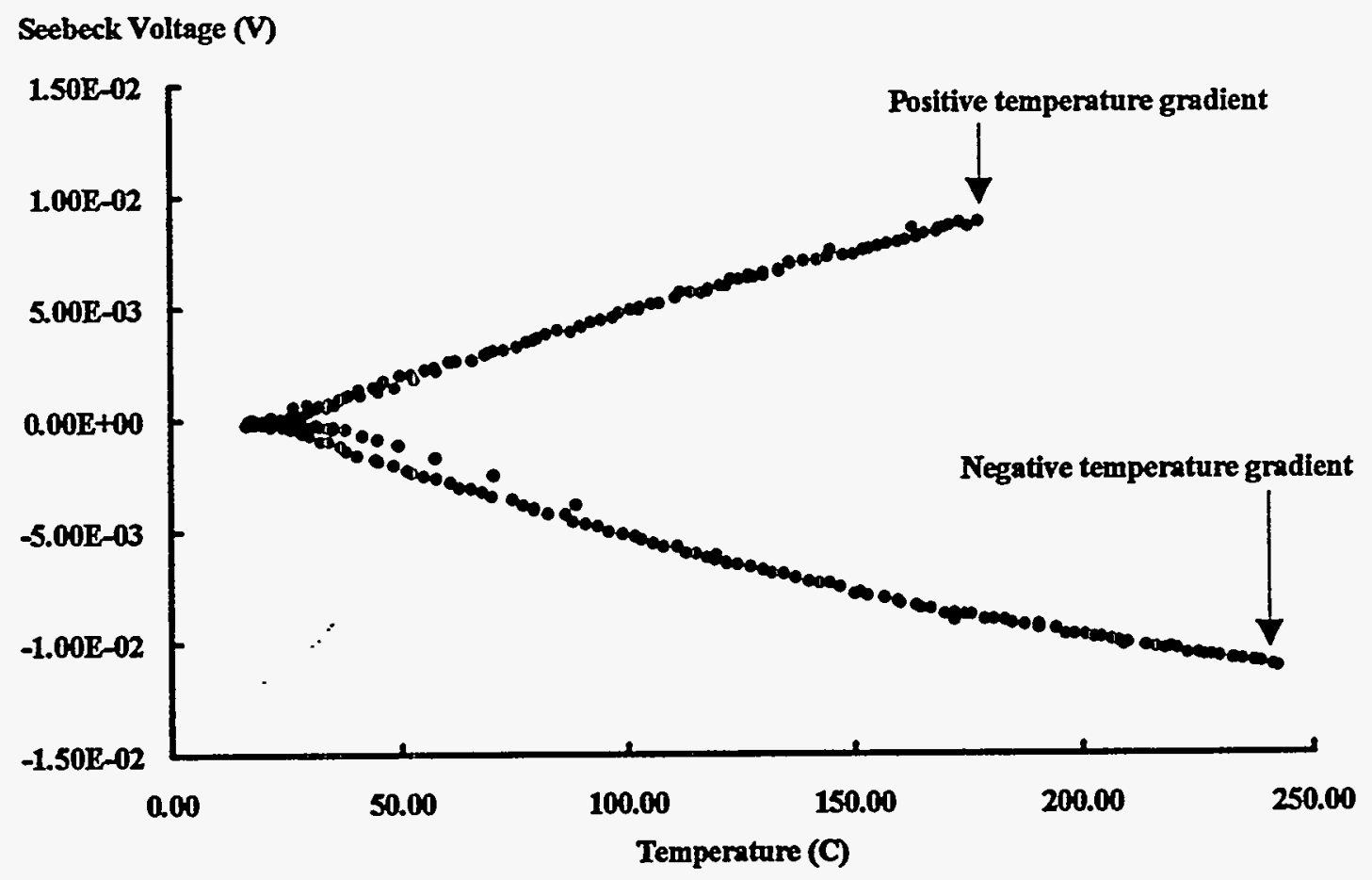

Fig. 25. Seebeck voltage of bilayer film consisting of 6,498 angstroms of Bi0.9Sb0.1 and 400 angstroms of $\mathrm{PbTe} 0.8 \mathrm{Se} 0.2$. 


\section{Seebeck Voltage (V)}

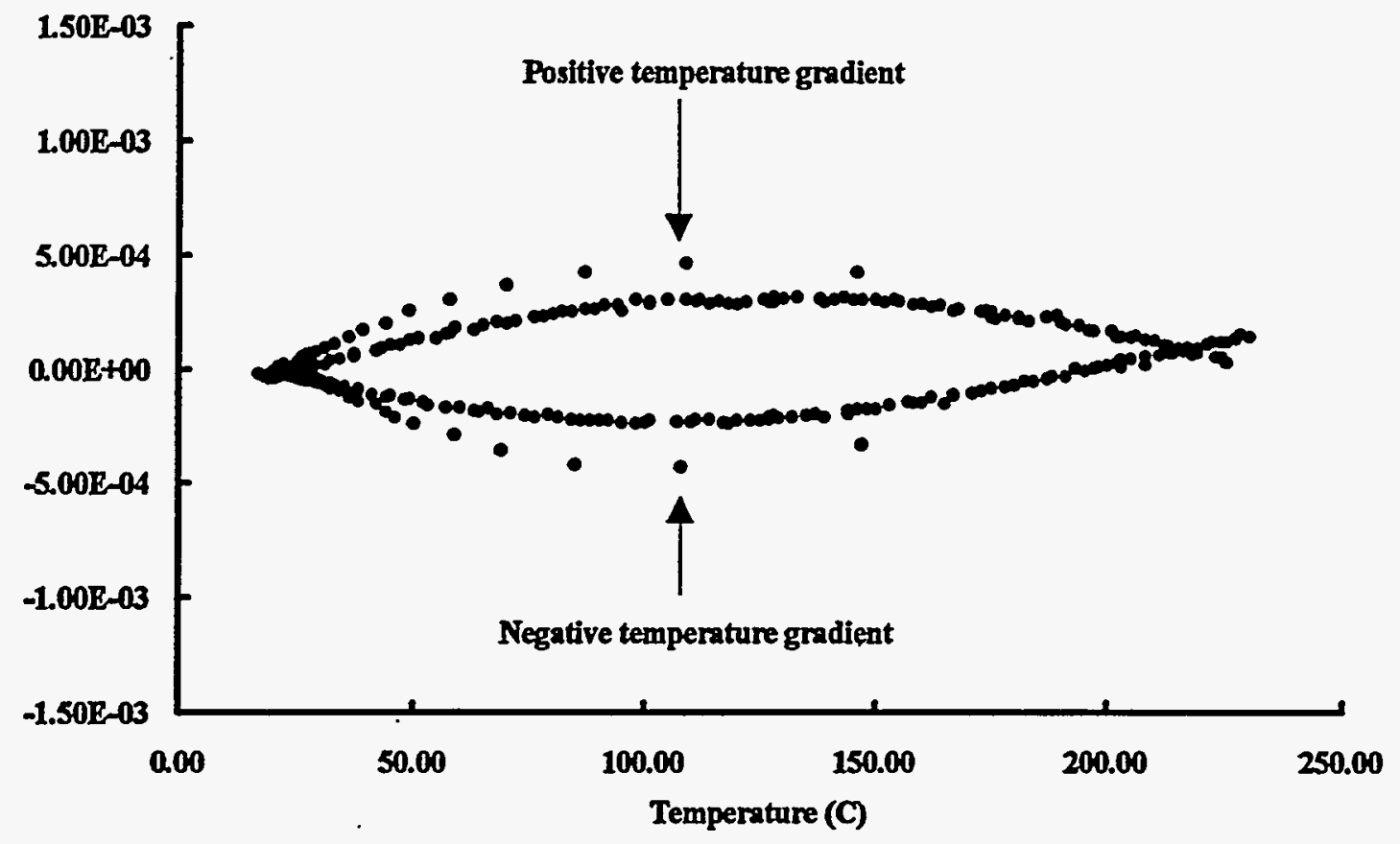

Fig. 26. Seebeck voltage of bilayer film consisting of 64 angstroms of Bi0.9Sb0.1 and 115 angstroms of $\mathrm{PbTe} 0.8 \mathrm{Se} 0.2$.

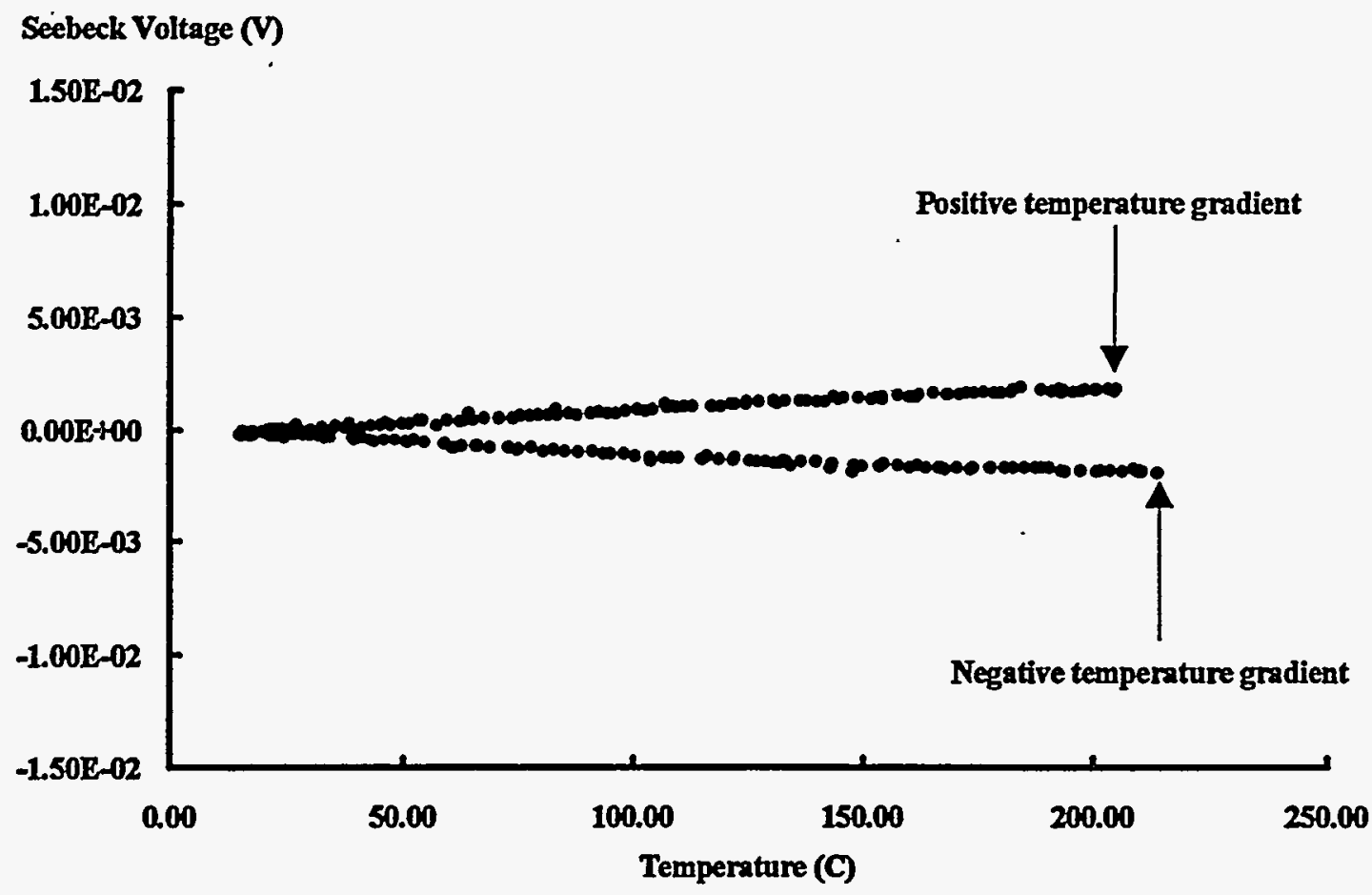

Fig. 27. Seebeck voltage of multilayer film consisting of alternating layers of $\mathrm{Bi}_{0.9} \mathrm{Sb}_{0.1}$ and $\mathrm{PbTe} 0.8 \mathrm{Se} 0.2$ on a single-crystal sapphire substrate. 
Layers of $\mathrm{Bi0} .9 \mathrm{Sb}_{0.1}$ were 143 angstroms thick, layers of $\mathrm{PbTe} 0.8 \mathrm{Se} 0.2$ were 115 angstroms thick, and the total film thickness was 17,029 angstroms. Reduced dimensionality in this multilayer film also has a profound effect on the observed Seebeck voltage. The Seebeck coefficient is approximately $-12.4 \mu \mathrm{V} / \mathrm{K}$. This observation also supports the hypothesis that

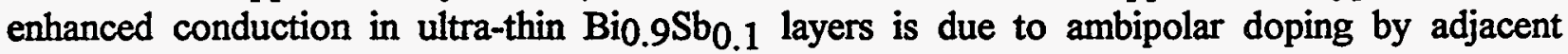
$\mathrm{PbTe} 0.8 \mathrm{Se} 0.2$ layers. Unlike the bilayer film with reduced dimensionality, there is no indication of a temperature-induced transition from n-type to p-type behavior.

Summary of Results. A summary of these results, alone with those for films deposited on heated single-crystal substrates is presented in Table II. First, it is possible to synthesize

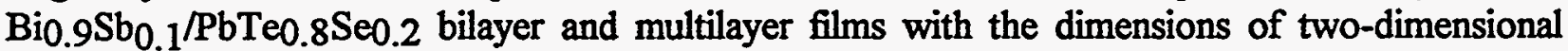
quantum wells (2D QWs). Layers are crystalline with preferred orientation. Reduced dimensionality in such films results in enhanced electronic conduction in Bio.9 $\mathrm{Sb}_{0.1}$ layers. However, the Seebeck coefficient is adversely effected by such reduced dimensionality. Therefore, we conclude that any enhancement in electronic conduction is probably due to inadvertant ambipolar dopint of the $\mathrm{Bi} 0.9 \mathrm{Sb} 0.1$ layer by the $\mathrm{PbTe} 0.8 \mathrm{Se} 0.2$ layer. The enhancement is probably not due to quantum-well confinement. The thick

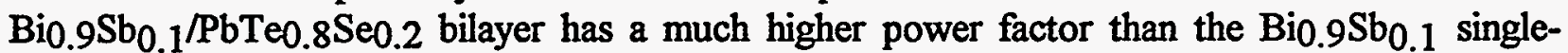
layer. This is probably due to the ability of the $\mathrm{PbTe} 0.8 \mathrm{Se} 0.2$ cap to prevent any oxidation of the

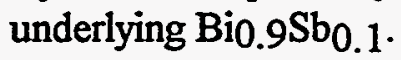

\section{Discussion}

New Materials. If reduced Seebeck coefficients are indeed due to ambipolar doping, the problem can be minimized by changing the barrier layer to a material that cannot provide any dopants, or to a material that can only provide dopants of a single polarity. For example, $\mathrm{Bi} 2 \mathrm{Te} 3$ or $\mathrm{BiTe}$ barrier layers might result in Te-doping of the Bio.9Sb0.1 layer. However, excess $\mathrm{Bi}$ diffusing into the Bi0.9Sb0.1 layer would probably have minimal effect. Another general approach suggested by these data are modulation-doped thermoelectric films. This approach has also been suggested by Yee [1992]. Modulation-doped films based upon PbTe, IrSb3, and (Fe,Os)Si2 could be made.

Comparison to Published Values. Recently, thermoelectric properties of extruded and singlecrystal Bi0.91Sb0.09 alloys have been published by Sidorenke and Mosolon [1992]. A representative Seebeck coefficient for these bulk materials is slightly less than $-100 \mathrm{mV} / \mathrm{K}$ at 200 $\mathrm{K}$, which is greater than the average ambient-temperature Seebeck coefficients determined for the sputtered single-layer, bilayer, and multilayer films. Similarly, a representative electrical resistivity for these bulk materials is about $0.1 \mathrm{~m} \Omega-\mathrm{cm}$ at $200 \mathrm{~K}$, which is less than the ambient-temperature resistivities of the sputtered films. Consequently, the ZT of the bulk material (ZT $\cong 0.5)$ is much higher than that estimated for the best sputtered films (ZT $\cong 0.02)$. The thermal conductivity of the bulk material is $40 \mathrm{~mW} / \mathrm{cm}-\mathrm{K}$. Since thermal conductivities of the sputtered films have not been determined, they were also assumed to be about $40 \mathrm{~mW} / \mathrm{cm}-\mathrm{K}$. However, phonon scattering in multilayer films could significantly decrease the thermal conductivity of this alloy, thereby enhancing the overall performance of the material. 
Table II. Summary of Thermoelectric Measurements of Bi0.9Sb0.1/PbTe0.8Te0.2 Sputtered Films on Single-Crystal Sapphire.

\begin{tabular}{|c|c|c|c|c|c|c|c|c|c|}
\hline Film Type & Description & $\begin{array}{c}\mathrm{Bi}_{0.9} \mathrm{Sb}_{0.1} \\
\text { (Angstroms) } \\
\end{array}$ & $\begin{array}{c}\mathrm{PbTe}_{0.8} \mathrm{Se}_{0.2} \\
\text { (Angstroms) }\end{array}$ & $\begin{array}{l}\text { Entire Film } \\
\text { (Angstroms) }\end{array}$ & $\begin{array}{c}\alpha \\
(\mu \mathrm{V} / \mathrm{K})\end{array}$ & $\begin{array}{c}\rho \\
(\mathrm{m} \Omega-\mathrm{cm})\end{array}$ & $\begin{array}{c}\rho^{q} \\
(\mathrm{~m} \Omega-\mathrm{cm})\end{array}$ & $\begin{array}{l}\alpha^{2} / \rho \times 10^{9} \\
(W / c m-K)\end{array}$ & $\begin{array}{c}\alpha^{2} / \rho^{*} \times 10^{9} \\
(W / \mathrm{cm}-\mathrm{K})\end{array}$ \\
\hline Single-layer & Cold + Ni Strips & 8,800 & none & 8,800 & -45.3 & 9.25 & 9.25 & 221.85 & 221.85 \\
\hline Single-layer & $\begin{array}{l}\text { Cold+ Ni Strips } \\
\text { Cold } \\
\text { Hot }\end{array}$ & none & 7,896 & 7,896 & $\begin{array}{l}-232 \\
-211 \\
-160\end{array}$ & $\begin{array}{r}1,700 \\
2,370 \\
400\end{array}$ & & $\begin{array}{l}31.66 \\
18.79 \\
64.00\end{array}$ & \\
\hline Single-layer & Cold + Ni Strips & none & 25,959 & 25,959 & -187 & 2,850 & & 12.27 & \\
\hline Bilayer & $\begin{array}{l}\text { Cold + Ni Strips } \\
\text { Cold + Ni Strips }\end{array}$ & 64 & 115 & 179 & $\begin{array}{r}\text { noisy } \\
-4.4 \\
\end{array}$ & $\begin{array}{l}0.58 \\
1.00\end{array}$ & $\begin{array}{l}0.21 \\
0.36\end{array}$ & 19.36 & 53.78 \\
\hline Bilayer & $\begin{array}{l}\text { Cold + Ni Strips } \\
\text { Hot }\end{array}$ & 6,498 & 400 & 6,898 & $\begin{array}{l}-59.6 \\
-52.4 \\
\end{array}$ & $\begin{array}{l}1.18 \\
1.15\end{array}$ & $\begin{array}{l}1.11 \\
1.08\end{array}$ & $\begin{array}{l}3,010.31 \\
2,387.62 \\
\end{array}$ & $\begin{array}{l}3,200.14 \\
2,542.37\end{array}$ \\
\hline Multilayer & $\begin{array}{l}\text { Cold + Ni Strips } \\
\text { Hot + Ni Strips } \\
\text { Hot }\end{array}$ & 143 & 115 & 17,029 & $\begin{array}{l}-12.4 \\
-1.06 \\
\text { noisy }\end{array}$ & $\begin{array}{l}1.18 \\
1.23 \\
1.51\end{array}$ & $\begin{array}{l}0.65 \\
0.68 \\
0.84\end{array}$ & $\begin{array}{r}130.31 \\
0.91\end{array}$ & $\begin{array}{r}236.55 \\
1.65\end{array}$ \\
\hline
\end{tabular}

Notes: $\rho$ is the resistivity based upon the cross-sectional area of the film; $\rho^{*}$ is the resistivity based on the cross-sectional area of Bi0.9Sb0.1 layers alone. The description indicates whether films were deposited on hot or cold substrates; it also tells whether or not nic el strips were deposited on the substrate to serve as electrical contacts. 
Measurements at Cryogenic Temperatures. We believe that temperature-dependent measurements of electrical conductivity should be made from low to high temperature $(150 \mathrm{~K}$ to ambient). Such measurements will allow us to determine the importance of carrier trapping at atomically-rough interfaces. Liberation of trapped carriers should be thermally activated. In recognition of this need, we are completing construction of a vacuum system with a differential temperature stage and four-point probe that will allow measurements of electrical conductivity and Seebeck coefficient between the boiling point of liquid nitrogen and ambient temperature. Vacuum is established and maintained by a turbomolecular pump backed by a mechanical roughing pump. This system will also allow measurements at high temperature and under a very good vacuum.

Improved Theoretical Model. In the future, a more complete theoretical model should be developed to predict the transport properties of actual films. As previously discussed, the Seebeck coefficient, the electrical conductivity, and the thermal conductivity determine the thermoelectric figure of merit. These three important transport parameters depend the strength of various scattering mechanisms, which include electron-impurity scattering, electron-phonon scattering, and phonon-phonon scattering. Intrinsic and extrinsic properties of the crystalline film, such as the energy band structure, the phonon spectrum, and the concentrations of impurities and defects, determine the magnitudes of scattering cross-sections. After all the constants in these cross-sections have been estimated, Boltzmann's equation can be solved to obtain the distributions for the free carriers, which are used to evaluate the Seebeck coefficient, the electrical conductivity, and the thermal conductivity.

Thermoelectric Quantum Wires. Chapline of LLNL extended the Hicks-Dresselhaus theory for 2D QWs to quantum wires, the 1D case, and found that the enhancement of ZT depends upon the diameter of the wire [1993]. Chapline concluded that

$$
Z_{1 D}>Z_{2 D}>Z_{3 D}
$$

provided that the diameter of the quantum wire is less than 15 angstroms. More recently, Hicks and Dresselhaus have published the theory for ID QWs [1993]. It may be possible to make such 1D structures by chemically depositing thermoelectric materials inside zeolites or aerogels. Organometallic films left inside these materials after infiltration could be decomposed by microwave heating. Additional heating could be used to alloy elemental residue. For example, combinations of bismuth methoxyethoxide $\left(\mathrm{Bi}\left(\mathrm{OCH}_{2} \mathrm{CH}_{2} \mathrm{OCH}_{3}\right)_{3}\right.$ and either tellurium isopropoxide $\left(\mathrm{Te}\left(\mathrm{OC}_{3} \mathrm{H}_{7}\right) 4\right.$ or tellurium tert-butoxide $\left(\mathrm{Te}\left(\mathrm{OC}_{4} \mathrm{H} 9\right)_{4}\right)$ could be used to synthesize $\mathrm{Bi}_{2} \mathrm{Te}$. Since the tellurium compounds are liquids, they will require no carrier (solvent). However, the bismuth compound is solid and would have to be dissolved in methoxyethanol. It may also be possible to produce filamentary aerogels from thermoelectric compounds.

Cost of Sputtering Materials. We believe that multilayer thermoelectric materials can be fabricated for less than the DOE target cost of $\$ 30$ per watt for power generators [James Merritt, DOE, 1993], provided that production is done in a large-volume plant. The cost of multilayer thermoelectric materials (\$ per watt) as a function of the dimensionless figure of merit (ZT) is shown in Fig. 28. 
Cost (\$ per watt)

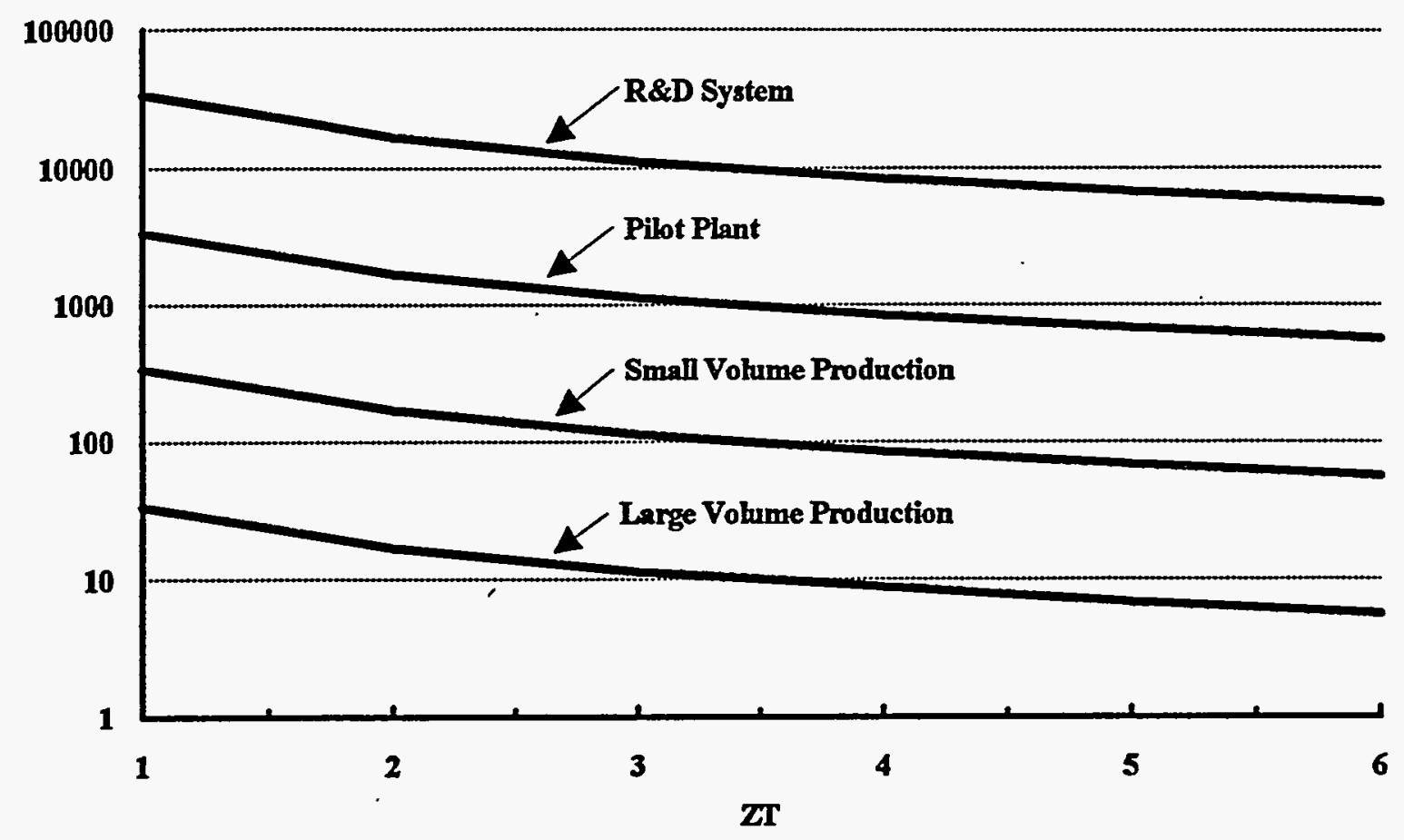

Fig. 28. Cost sputtered films in thermoelectric generators (\$ per watt of electrical power produced).

We assumed four different scenarios for sputter deposition of the films. The cases considered include fabrication in: (a) a small R\&D system operating at a cost of $\sim \$ 1000 / \mathrm{ft}^{2} / \mathrm{mm}$; (b) a pilot plant operating at a cost of $\sim \$ 100 / \mathrm{ft}^{2} / \mathrm{mm}$; (c) a small-volume manufacturing facility operating at a cost of $\sim \$ 10 / \mathrm{ft}^{2} / \mathrm{mm}$; and (d) a large-volume manufacturing facility operating at a cost of $\sim$ $\$ 1 / \mathrm{ft}^{2} / \mathrm{mm}$. Data for scenarios (a) and (b) were obtained Optical Coatings Laboratory, Incorporated. Data for scenario (c) were obtained from TRW Technar and were collected during the deposition of aluminum (and gold) films for air-bag sensors in automobiles. These highquality medium-volume aluminum films were made at a cost of $\sim \$ 4 / \mathrm{ft}^{2} / \mathrm{mm}$. A cost of $\$ 10 / \mathrm{t}^{2} / \mathrm{mm}$ were assumed in the calculation. Data for scenario (d) are from the manufacture of architectural glass and aluminized Mylar films. For example, aluminized Mylar films are used to make the helium-filled balloons sold in supermarkets. These films retail for $\leq \$ 1 / \mathrm{ft}^{2} / \mathrm{mm}$. Estimates of device power density, necessary for the calculation of power-specific costs, were done as outlined in Direct Energy Conversion [Angrist, 1976]. To summarize, thin films made of conventional thermoelectric materials (ZT 1) could be produced by sputtering in a large-volume facility at a cost of $\$ 33$ per watt, which is close to the desired target. The cost should be somewhat lower with multilayer QW films since they will have higher ZTs. MBE, the alternative approach, is approximately $140 \mathrm{X}$ more expensive due to inherently slow deposition rates. Therefore, the target for cost will be difficult to reach by this approach. Note that improvements in ZT will also decrease device weight. 
Prototypical Thin Film Device. In the future, we hope to build a prototype thin-film thermoelectric device by depositing both $\mathrm{n}$ - and p-type films onto a dielectric substrate (Fig. 29). The n- and p-type films could also be incorporated into a planar, layered device. One end of the device will be heated while the other is cooled. Current generated by the device will be determined by monitoring the voltage across a thin-film load resistor..

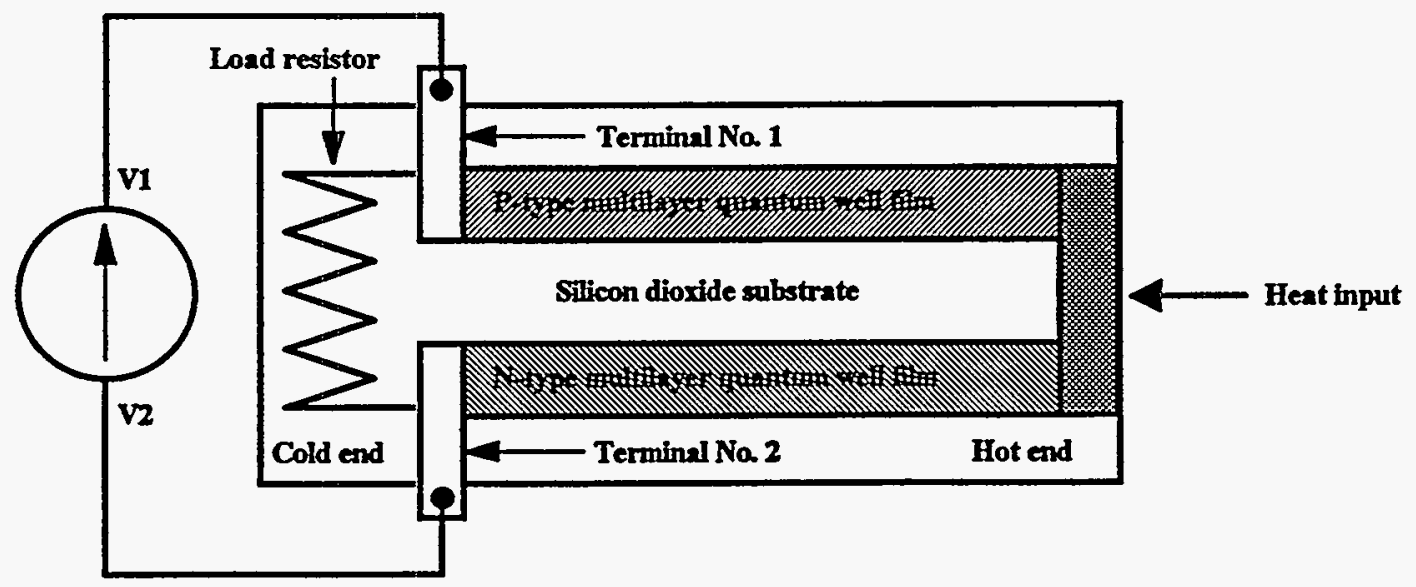

Fig. 29. Thermoelectric device based upon 2D QW films.

Possible Applications of Thermoelectric Films. Given the environmental problems associated with chlorofluorocarbon (CFC) refrigeration, the demand for non-CFC alternatives such as thermoelectrics should continue to increase. The market for efficient, silent thermoelectric refrigerators and air conditioners for use in homes would be tremendous. Hi-Z Technology of San Diego, California is involved in developing low-temperature, $1 \mathrm{~kW}$ thermoelectric generators to replace mechanical alternators on diesel engines [Bass, 1992]. These devices are expected to reduce fuel consumption and associated pollution. A typical mechanical alternator requires 3 to 5 hp from the crankshaft, while the thermoelectric generator uses low-grade waste heat from the exhaust (engine load is reduced). Since the thermoelectric generator has no moving parts, overall vehicle reliability should increase. Lighter and more efficient thermoelectric generators could be used to replace mechanical alternators in automobiles. In addition to reducing fuel consumption and pollution, this new technology would improve the perceived quality of US-built automobiles and provide new high-tech jobs for those involved in materials and device manufacturing. Efficient thermoelectric materials are of particular interest to the U.S. Navy, the Department of Defense in a more general sense, and the National Aeronautics and Space Administration for cooling and power generation applications. For example, Peltier refrigerators are used to cool night-vision equipment and other high-performance electronics. Thermoelectric generators are ideal for some military applications because of their silent operation. The exceptional reliability of thermoelectric generators is already exploited for space exploration. The development of thermoelectric thin film technology at Lawrence Livermore National Laboratory has attracted the attention of Boeing Defense and Space System and may be incorporated into future devices. Since thermoelectric generators are both reliable and silent, they could also serve as power sources for remote sensors deployed to monitor the environment and to detect nuclear proliferation activities. Such generators could be powered by available waste heat, a radioisotope source, or by the sun. If we are able to synthesize promising thermoelectric thin films, we 
anticipate several other applications. For example, we will be able to fabricate miniaturized thermal sensors and analytical instruments, including miniature differential scanning calorimeter (MDSC). Thermoelectric devices incorporated into such instruments can be used for both heating and cooling, depending upon the direction of current flow. The energy input to the device can be regulated very precisely. Devices can also be fabricated for thermal cycling solutions of DNA during replication (PCR technique). For example, a single strand of DNA could be replicated one million times by thirty thermal cycles between 50 and $95^{\circ} \mathrm{C}$. Thin film coolers and power generators could be incorporated directly into microelectronics. Solar-heated thermoelectric power generators based upon thin films will also be possible.

\section{Summary}

We have successfully synthesized $\mathrm{Bi}_{2} \mathrm{Te} / \mathrm{B}_{4} \mathrm{C}, \mathrm{Si} 8 \mathrm{Ge}_{20} / \mathrm{Si}$, and $\mathrm{Bi} 0.9 \mathrm{Sb} 0.1 / \mathrm{PbTe} 0.8 \mathrm{Se} 0.2$ multilayer films with the dimensions of two-dimensional quantum wells. Initially, Seebeck coefficients and electrical conductivities were evaluated from ambient temperature to $200^{\circ} \mathrm{C}$. In the case of the $\mathrm{Bi}_{2} \mathrm{Te} 3 / \mathrm{B}_{4} \mathrm{C}$ and $\mathrm{Si}{ }_{0} \mathrm{Ge}_{2} / \mathrm{Si}$ systems, the authors were unable to synthesize films with sufficiently good electronic conductivity to make them suitable thermoelectric materials. In

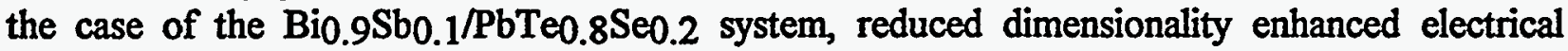
conductivity of the Bi0.9Sb0.1 layer, but at the expense of the Seebeck coefficient. Ambipolar doping of the Bio.9Sb0.1 layer by adjacent barrier layers hurt the overall thermoelectric performance. New combinations of materials are now being investigated as a means of solving this problem. A high-vacuum system has been built and is now being used to evaluate thermoelectric properties down to liquid nitrogen temperatures. Single-layer and bilayer Bio.9Sb0.1/PbTe0.8Se0.2 films developed at Lawrence Livermore National Laboratory have recently demonstrated sufficient thermoelectric performance at low temperature to make them attractive for special device applications envisioned by Boeing Defense and Space Systems. Lowtemperature data will be presented in future reports.

\section{Acknowledgements}

The practical thermoelectric advice of Mr. Norbert Elsner, President of Hi-Z Technology, Incorporated is greatly appreciated. The $\mathrm{Si}_{80} \mathrm{Ge}_{20}$ and $\mathrm{Si}$ sputtering targets were provided by Hi-Z Technology. Initial funding for this project was provided by Lawrence Livermore National Laboratory LDRD. This support enabled the authors to develop techniques for the synthesis and evaluation thermoelectric thin films. The $\mathrm{Bi}_{2} \mathrm{Te} 3 / \mathrm{B}_{4} \mathrm{C}$ and $\mathrm{Si}_{80} \mathrm{Ge}_{2} / \mathrm{Si}$ systems were explored. Subsequent funding was provided by the U.S. Department of Energy Office of Basic Energy Sciences (OBES) for. detailed exploration of the Bi0.9Sb0.1/PbTe0.8Se0.2 system. Measurements are now being extended to cryogenic temperatures. Early data on the Bio.9Sb0.1/PbTe0.8Se0.2 is summarized in this report to provide a coherent overall picture of the research. 


\section{References}

Amano, T., Beaudry, B. J., Gschneidner, K. A., High-Temperature Thermodynamic Properties of Alpha and Gamma Lanthamum Sesquisulfides and Related Compounds, J. Appl. Phys. 59, 10 (1986) 3437-3440.

Angrist, S. W., Chapt. 4, Thermoelectric Generators, Direct Energy Conversion, 3rd Ed., Allyn and Bacon, Inc., Boston, MA, 1976.

Frahm, R., Barbee, T. W., Jr., Warburton, W. K., In-situ Structural Study of Thin Film Growth by QEXAFS, Phys. Rev. B44 (1991) 2822.

Barbee, T. W., Jr., Multilayer Optics for the Soft X-Ray and Extreme Ultra-Violet, Physica Scripta, T31 (1990) 147.

Barbee, T. W., Jr., Wong, J., EXAFS of Near Monolayer Hafnium Film, Physica B158 (1989) 670.

Barbee, T. W., Jr., Combined Microstructure X-Ray Optics, Rev. Sci. Instrum. 60 (1989) 1588.

Barbee, T. W., Jr., Multilayer Structures: Atomic Engineering in It's Infancy, in Physics, Fabrication and Application of Multilayer Structures, Dhez, P. Weisbach, C. Eds., Plenum Press, New York, NY (1988) 17.

Multilayers: Synthesis, Properties, and Non-Electronic Applications, Materials Research Society Symposium, Boston, MA, December 2-4, 1987, Proceedings, Barbee, T. W., Jr., Spaepen, F., Greer, L., Eds. 103 (1988).

Barbee, T. W., Jr., Synthesis of Myultilayer Structures by Physical Vapor Deposition Techniques, in Synthetic Modulated Structures, Chang, L. L., Giessen, B. C., Eds., Adacemic Press, Orlando, FL (1985).

Gardner, D. S., Michalka, T. L., Saraswat, K. C., Barbee, T. W., Jr., Meindel, J. D., Layered and Homogeneous Films of Aluminujm and Aluminum/Silicon with Titanium, Zirconium, and Tungsten for Multilevel Interconnects, International Symposium on VLSI Technology, Systems, and Applications, Taipei, Taiwan, May 8-10, 1985, Proceedings of Technical Papers, National Science Council, Industrial Technology Research Institute (1985) 157-161.

Barbee, T. W., Jr., X-Ray Evanescent Standing Wave Fluorescence Studies Using a Layered Synthetic Microstructure, Matl. Lett. 3 (1984) 17.

Barbee, T. W., Jr., Keith, D. L., Nagel, L., Tiller, W. A., Controlled Reactive Sputter Synthesis of Refractory Oxides $\mathrm{SiO}_{2}$, The Silicon-Oxygen System, J. Electrochem. Soc. 131, 2 (1984) 434-439. 
Bass, J. C., Elsner, N. B., Current Thermoelectric Program at Hi-Z Technology, Inc., Proc. XIth Intl. Conf. Thermoelectrics, K. R. Rao, Ed., Univ. Texas, Arlington, TX, Oct. 7-9, 1992.

Bender, K., Gogu, E., Hennig, I., Schweitzer, D., Electric Conductivity and Thermoelectric Power of Various Polypyrroles, Synthetic Metals 19 (1987) 85-88.

Birkholz, U., Grob, E., Riffel, M., Roth, H., Stohrer, U., Wittmer, W., Measurement of the Efficiency of a HMS-FeSi2 Thermoelectric Generator, Proc. XIth Intl. Conf. Thermoelectrics, K. R. Rao, Ed., Univ. Texas, Arlington, TX, Oct. 7-9, 1992.

Boikov, Yu. A., Gribanova, O. S., Danolov, V. A., Deryagina, I. M., in Proc. Intl. Conf. Thermoelectric Energy Conversion, Nancy, 1989, Sherrer, H., Sherrer, S., Eds., Inst. Natl. Polytech. de Lorraine, Nancy, 1989, pp. 18-22.

Boikov, Yu. A., Gribanov, O. S., Danilov, V. A., Kutasov, V. A., Electrophysical Parameters of Epitoxial N-Type Bi2Te3 Films, Sov. Phys. Solid State 33, 11 (1991) 1926-1929.

Caillat, T., Fleurial, J-P., Borshchevsky, A., Use of Mechanical Alloying to Prepare and Investigate New Potential Thermoelectric Materials, Proc. XIth Intl. Conf. Thermoelectrics, K. R. Rao, Ed., Univ. Texas, Arlington, TX, Oct. 7-9, 1992.

Charles, E., Groubert, E., Boyer, A., J. Mater. Sci. Lett. 7 (1988) 575.

Cook, B. A., Harringa, J. L., Beaudry, B. J., Han, S. H., Optimization of the P/Ga Ration in NType SisoGe20 Thermoelectric Alloys Prepared by Mechanical Alloying, Proc. XIth Intl. Conf. Thermoelectrics, K. R. Rao, Ed., Univ. Texas, Arlington, TX, Oct. 7-9, 1992.

Cormish, A. J., Arrays of Inorganic Semiconducting Compounds, J. Electrochem. Soc. 106, 8 (1959) 685-689.

Cutler, M., Fitzpatrick, R. L., Leavy, J. F., The Conduction Band of Cerium Sulfide Ce3-xaS4, J. Phys. Chem. Solids, 24 (1963) 319-327.

Cutler, M., Leavy, J. F., Fitzpatrick, R. L., Electronic Transport in Semimetallic Cerium Sulfide, Phys. Rev., 133, 4A (1964) Al143-A1152.

Cutler, M., Leavy, J. F., Electronic Transport in High-Resistivity Cerium Sulfide, Phys. Rev., 133, 4A (1964) A1153-A1162.

Durczewski, K., Ausloos, M., Theory of the Thermoelectric Power of Model Semimetals and Semiconductors, Condensed Matter, Z. Phys. B 85 (1991) 59-68.

Egli, P. H., Thermoelectricity, John Wiley and Sons, New York, NY, 1958.

Elsner, N. B., personal communications, 1992-94. 
Farmer, J. C., et al., Thermoelectric Materials with Exceptional Figures of Merit, Chemistry and Materials Science Progress Report, Weapons-Supporting Research and Laboratory Directed Research and Development, First Half, FY 1993, UCID-20622-93-1, July, 1993, pp. 51-52.

Farmer, J. C., Barbee, T. W., Foreman, R. J., Summers, L. J., Deposition and Evaluation of Multilayer Thermoelectric Films, Proc. Symposium on Microstructures and Microfabricated Systems, 185th Electrochem. Soc. Meeting, San Francisco, CA, May 22-27, 1994, Electrochem. Soc., Pennington, NJ, Vol. 94-14, pp. 231-242, 1994.

Farmer, J. C., Barbee, T. W., Foreman, R. J., Summers, L. J., Deposition and Evaluation of Multilayer Thermoelectric Films, 185th Electrochem. Soc. Meeting, San Francisco, CA, May 22-27, 1994, Electrochem. Soc., Pennington, NJ, Ext. Abs., Vol. 94-1, pp. 1661-62, 1994.

Farmer, J. C., Ghamaty, S., Elsner, B., Synthesis and Evaluation of Novel Thermoelectric Thin Films, Paper No. 74, Symposium on Materials Synthesis and Characterization, Division of Industrial and Engineering Chemistry, 207th Meeting of the American Chemical Society, San Diego, CA, March 13-17, 1994, Abstracts, American Chemical Society, 1994.

Farmer, J. C., et al., Multilayer Thermoelectric Films: A Novel Approach for Achieving Exceptional Figures of Merit, 1993-94 Annual Report, Chemistry and Materials Science Department, Lawrence Livermore National Laboratory, in preparation.

Fleurial, J-P., Thermal and Electrical Transport Properties Modeling of Bi2Te3-Based Alloys, Proc. XIth Intl. Conf. Thermoelectrics, K. R. Rao, Ed., Univ. Texas, Arlington, TX, Oct. 7-9, 1992.

George, J. Pradeep, B., Solid State Commun. 56 (1985) 117.

Gladun, C., Heinrich, A., Monch, I., Schumann, J., Thomas, J., Thermoelectric Power and Sensor Application of Semiconducting CrSi and FeSi Thin Films, Proc. XIth Intl. Conf. Thermoelectrics, K. R. Rao, Ed., Univ. Texas, Arlington, TX, Oct. 7-9, 1992.

Gschneidner, .K. A., Nakahara, J. F., Beaudry, B. J., Takeshita, T., Lanthanide Refractory Semiconductors Based on the Th3P4 Structure, Proc. Mat. Res. Soc. 97 (1987) 359-370.

Goldsmid, H. J., Thermoelectric Refrigeration, Plenum Press, New York, NY, 1964.

Harman, T. C., PbTeSe/BiSb Short Period Superlattice as a New Thermoelectric Cooling Material, Proc. 1st Natl. Thermogenic Cooler Conf., Center for Night Vision and ElectroOptics, U.S. Army, Ft. Belvoir, VA, 1992.

Hicks, L. D., Dresselhaus, M.S., Thermoelectric Figure of Merit of a One-Dimensional Conductor, Phys. Rev. B 47, 24 (1993) 16 631-634. 
Hicks, L. D., Dresselhaus, M.S., Effect of Quantum-Well Structures on the Thermoelectric Figure of Merit, Phys. Rev. B 47, 19 (1993) 12 727-731.

Hicks, L. D., Dresselhaus, M. S., BiSb/PbTeSe Superlattices as a New Thermoelectric Cooling Material: Optimization of the Figure of Merit, March 15, 1993.

Hicks, L. D., Dresselhaus, M. S., The Effects of Quantum Well Structures on the Thermoelectric Figure of Merit, Proc. 1st Natl. Thermogenic Cooler Conf., Center for Night Vision and Electro-Optics, U.S. Army, Ft. Belvoir, VA, 1992.

Hyun, D-B., Ha, H-P., Shim, J-D., Electrical and Thermoelectric Properties of Bi, $\mathrm{Te}_{3}-\mathrm{Bi}_{2} \mathrm{Se} 3$ Single Crystals, Proc. XIth Intl. Conf. Thermoelectrics, K. R. Rao, Ed., Univ. Texas, Arlington, TX, Oct. 7-9, 1992.

Ikeda, K., Gschneidner, K. A, Beaudry, B. J., Ito, T., Electrical Resistivity Studies in the LaSx (1.333 $\leq x \leq 1.500)$ System, Phys. Rev. B 25, 7 (1982) 4618-4622.

Jankowski, A., Makowiecki, D., W/B4C Multilayer X-Ray Mirrors, Optical Engineering 30, 12 (1991) 2003.

Jankowki, A, Foreman, R, Makowiecki, D., Fabrication of Advanced X-Ray Optics with Magnetron Mini-Source Arrays, SPIE Conf. Proc. Multilayer Optics for Advanced X-Ray Applications 14 (1991) 1547.

Kamarzin, A. A., Mironov, K. E., Sokilov, V. V., Malovitsky, Yu. N., Vasil'Yeva, I. G., Growth and Properties of Lanthamum and Rare-Earth metal Sesquisulfide Crystals, J. Cryst. Growth $52(1981)$ 619-622.

Macklin, W. J., Moseley, P. T., On the Use of Oxides for Thermoelectric Refrigeration, Matls. Sci. Eng. B7 (1990) 111-117.

Maddison, D. S., Roberts, R B., Unsworth, J., Thermoelectric Power of Polypyrrole, Synthetic Metals 33 (1989) 281-287.

Maddison, D. S., Unsworth, J., Electrical Conductivity and Thermoelectric Power of Polypyrrole with Different Doping Levels, Synthetic Metals 26 (1988) 99-108.

Matsubara, K., Miki, T., Nagao, K., Kishimoto, K., Nakanshi, O., Ueda, O., Fugii, K., Characterization and Thermoelectric Properties of $\mathrm{New}_{\text {b-FeSi2 }}$ Ceramics Developed by an $\mathrm{RF}_{-}$Plasma Processing in $\mathrm{O}_{2}$ and $\mathrm{SiH}_{4}$ Gases, Proc. XIth Intl. Conf. Thermoelectrics, $\mathrm{K}$. R. Rao, Ed., Univ. Texas, Arlington, TX, Oct. 7-9, 1992.

McKernan, W., Makowiecki, D., Ramsey, P., Jankowski, A., Magnetron Sputter Deposition of Boron and Boron Carbide, Surface and Coating Technology 49 (1991) 411. 
Nakahara, J. F., Takeshita, T., Tschetter, M. J., Beaudry, B. J., Gschneidner, K. A., $A$ Study of the Thermoelectric Properties of Ca, Sr, and Hg Substituted Lanthanum Sulfides, Chapt. 14, Proc. First European Conf. Thermoelectrics, D. M. Rowe, Ed., Peter Peregrinus Ltd., London (1988) 161-70.

Nakahara, J. F., Beaudry, B. J., Gschneidner, K. A., Takeshita, T., The Effect of Sm, Eu, and $\mathrm{Yb}$ on the Thermoelectric Properties of Th3P4-Type Lanthamum Sulfide, Proc. Mat. Res. Soc. 97 (1987) 379-384.

Nakahara, J. F., Takeshita, Tschetter, M. J., Beaudry, B. J., Gschneidner, K. A., Thermoelectric Properties of Lanthamum Sulfide with Sm, Eu, and Yb Additives, J. Appl. Phys. 63, 7 (1988) 2331-2336.

Nakahara, J. F., Tschetter, M. J., Beaudry, B. J., Takeshita, T., Gschneidner, K. A., The Seebeck Coefficient and Electrical Resistivity of Some Rare Earth Ternary Sulfides La3-x $M_{x} S_{4} M=$ $S m, E u, Y b)$, Proc. Sixth Intl. Conf. Thermoelectric Energy Conversion, K. R. Rao, Ed., University of Texas, Arlington, TX, March 12-14, 1986, pp. 35-38.

Noro, H., Sato, K., Kagechika, H., The Thermoelectric Properties and Crystallography of Bi-SbTe-Se Thin Films Grown by Ion Beam Sputtering, J. Appl. Phys. 73 (1993) 1252-1260.

Ohta, T., Vining, C. B., Allevato, C. E., Characteristics of a Promising New Thermoelectric Material: Ruthenium Silicide, Proc. 26th Intersociety Energy Conversion Engineering Conf., Vol. 3, August 4-9, 1991, Boston, MA, American Nuclear Society, La Grange Park, IL, 1991, pp. 196-201.

Ohta, T., P-Type Thermoelectric Characteristics of Polycrystal Ruthenium Sesquisilicide, Proc. XIth Intl. Conf. Thermoelectrics, K. R. Rao, Ed., Univ. Texas, Arlington, TX, Oct. 7-9, 1992.

Park, Y. W., Yoon, C. O., Lee, C. H., Conductivity and Thermoelectric Power of the Newly Processed Polyacetylene, Synthetic Metals, 28 (1989) D27-D34.

Rosi, F. D., Thermoelectricity and Thermoelectric Power Generation, Solid-State Electronics 11 (1968) 833-868.

Roy, R. Sen, S. K., Digar, M., Bhattacharyya, S. N., Conductivity and Thermoelectric Power in Conducting Polypyrrole Films, J. Phys.: Condens. Matter 3 (1991) 7849-7856.

Slack, G. A., Hussain, M. A., The Maximum Possible Conversion Efficiency of SiliconGermanium Thermoelectric Generators, J. Appl. Phys. 70, 5 (1991) 2694-2718.

Stolzer, M., Stordeur, M., Properties of Magnetron Sputtered Bi0.5Sb 1.5Te3 Films, Proc. XIth Intl. Conf. Thermoelectrics, K. R. Rao, Ed., Univ. Texas, Arlington, TX, Oct. 7-9, 1992. 
Stordeur, M., Sobotta, H., Optical and Electrical Investigations of N-Type Bi2Se3 Single Crystals, Proc. XIth Intl. Conf. Thermoelectrics, K. R. Rao, Ed., Univ. Texas, Arlington, TX, Oct. 7-9, 1992.

Takeshita, T., Beaudry, B. J., Gschneidner, K. A., Thermoelectric Properties of Ytterbium Sulfides, Proc. 18th Intersociety Energy Conversion Engineering Conf., August 21-26, 1983, pp. 240-244.

Takeshita, T., Beaudry, B. J., Gschneidner, K. A., Preparation of Thermoelectric Properties of Some Rare Earth Chalcogendies, The Rare Earths in Modern Science and Technology, Vol. 3, McCarthy, Siber, and Rhyoe, Eds., Plenum Publishing Corp., 1982, pp. 255-256.

Takeshita, T., Beaudry, B. J., Gschneidner, K. A., The Rare Earth Sulfides $R_{2} S_{3}-X(R=S c, E r$, and Lu) as High Temperature Thermoelectric Elements, Proc. Fourth Intl. Conf. Thermoelectric Energy Conversion, K. R. Rao, Ed., IEEE, New York, NY, 1982, pp. 48-51.

Vining, C. B., A Model for the High-Temperature Transport Properties of Heavily Doped NType Silicon-Germanium Alloys, J. Appl. Phys. 69, 1 (1991) 331-341.

Vining, C. B., Thermoelectric Limit ZT I: Fact or Artifact, Proc. XIth Intl. Conf. Thermoelectrics, K. R. Rao, Ed., Univ. Texas, Arlington, TX, Oct. 7-9, 1992.

Wood, C., Materials for Thermoelectric Energy Conversion, Rep. Prog. Phys. 51 (1988) 459539.

Wakaki, M., Ohkubo, O., Okumura, T., Yamashita, M., Kibayashi, Y., Yamaguchi, T., FarInfrared Characterization of Narrow Gap Semiconductors for Thermoelectric Cooling, Proc. XIth Intl. Conf. Thermoelectrics, K. R. Rao, Ed., Univ. Texas, Arlington, TX, Oct. 7-9, 1992.

Yoon, C. O., Na, B. C., Park, Y. W., Thermoelectric Power and Conductivity of the StretchOriented Polyacetylene Film Doped With MoCl5, Synthetic Metals 41-43 (1991) 125-128. 